\title{
Diagnostic and therapeutic protocols in medical practice
}

Citation for published version (APA):

Vissers, M. (1996). Diagnostic and therapeutic protocols in medical practice. [Doctoral Thesis, Maastricht University]. Rijksuniversiteit Limburg. https://doi.org/10.26481/dis.19960411mv

Document status and date:

Published: 01/01/1996

DOI:

10.26481/dis. $19960411 \mathrm{mv}$

Document Version:

Publisher's PDF, also known as Version of record

\section{Please check the document version of this publication:}

- A submitted manuscript is the version of the article upon submission and before peer-review. There can be important differences between the submitted version and the official published version of record.

People interested in the research are advised to contact the author for the final version of the publication, or visit the DOI to the publisher's website.

- The final author version and the galley proof are versions of the publication after peer review.

- The final published version features the final layout of the paper including the volume, issue and page numbers.

Link to publication

\footnotetext{
General rights rights.

- You may freely distribute the URL identifying the publication in the public portal. please follow below link for the End User Agreement:

www.umlib.nl/taverne-license

Take down policy

If you believe that this document breaches copyright please contact us at:

repository@maastrichtuniversity.nl

providing details and we will investigate your claim.
}

Copyright and moral rights for the publications made accessible in the public portal are retained by the authors and/or other copyright owners and it is a condition of accessing publications that users recognise and abide by the legal requirements associated with these

- Users may download and print one copy of any publication from the public portal for the purpose of private study or research.

- You may not further distribute the material or use it for any profit-making activity or commercial gain

If the publication is distributed under the terms of Article $25 \mathrm{fa}$ of the Dutch Copyright Act, indicated by the "Taverne" license above, 
Diagnostic and therapeutic protocols in medical practice 



\title{
Diagnostic and therapeutic protocols in medical practice
}

\author{
PROEFSCHRIFT
}

ter verkrijging van de graad van doctor

aan de Rijksuniversiteit Limburg te Maastricht,

op gezag van de Rector Magnificus, Prof. Mr. M.J. Cohen,

volgens het besluit van het College van Dekanen,

in het openbaar te verdedigen

op donderdag 11 april 1996

om 16.00 uur

door

Marieke Vissers 


\section{Promotoren:}

Prof.dr.ir. A. Hasman

Prof.dr. C.J. van der Linden (Katholieke Universiteit Nijmegen)

\section{Co-promotor:}

Dr. J.W.M. Greve

\section{Beoordelingscommissie:}

Prof.dr. P. Pop (voorzitter)

Prof.dr. D.J. Gouma (Universiteit van Amsterdam)

Prof.dr. J.W. Stapert

Prof.dr. R.W. Stockbrügger

Prof.dr. P.F. de Vries-Robbé (Katholieke Universiteit Nijmegen)

CIP-DATA KONINKLUKE BIBLIOTHEEK, DEN HAAG

Vissers, Maricke

Diagnostic and therapeatic protocols in medical practice /

Maricke Vissers. - |S.1. : s.n.|. - III.

Thesis Rijksuniversiteit Limburg. Maastricht. With ref. -

With summury in Duich.

ISBN 90-9009313-3

Subject headings: protocol processing systems / decision support tochniques ; medical practice.

Omslag en lay-out: M. Vissers, Medische Informatica RL, Maastricht Productie: Datawyse | Universitaire Pers Maastricht

In de drukkosten van het proefschrift werd bijgedragen door: SíAC. Triple-Pi, Pie Medical Equipment BV, Cendata en Hewlett Packard.

Hierbij wil ik collega's, vrienden en familieden bedanken die bijgedragen hebben aan de totstandkoming van dit proefschrift. 


\section{Contents}

2 Protocols and other decision support techniques in medicine

3 Selection and development of research protocols

4 Development, implementation and a first evaluation of a protocol processing system (ProtoVIEW)

5 Consultation behaviour of residents supported with a protocol processing system (ProtoVIEW) at the emergency ward

6 Effects of a supportive protocol display system (ProtoVIEW) on clinical behaviour of residents in the accident \& emergency department

7 Influence of computer support on treatment of isolated fractures; results of a follow-up study

8 The introduction of a computerized protocol into clinical practice; is there anything to gain?

9 Summary and closing remarks

Samenvatting

Curriculum Vitae

Publications 

Chapter 1

Introduction 

The vast majority of everyday clinical decisions is straightforward and simple. Difficulties in the diagnostic and therapeutic process arise when physicians encounter medical problems with which they are not familiar. This happens frequently to physicians in training for whom many medical problems are new. However, even the more experienced physicians regularly encounter complex situations in which correct decisions are far from obvious. Physicians deal with uncertainty by asking a colleague's advice, consulting literature, textbooks or visiting conferences. Another source to reduce uncertainty in medical decision making is clinical protocols or practice guidelines. The first protocols were introduced to educate students and nurses. Later, protocols aimed to support physicians to reduce uncertainty, variation in practice, and inappropriate care. The first protocols were developed at hospitals with the aim to be used locally. In the past decades there has been a growing interest in the development of more scientifically valid protocols to be used nationwide. Several organizations issued methods to develop protocols based on a variable mixture of expert opinion on the one hand and scientific evidence of the highest quality on the other.

Despite the enormous proliferation of national protocols, most protocols are still developed locally to be used locally. Often, national protocols are less successful in changing physicians' practices than locally developed protocols. Reasons might be that it is more laborious to distribute national protocols to the physicians concerned and to convince the physicians to change their practice towards the protocols. Some factors that seem to influence such change in practice positively are: the participation of local physicians (or their representatives) in the protocol development process and the modification of national protocols to local circumstances. However, several questions concerning protocol usage remain.

First, the kind of modification of a national protocol to an optimal local one might not be evident if local experience with diagnostic and therapeutic procedures differs from that reported in the literature. Second, even if physicians can be convinced of the benefit of the protocols and agree to its usage, one can wonder whether they know when to consult them. Finally, more research is needed concerning the format in which protocols should be presented to physicians. The conventional paper based format seems to be unsatisfactory for many medical problems. Physicians are often reluctant to use protocols if these are complex or inflexible and they want medical information in a concise, directive, readerfriendly and comprehensible form. The more flexible way of presenting algorithms with the help of a computer system may be useful in overcoming limitations of paper based protocols.

This thesis, focuses on various aspects of protocol usage that may influence the practice of physicians. 
The aims of the research were:

To develop, implement, and evaluate an automated protocol processing system to solve some problems and limitations of paper based protocols.

To investigate the effect of mandatory and optional protocol consultation on protocol adherence and treatment using an automated protocol processing system.

To investigate to what extent nationally developed protocols are transferable to a local situation.

\section{Thesis outline}

This thesis consists of several articles. As a consequence redundant information could not be avoided. However, an advantage is that most chapters can be read without necessarily having read other chapters.

Chapter 2 provides background information on protocols and other decision support techniques and the use of computers in this respect. In chapter $\mathbf{3}$ we present two surgical! domains in which a locally developed protocol and an adapted nationally developed protocol were used. This enabled us to investigate protocol usage from different perspectives. In chapter 4 the development and implementation of a prototype passive protocol processing system (ProtoVIEW) is described. ProtoVIEW aims to present protocols in a convenient and userfriendly way. This chapter also presents the results of a first evaluation of ProtoVIEW used by interns.

ProtoVIEW supplied with trauma protocols was evaluated in routine clinical practice by means of a controlled crossover trial at the Accident \& Emergency department of the University Hospital in Nijmegen. The consultation behaviour of surgical residents using ProtovlEW in routine clinical practice as well as the attitude of residents towards ProtoVIEW as an information source is presented in chapter 5. The effec: of mandatory protocol consultation (using ProtoVIEW) on protocol adherence is presented in chapter 6 and the effect on treatment is presented in chapter 7 . The potential benefit and the validity of an adapted nationally developed protocol at a local level was investigated by a retrospective patient record analysis. The results are presented in chapter $\mathbf{8}$. Chapter $\mathbf{9}$ consists of a summary, a general discussion and conclusions. 
Chapter 2

Protocols and other decision support techniques in medicine 


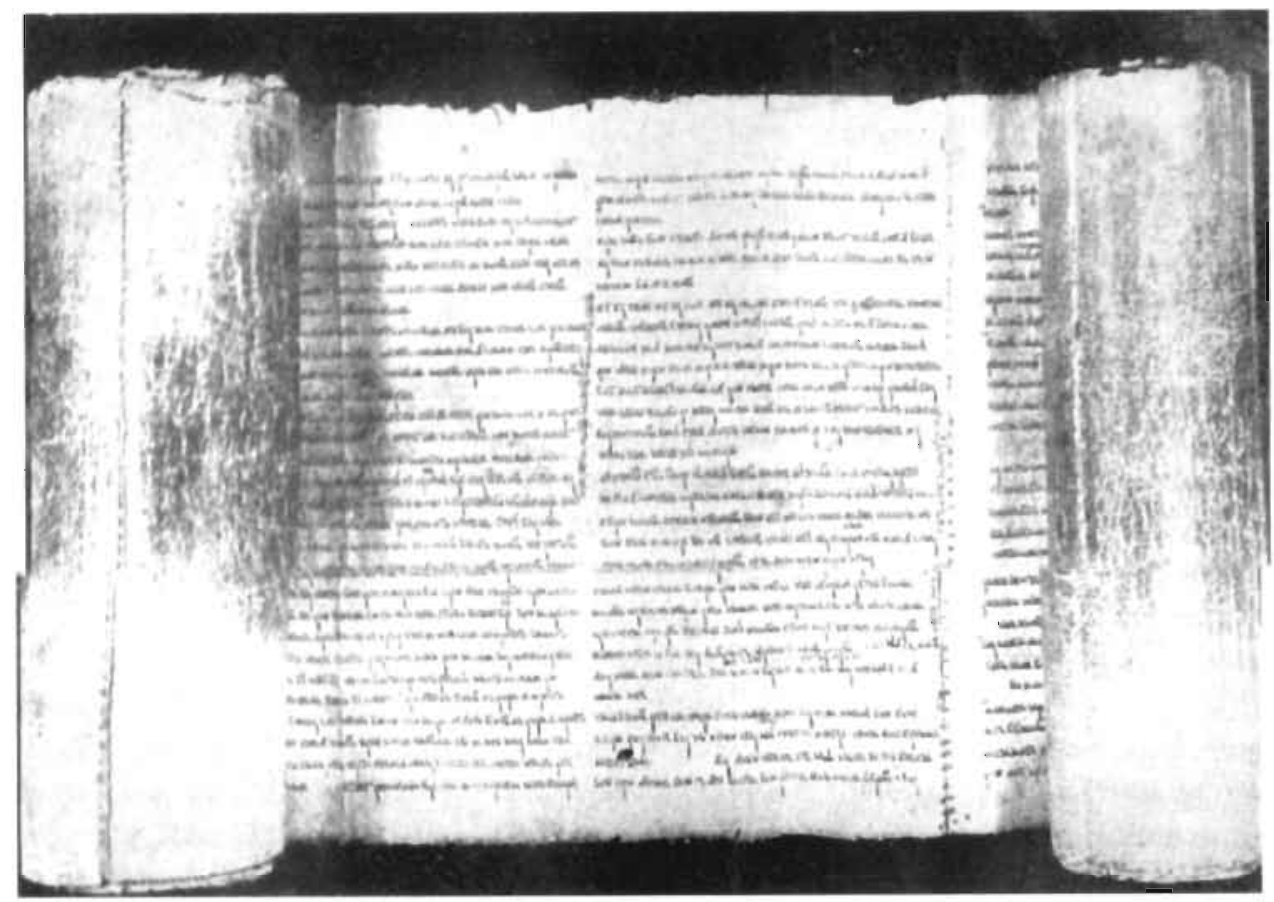

Figure 1 Example of a papyrus roll (Dead sea scrolls) 


\section{Introduction}

The pace with which biomedical and technological innovations and developments become available for clinical medicine makes it increasingly difficult for health care professionals to keep up to date. Diagnostic and therapeutic decisions have to be made continually during patient management. The ultimate goal of each medical decision is to choose the action that is most likely to deliver the most beneficial outcome to the patient ${ }^{15}$. Several decision support methods and tools have emerged to aid physicians in achieving this goal such as: protocols, pattern recognition, artificial intelligence (Al) and decision, analysis.

This chapter provides a general background on several decision support techniques used in medicine. Several aspects of protocols such as their origin, development, dissemination and evaluation will be discussed in more detail.

\section{Protocols in medicine}

\subsection{Origin of protocols}

The word 'protocol' stems from the Greek words rpôtos - first - and $\kappa \hat{\alpha} \lambda \lambda \alpha$ - glue In medieval Latin the word 'protocollum' occurs, meaning the first sheet of a papyrus roll. glued to the cylinder around which the papyrus. was rolled. On this first sheet the authenti. cation and data of manufacture of e.g. a law document were mentioned. In a later stage specific details could be attached to the protocollum. In medical practice a protocol can be viewed as a set of (first choice) instructions which are glued together telling the physician what to do in a predefined situation. We shall mainly use the term 'protocol' throughout this thesis although several (not always) interchangeable terms such as recommendations, standards, statements, (practice) guidelines, practice parameters, practice policies and. clinical algorithms are used. Protocols may consist of rather vague recommendations or be as precise as a drug prescription providing a strategy for almost each thinkable patien. Statistical methods might be used to evaluate scientific data justifying each protocol step, but for other steps scientific evidence may be lacking completely.

The first protocols were introduced to educate students, physician assistants and nurses ${ }^{50,84}$ in patient care and technicians in interpreting $X$-rays ${ }^{201}$ but soon protocols were also developed to aid physicians in patient care $^{\text {is }} \mathrm{x}$. The growing interest in standardizing medical practice might be explained by several factors. In 1960 the NIH discovered discrepancies in terminology concerning cardiac and pulmonary disorders between American and British physicians ${ }^{61}$ and from the early seventies on several studies demonstrated wide variations in medical practice among physicians ${ }^{26}$, hospitals ${ }^{40}$, and different geographical areas ${ }^{8,71.49}$. Some variation in practice patterns can be expected due to differences in patient populations, available resources and patients' preferences ${ }^{14}$ but uncertainty in medical decision making also seems to play an important role ${ }^{172 t}$. Physicians' uncertainty may attribute to inappropriate medical care which is an important impetus to the development of protocols ${ }^{92}$. Furthermore, pressure on health care profession 
als to improve cost effectiveness of medical care increased. Reported aims of protocols are to decrease physicians uncertainty, reduce rates of inappropriate care while reducing overall health care costs ${ }^{92}$.

\subsection{Methods for developing protocols}

The increased attention for protocols resulted in several approaches for development of protocols $\mathrm{s}^{3,18,44.69}$. However, it is still unknown which of these approaches produce sounder and more usable protocols ${ }^{3}$. The methodological approaches for developing protocols have been classified by Eddy as follows ${ }^{17}$ : global subjective judgement, the evidence based approach, the outcome based approach and the preference based approach. Woolf ${ }^{\text {tos }}$ distinguishes informal consensus conferences, formal consensus conferences, the evidence based approach and, finally, the explicit approach.

\subsection{Protocols based on consensus}

Protocols that are based on opinions of a panel of experts not requiring a formal analysis of supporting scientific evidence are called 'global subjective judgement.' protocols by Eddy. Woolf uses terminology like 'informal' and 'formal consensus conferences'. Opinions are obtained by voting after a meeting or forum discussion, by Delphi ${ }^{27}$ method, nominal group ${ }^{11}$ method or a mixture of these methods. The consensus conferences are becoming increasingly popular. They are simple, fast, inexpensive and the most accessible method for setting a policy so far ${ }^{104}$. The consensus development program advocated by the NIH has been adopted as a useful technique in the United States ${ }^{27.44}$ and in many other countries $^{56,91}$.

The NIH program brings together an independent panel consisting of scientists, medical practitioners and informed laypeople to seek consensus on recommendations about beforehand posed medical questions in a. structured $2 \frac{1}{2}$ day conference. The first $11 / 2$ days consist of a plenary session in which experts present evidence followed by an open discussion among panellists and audience (consisting of i.a. a group of medical practitioners). Next, the panel writes a draft consensus statement in a closed session. The following morning the consensus statement is presented to experts and audience for comments. In a final executive session revisions are considered on the basis of the comments and a final consensus statement is completed ${ }^{44}$.

Similar consensus development programmes have been organised in the Netherlands ${ }^{24.3}$ and in other countries ${ }^{2}$. The development of national practice standards for Dutch general practitioners started in $1989^{* 6}$ and collaboration with other European countries has been sought ${ }^{\text {iv }}$ :

Opponents of these conferences argue that these conferences are too much focused on achieving consensus ${ }^{74}$. The results highly depend on a compromise between viewpoints expressed by a small group of experts, under time pressure ${ }^{105}$ while the impact of the resulting protocols on actual clinical practice is limited, non existent, and often not even evaluated $^{\text {ot.os. }} 4$ 


\subsubsection{Evidence based protocols}

A more scientific approach to develop protocols according to Eddy and Woolf is the evidence-based approach. Policy makers are asked to identify, describe, and analyze scientific evidence to justify a. policy. More formal analytic method's to synthesize evidence include meta-analysis (criteria-based"s or by pooling data from multiple studies ${ }^{57}$ ), decision analysis $^{72}$ and bayesian statistics ${ }^{21}$. Recently, the Cochrane Collaboration started to systematically review randomized clinical trials of medical interventions ${ }^{20}$. The aimi is to encourage evidence based decision making by offering fast and easy access to these reviews.

Since only a small proportion of current interventions have been validated through clinical studies, the scientific approach often cannot be applied. Especially in relatively new medical fields one has to rely on expert opinions or combine opinions with scarce scientific evidence when developing a protocol ${ }^{2 !}$.

\subsubsection{Outcome and preference based protocols}

Finally, two more explicit approaches ${ }^{10}$ for guideline development have been discussed. First the outcome based approach which adds, to: the evidence based approach the estimation of outcomes of alternative strategies. The estimates are based on benefits, harms and costs of potential interventions specified by protocol developers. In a 'balance sheet' the potential benefits, harms, and costs of each option are tabulated. The results can be reviewed by patients, clinicians, and policymakers.

Finally, the preference based approach includes patients' preferences ${ }^{18}$ for outcomes which are also tabulated. Until now these methods have been used only in research programs since they require at lot of time and money. These methods make use of decision analysis which will be discussed in more detail in section 3.1.3.

\subsection{Introduction of protocols into clinical practice}

Once a protocol has been developed, it. must be introduced inte clinical practice to bring about a change in physicians' behaviour ${ }^{4 x}$. Successful introduction of protocols seems to depend on many factors, including the clinical context and the methods by which they are developed, disseminated, and implemented ${ }^{37}$.

\subsection{Dissemination of protocols}

Especially when protocols are developed at a national level, dissemination strategies need much attention ${ }^{37}$. Several dissemination strategies are used to distribute NIH consensus statements such as: press conferences, mailing lists, publication in JAMA and other medical journals. The effects of several NIH consensus development programs on physician practice have been evaluated and it has been shown that NIH conferences usually failed to bring about change in physician practice. ${ }^{51.5257}$. Since the dissemination strategies were frequently not sufficient, it was concluded that this needs more attention ${ }^{45}$. Dissemination by a local opinion leader showed to be more successful ${ }^{5 x}$. 


\subsubsection{Changing practice of physicians}

Several general methods are propagated for changing physicians' practice behaviour. These include education, feedback, participation by physicians in an effort to bring about change, administrative rules, financial incentives, and financial penalties ${ }^{32}$. Combinations of these methods showed to be more effective than single methods ${ }^{32,98}$. Providing physicians with individual feedback by a respected colleague showed to remain effective also when feedback was performed routinely for many years ${ }^{100,10 t}$. Grimshaw et al. ${ }^{37}$ found that locally developed protocols more easily change physicians' behaviour than nationally developed protocols. Since local groups often lack the technical skills needed to develop protocols $^{37}$, these protocols are less likely to be scientifically valid ${ }^{36}$. On the other hand, locally developed protocols have several benefits compared to nationally developed protocols. Less attention needs to be paid to the dissemination of the protocols and it is less difficult to convince physicians about the benefits of a newly developed protocol since they were involved in their creation ${ }^{67}$. Finally, local protocols fit, better in the health care environment. Since local protocols are more likely to change practice ${ }^{37,67}$, an attractive solution would be to modify national scientifically valid protocols taking into account local setting and resources.

\subsubsection{Format and style of protocols}

Not much is known about the way protocols should be presented to the physicians. Protocols were introduced almost 30 years ago, usually displayed as flow charts or decision tables $^{25,89.99}$. Considerable diversity in the style was found among protocols used by general practitioners $^{\circ 7}$ and among consensus statements issued by $\mathrm{NIH}^{47}$. Although the protocols reviewed by Grimshaw et al. " that were successful in clinical practice used a wide range of styles and formats, more research is needed to determine the factors that make a certain format successful"? The least we can say is that protocol information has to be reader friendly and comprehensible ${ }^{48}$ as doctors are often reluctant to use algorithms when they are complex of inflexible".

\subsubsection{Effectiveness of protocols}

Many think protocols are the right tool to reduce inappropriate variation in service, to improve quality of care ${ }^{16,5 !, 00,97}$ and to produce better health outcomes. Critics on the other hand say that protocols turn physicians into robots who lose their autonomy leading to a decrease of quality of care ${ }^{45.01, \% 1}$.

The ongoing discussion about the effectiveness of protocols emphasises the importance of their scientific evaluation (and the dissemination strategy) in real clinical settings.". ${ }^{3.0}$. This should include the assessment of the attitude of physicians towards the proposed change in behaviour and the impact of protocols on professional behaviour, patient outcomes, and health care costs ${ }^{1,10}$. Grimshaw et al." reviewed published evaluations of the application of clinical protocols. Since the randomized trial cannot be regarded as the only robust design in the evaluation of protocols (see section 3.4), the review included studies that used a simple randomized, a randomised crossover or a controlled before-and-after design.

All but four out of 59 clinical protocols resulted in improvements in the process of 
medical care and all but two out of 11 evaluations that also measured the outcome of care reported improvements in outcome. Their conclusion was that protocols can change clinical practice if they are appropriately developed, disseminated, and implemented.

\section{Decision support techniques and the use of computers}

During the sixties the first decision support techniques were implemented on computers to support physicians in their decision making process. The basis for the introduction of computer assisted medical decision making was laid by Ledley and Lusted with their article in $1959^{4}$.

\section{1 Computerized Decision Support Systems (CDSSs)}

Reggia and Tuhrim" define a CDSS as an interactive computer system that directly assists physicians or other health professionals in their clinical decision making task. In the past decades many different CDSSs have been developed. Most CDSSs are based upon pattern recognition and statistical techniques and $\mathrm{Al}$.

\subsubsection{Pattern recognition}

A major approach to developing CDSSs involves the use of statistical pattern recognition techniques. Pattern recognition makes use of statistical methods to suppori decision making. The statistical approach requires information about the probabilities of patient data such as signs, symptoms and laboratory findings given the disease (conditional probabilities). An example is de Dombal's acute abdominal pain program, based upon Bayesian probability theory". This system uses sensitivity and specificity of various signs, symptoms and test results and disease-prevalence data, derived from a pool of patient data, to calculate the posterior probability of seven possible explanations for acute abdominal pain (Figure 2).

$$
P(D \mid S)=P(S \mid D) * P(D) / P(S)
$$

Figure 2 With Bayes: theorem one can calculate the probability of having a disease given a symptom (P(D) S)) when probabilities of: exhibiting the disease (P(D)), having the symptom $P(S)$, having symptom given the disease P(S|D) are known.

To keep the computations manageable usually conditional independence of the findings for the various diagnoses has to be assumed. Moreover the set of diagnoses should be exhaustive and mutually exclusive although corrections can be made for the latter case. Since the determination of the probability distribution requires data from many patients. the application of statistical tools is limited to specialized medical domains.

Apart from Bayes-like classifiers, linear and logistic discriminant functions have been used to discriminate between two decision categories. In case of a multi-class problem, voting schemes are to be used to select among the outcomes of the discriminant functions for pairwise class comparisons. When decision boundaries are not linear or quadratic, 
neural nets may be used to map a set of attribute values onto a set of decision categories. The probabilities, the regression coefficients, or the weights in the neural networks can be considered as the representation of the knowledge encoded in the classifier.

Another pattern recognition technique is case based reasoning. CDSSs of this type do not have an explicit knowledge base. The knowledge they use is implicitly present in a database of individual patient records. The inference mechanism for case based reasoning has to identify a subset of the database patients who are similar to a new patient ${ }^{33}$.

\subsubsection{Artificial intelligence (AI)}

Al is the branch of computer science concerned with building systems that produce output similar to experts, largely through the use of nonnumeric symbol processing ${ }^{73}$. AI emerged during the fifties. Its techniques use knowledge to manipulate data in ways that generate novel inferences that were not explicitly programmed. The knowledge is stored in a so-called knowledge base containing encoded knowledge needed to solve problems in some particular area. The inference mechanism is a program that, given a case description, uses the knowledge in the knowledge base to generate new information about the case ${ }^{71}$. The knowledge may be extracted from experts by interviewing them and may be completed with information from textbooks and literature. Subsequently a suitable knowledge representation has to be selected after which the knowledge can be transferred to the knowledge bases. Symbolic knowledge can be represented by production rules, frames. semantic networks or predicate calculus. A production rule, for example, is a conditional statement (if. then..) that relates observations to associated conclusions (Figure 3).

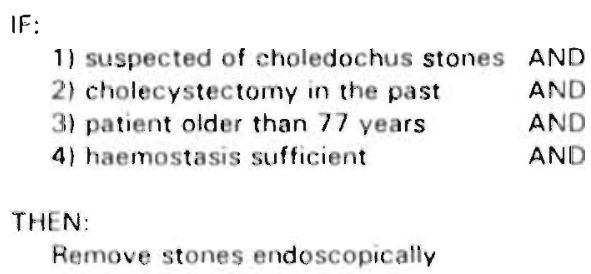

Figure 3 Representation of knowledge in a rule.

Apart from the way knowiedge is represented, one also has to cope with uncertainty. It is often impossible to reduce the medical problem to a collection of rules where the consequences follow from the antecedents with absolute certainty. In MYCIN ${ }^{82}$ uncertainty is included in the rules in the form of certainty factors. A method to propagate certainty factors was developed. Other systems use a Bayesian approach with (subjectively) estimated probabilities. In case concepts are not crisply defined fuzzy set theory may be used ${ }^{78,109}$.

MYCIN is an early example of an expert system. The system supported physicians in the management of patients with meningitis. Although MYCIN performed well, it was never used clinically because of an unacceptably long consultation time and because of the development of broad spectrum antibiotics. More recently, ONCOCIN ${ }^{47}$ was developed by 
the same research group and uses knowledge about chemotherapy protocols for cancer. ONCOCIN has shown to be promising as a system capable of providing treatment to provide advice on drug selection, dosing, and test selection ${ }^{42.24}$. An attractive aspect of rule based expert systems is the intuitive way of reasoning which is easily understood by physicians ${ }^{5.85}$. Limitations however are the narrow, specialized domains of expertise ${ }^{\mathrm{N}}$. The acquisition and maintenance of knowledge is a laborious and expensive process which seems to be an important obstacle in the widespread use of rule based expert systems ${ }^{n}$.

\subsubsection{Decision analysis}

Decision analysis is a statistically oriented approach which has been advocated for clinical use ${ }^{58}$ but has also been incorporated into $\operatorname{CDSS}^{11.71}$ Decision analysis can be of help to clarify a decision problem and to choose the alternative that is most likely to help the patient. This technique involves the creation of a decision tree (Figure 4).

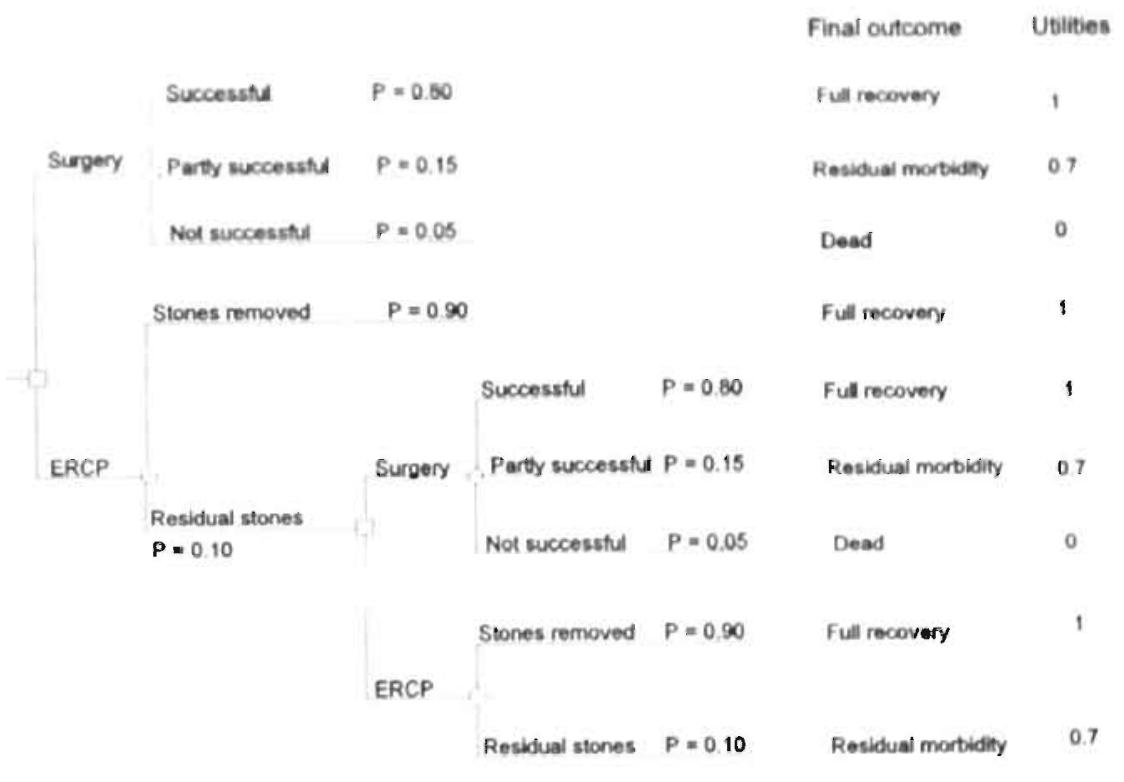

Figure: 4 Simple decision tree for patient suspected of bile duct stones

$\square$ are decision nodes, $O$ are chance nodes (fake data)

Early events are placed to the left and later events are placed to the right. There are two types of branching nodes in the tree, decision nodes - represented by a small square showing choices between several diagnostic or therapeutic options and chance nodes represented by a small circle - showing several. outcome alternatives. Associated with each outcome alternative is the probability of the outcome occurring. Utilities are assigned to the ultimate outcomes which reflect patient's outcome preferences e.g. in terms of quality of life or duration of survival. The patient or physician has to choose the option with the highest expected utility. This expected utility can be obtained by backfolding the tree. The 
result is a clinical algorithm. The main advantage of this technique is that also the patient's perspective can be taken into account so that as a result the outcome can be different for each patient. Shortcoming of this method is that it can be difficult to obtain reliable probabilities and to assign balanced utilities. Sensitivity analysis can be used to examine the impact if probabilities are inaccurately estimated.

\subsubsection{Computerized protocols}

Protocols are commonly presented to the physicians in paper based format. However, CDSSs that implement clinical protocols (usually in flow chart format') have been developed. An example is a CDSSs that implements a clinical algorithm that generates chemotherapy advice in oncology ${ }^{102}$. The information system integrates the general rules of the chemotherapy regimen with the specific needs of individual patients on a visit-by-visit basis. A multi-centre study showed that protocol adherence was much better in the group that used the computerized algorithms ${ }^{103}$.

Another protocol based system for clinical oncology data management and to support chemotherapy treatment is ONCOCIN ${ }^{42}$ which is based on AI techniques. ONCOCIN combines patient's clinical information with encoded protocol information, plus additional knowledge provided by expert oncologists, to provide management advice.

Since free text descriptions of the existing clinical algorithms often contain information that a human will understand but that cannot directly be interpreted by an expert system, it is not always easy to translate free text protocol information into formal rules for a rule based system ${ }^{12}$. The process of encoding oncology protocols to be used by ONCOCIN also revealed serious omissions and ambiguities. To help physicians develop protocols that are free of ambiguity OPAL (an automated authoring environment for oncology protocols) was developed ${ }^{6:}$.

Finally, other computer based protocol advisors are the $\mathrm{CARE}^{62}$ and HELP ${ }^{7}$ system. These are critiquing systems that are integrated with an electronic medical record system. These systems provide information on various patient treatment issues and have been shown to alter physician behaviour significantly ${ }^{62,70}$. A drawback of these systems is that clinical data have to be standardized before they can be stored in an electronic medical record system.

\section{2 The role of the user}

Several different approaches for building CDSSs have been discussed. The ultimate goal of CDSSs is 10 assist users in medical decision making regardless of the underlying approach. Since the user has to interact with, rely on and apply the information provided by the computer, it is useful to classify CDSSs according to the way they interact with the user.

\subsection{Reference systems}

This kind of systems is used as a 'reference book'. An example is DeSyGNER ${ }^{33}$ which contains knowledge that has to be searched for by the user. The system aids the user when searching the knowledge base for relevant information. Reference systems should be easy 
to use and the user must be able to navigate through the system without getting lost. The World Wide Web (WWW) browser is an example of such an approach. With the WWW browser one can explore a part of the Internet containing multimedia information in numerous domains. Multimedia integrates different types of information such as text, sound, video and images.

\section{3:2.2 Solicited advice}

Solicited advice systems provide advice on the request of the user. In this case the user has a more passive role. An example of such a system is the abdominal pain program from Leeds". This kind of system requires that patient data be entered. Next the system provides advice based on these data and its own knowledge. However, typing in information takes time and the user has to wait for the results.

$\mathrm{QMR}^{\circ 4}$ and DXplain ${ }^{4}$ are mixtures of reference and solicited advice systems. The user can take the initiative and ask for information, but QMR and DXplain can also derive diagnostic suggestions from the information supplied by the user.

\subsubsection{Prompting/unsolicited advice systems}

Unsolicited (critiquing, or reminder) systems do not wait for physicians or other health workers to ask specifically for assistance. Such systems do not directly interact with the user to obtain information but generate case specific advice based on patient data entered in an electronic medical record. Examples of such programs are HyperCritic". the HELP system ${ }^{7}$ and the medical record system $\mathrm{CARE}^{62}$ (see section 3.1.4).

\subsection{Problems related with introduction of CDSSs in clinical practice}

Until now, just a few CDSSs are being used in daily clinical practice. Obstacles to successful introduction have been put forward by several authors ${ }^{10,26,40.10 \pi}$. Wyatt ${ }^{107}$ described three major barriers and possible solutions to successful introduction of CDSSs.

The first barrier is inappropriate system development and function when design and development are performed separately from implementation. Due to constantly evolving medical environments, systems should be developed by building subsequent prototypes which are changed and upgraded regularly in collaboration with system users. Moreover, a system needs to be fast and easy to use. A second barrier to success is poor project management. The introduction of a system changes work-patterns. Hence, productivity is likely to reduce temporarily and benefits may emerge only at later stages. To increase system acceptance opinion leaders must be committed to the system's success during introduction and implementation of the system and system users should be properly informed and warned about the organisational changes and side effects. A final obstacle to success is lack of involvement of system users. Clinicians may distrust the system's advice and the system's role may not be clear. Enough attention has to be: paid to the preparation and training of system users.

Berg stresses that to make decision support techniques (including paper based protocols) work requires adaptation of both the initial design of the technique itself and medical practice. During development and implementation designers should give in to local needs 
such as local rules, available techniques and customs. To ensure that the technique will be used, medical practice should be adapted in such a way that the technique becomes an unavoidable part of daily life and users become dependent of it.

There are a few examples of successful CDSSs which seem to fulfill users needs and are integrated into the everyday clinical practice ${ }^{7.62}$. To achieve wide distribution of these successful systems it is vital that they can be easily transferred from one location to another. Until now only a few decision support systems could be transferred from their initial development site to other locations ${ }^{110.111}$. A reason for non-transferability is that successful systems have to give up much of their original design and scientific potential to get incorporated into practices. The successful transfer of a system may involve resolving differences in medical terminology, patient population, disease presentation, varying standards of practice, organization and the way the technique is to be used ${ }^{5,06,73}$. Also technical issues such as differences in knowledge acquisition methods, knowledge representation techniques and in the epidemiological composition of training databases may influence the transfer of knowledge based systems ${ }^{7}$. More research will be needed to resolve the problem of non-transferability.

A conclusion, concerning protocols, might be that a more widespread usage of protocols might be achieved by creating sufficient space for local or individual variation ${ }^{37}$. But when developers (or adaptors) give in too much to local needs, many incompatible local protocols will result ${ }^{170}$. When writing a protocol based on international data ${ }^{19}$, Eddy was confronted with non transferability of databases and had to give in to many compromises in order to keep the protocol feasible ${ }^{22}$. So, the question remains to what extent nationally (leveloped protocols can be transferred smoothly to local situations ${ }^{36}$.

\subsection{Evaluation of CDSSs in field trials}

A lot of CDSSs have been tested in laboratory settings mainly with respect to validity of the advice. It is naive to assume that all CDSSs which show promising in laboratory tests will also be effective when used clinically. Evaluation should also include features such as reliability, validity and acceptability of the advice in clinical practice. A final evaluation should assess the impact of the system's advice on clinician's performance and patient outcome $e^{40,14 x}$. The method by which a CDSS should best be evaluated depends highly on the research question to be answered. The assessment of the reliability of the system's advice may require a different study design than a study to assess its acceptability. In a literature review, van der Loo ${ }^{50}$ classified published evaluation studies of information technologies. $\mathrm{He}$ found that for different types of automated information systems, a rather large number of study designs, data collection methods and effect measures are used. Various aspects of the assessment and evaluation of information technologies in medicine have recently been published ${ }^{60}$.

To measure the impact of the advice of a CDSS (or any other decision support technique) on physicians' decision making and patient outcome the 'randomized controlled trial'. which is used in drug assessment, may not always be adequate ${ }^{100}$. There are specific problems related to this design. One problem is the carry-over effect which occurs as the CDSS induces an educational effect. Management of control patients or competence of control 
doctors may be contaminated by doctors who have access to decision support. To quantify the effect, intervention and control periods should be alternated. Another problem is that impact of CDSSs is often measured at two levels, physicians and patients respectively. Depending on the number and kind of clinical conditions supported, large numbers of participants may be required to assess patient outcome ${ }^{46}$. A final problem is that blinding of physicians is difficult to establish which may result in an unbalanced Hawthorne effect. The Hawthorne effect is the tendency for humans to improve their performance if they know it is being studied. An unbalanced Hawthorne effect can occur when doctors with decision support will constantly be reminded to the fact that their decisions are being studied, a condition which control doctors may lack. One way of countering this problem is a crossover trial but the only definite solution would be to compare the impact of one CDSS with another.

Johnston et al. ${ }^{46}$ reviewed studies that assessed the impact of CDSSs on clinician performance or patient outcome in a clinical setting. Only 28 evaluations could be identified where controlled prospective study designs were used. They concluded that some CDSSs can improve physicians' performance while additional studies are needed to assess their effects on patient outcome.

\section{Conclusion}

Protocols are viewed by many as the most suitable tool to aid physicians in the decision making process ${ }^{18,25,51,00,104}$. The 'black box' reasoning (converting 'input' data into one 'output' conclusion ${ }^{26}$ ) of pattern recognition is seen as a major disadvantage of this technique. The intermediate decisions leading to the 'output' conclusion are usually not shown or not available in an interpretable format. Artificial intelligence - especially rule based systems is more capabie in explaining its reasoning process. Protocols guide physicians stepwise through a whole sequence of medical decisions. The reasoning logic is displayed step by step although the justification is usualiy not shown.

Although each decision technique intends to support (rather than replace) physicians, $\mathrm{AI}$ as well as pattern recognition tend to 'take over' control from physicians more than protocols do (although critiquing systems comment on decisions after they are taken). Furthermore protocols may cover broader areas than other decision support systems do. Protocols can be rather inexpensive when developed locally but the development of scientific valid protocols is much more expensive $\mathrm{e}^{17,105}$.

Physicians are encouraged to apply decision analysis more often in clinical practice ${ }^{\mathrm{x} x}$ but it is not always easy to find all required (high quality) data to complete the models and to obtain utilities ${ }^{41}$. Decision analysis however is a very suitable method with which to develop an (evidence-based) protocol. After a thorough analysis, the options leading to the most beneficial outcome for the patient should be incorporated in the protocol.

The future has to learn under which circumstances each of the discussed approaches will be useful in supporting physicians in their daily work. 


\section{References}

1 Abendroth TW, Greenes RA. Computer presentation of clinical algorithms. MD Comput 1989;6:295-299.

2 Andreasen PB. Consensus conferences in different countries. Int I Techn Assess Health Care 1988;4:305-308.

3 Audet AM. Greenfield S, Field M. Medical practice guidelines: current activities and future directions. Ann Int Med 1990:113:709-714.

4 Barnett GO, Cimino JJ, Hupp JA, Hoffer EP. DXplain: an evolving diagnostic decision-support system. JAMA 1987;258:67-74.

5 Berg M. Rationalizing medical work. Decision support techniques and medical practices. Disșẹtation 1995

6 Brook RH. Practice guidelines and practicing medicine. Are they compatible? JAMA 1989;262:3027-3030.

7 Cannon SR, Gardner RM. Experience with a computerized interactive protocol system using HELP. Comp Biom Res 1980; 13:399.409.

8 Chassin MR, Brook RH, Park RE, Keesey J, Fink A, Kosecoff J, Kahn K, Merrick N, Solomon DH. Variations in the use of medical and surgical services by the medicare population. N Engl $J$ Med 1986:3i4:285-290.

9 De Dombal FT, Leaper DJ, Staniland JR, McCann AP. Horrocks JC. Computer-aided diagnosis of acute abdominal pain. BMJ 1972;2:9-13.

10 De Dombal FT. Computer-aided decision support-glittering prospects, practical problems, and Pandora's box. Bailliere Clin Ob Gy 1990:4:841-849.

11 Delbecq A. Van de Ven A. A Group process model for problem identification and program planning. J Applied Behav Sci 1971;7:467-492.

12 Dupuits FMHM, Hasman A. Evaluation of a decision support system in a medical environment. Int J Biomedical Computing 1995;38:155-165.

13 Eddy DM. Variations in physician practice: the role of uncertainty. Health affairs 1984; 3:74-89.

14 Eddy DM. The challenge. JAMA 1990;263:287-290.

15 Eddy DM. Anatomy of a decision. JAMA 1990;263:441-443.

16 Eddy DM. Practice policies - what are they? JAMA 1990:263:877-880.

17 Edidy DM. Practice policies: where do they came from? JAMA 1990:263:1265-1272.

18 Eddy DM. Practice policies - guidelines for methods. JAMA 1990;263:1839.1841.

19 Eddy DM. Guidelines for policy statements: the explicit approach. JAMA 1990;263:2239-2243.

20 Eddy DM. Comparing benefits and harms: the balance sheet. JAMA 1990;263:2493-2505.

21 Eddy DM. Designing a practice policy Standards, guidelines, and options. JAMA 1990:26:3:3077-3.084

22 Eddy DM. Applying cost-effectiveness analysis. The inside story. JAMA 1992;268:2575-2582.

23 Eddy DM, Hasselblad V. Shachter R. A bayesian method for synthesizing evidence: The confidence profile method. Int $\rfloor$ İechnol Assess Health Care i 1990;6:31-55.

24 Everdingen van JJE. Consensusontwikkeling in de geneeskunde. Bohn, Scheltema en holkema Utrecht/Antwerpen 1988

25 Feinstein AR. An analysis of diagnostic reasoning III. The constructions of clinical algorithms. Yale $J$ Biol Med 1974:1:5-32.

26 Feinstein AR. Bibliography of publications on observer variability. J Chron Dis 1985:38:619-632.

27 Fink A. Koșecofí J, Chasșin M, Brook RH. Consensus methods: characteristics and guidelines for use. Am J Public Health 1984:74:979-983.

28 Forsythe DE, Buchanan BG. Broadening our approach to evaluating medical information systems. Proc 15th SCAMC 1991:8-12.

29 Freemantle N. Grilli R, Grimshaw J, Oxman A. Implementing findings of medical research: the 
Cochrane collaboration on effective professional practice. Qual Health Care 1995;4:45-47.

30 Gennip EMSJ. Talmon JL, eds. Assessment and evaluation of information technologies in medicine. IOS press, Ohmsha, 1995.

31 Gorry G, Kassirer J, Essig A, Schawatz W. Decision analysis as the basis for computer-aided management of acute renal failure. Am J Med 1973:55:473-484

32 Greco PJ, Eisenberg JM. Changing physicians' practices, New Engl J Med 1993; $329: 1271-1274$

33. Greenes RA. A "building block" approach to application development for education and decision support in radiology: implications for integrated clinical information systems environments. J Digit Imaging 1991:4 213-225.

34 Grimm RH, Shimoni K, Harlan WR, Estes EH. Evaluation of patient-care protocol use by various providers. New Eng J Med 1975:292:507.511

35 Grimshaw JM, Russell IT. Effect of clinical guidelines on medical practice: a systematic review of rigorous evaluations. The Lancet 1993:342:1317-1322

36 Grimshaw J, Russell I. Achieving health gain through clinical guidelines 1. Developing scientifically valid guidelines. Oual Health Care 1993:2:243-248

37 Grimshaw JM. Russell IT. Acheving health gain through clinical guidelines II: Ensuring guidelines change medical practice Qual Health Care 1994:3:45.52.

38 Grol R. National standard setting for quality of care in general practice: attitudes of general practitioners and response to a set of standards. Brit J Gen Pract 1990:40:361:364

39 Grol $R$, Wensing $M$, Jacobs $A$. Baker $R$. Quality assurance in genral practice the state of the art in Europe. Nederlands Huisartsen Genootschap. Utrecht, 1993

40 Heathfield HA, Wyatt J. Philosophes for the design and development of clinical decision-support systems. Method Inform Med 1993:32:1-8.

41 Hendra TJ, Marshall AJ. Increased prescription of thrombolytic treatment to elderly patients with suspected acute myocardial infarction associated with audit. BMJ 1992;304:423-426.

42 Hickam DH, Shortliffe EH, Bischoff MB. Scott AC. Jocobs CD. The treatment advice of a computer-based cancer chemotherapy protocol advisor. Ann Intern Med 1985; 103:928-936.

43 Ingelfinger FJ. Algorithms, anyone? N Eng J Med 1973:288:847:848.

44 Jacoby I: The consensus development program of the National Institutes of Health. Current practices and historical perspectives. Int $J$ Tech Assess Health Care 1985:1:420.432.

45 Jacoby I. Rose M. Transfer of information and its impact on medical practice: the US experience. Int J Techn Assess Health Care 1986:2:107-116.

46 Johnston ME, Langton KB, Haynes RB, Mathieu A. Effects of computer-based clinical decision support systems on clinician performance and patient outcome. Ann Intern Med 1994;120:135-142.

47 Kahan JP. Kanouse DE, Winkler JD. Stylistic variation in National Institutes of Health consensus statements, 1979-1983, Int J Technol Assess Health Care 1988;4:289-304

48 Kanouse DE, Jacoby I. When does information change practitioners' behavior? Int $J$ Tech Assess Health Care 1988:4:27-33.

49 Kent DL, Shortiffe EH, Carlson RW, Bischoff MB, Jacobs CD. Improvements in data collection through physician use of a computer-based chemotherapy treatment consultant. J Clin Oncol 1985:3:1409-1417:

50 Komaroff AL, Black WI, Flatley M, Knopp RH, Reifen B. Sherman H. Protocols for physician assistants - management of diabetes and hypertension. N Engl J Med 1974;290:307=312.

51 Komaroff A. Algorithms and the 'art' of medicine. Am J Pub Health 1982;72:10-12.

52 Kosecoff J. Kanouse DE, Rogers WH. McCloskey L. Winslow CM, Brook RH. Effects of the National Institutes of Health Consensus Development Program on physician practice. JAMA. 1987:258:2708-2713.

53 Kosecoff J, Kanouse DE, Brook RH. Changing practice patterns in the management of primary breast cancer: consensus development program. Health Serv Res 1990:25:809-823.

54 Ledley RS, Lusted LB. Reasoning foundations off medical diagnosis. Science 1959;130:9-21

55 Lei van der J. Musen MA, Does van der E, Man in 't veld A.J. Bemmel van JH. Comparison of 
computer aided and human review of general practitioners management of hypertension, Lancet 1991;338:1504-1508.

56 Lomas J. The consensus process and evidence dissemination. CMAJ 1986:134:1340-1341.

57 Lomas J, Anderson GM, Domnick-Pierre K, Vaỵda E, Enkin MW, Hannah WJ. Do practice guidelines guide practice? N Engl J Med 1989;321:1306-1311.

58 Lomas J, Enkin M, Anderson GM, Hannah WJ, Vayda E, Singer J. Opinion leaders vs audit and feedback to implement practice guidelines. JAMIA 1991;265:2202-2207.

59 Loo van der RP. Gennip van EMSJ, Bakker AR, Hasman A, Rutten FFH. Evaluation of auto. mated information systems in health care: an approach to classify evaluative studies. Proceeeding MIE'94: 75-81.

60 Margolis CZ. Uses of clinical algorithms. JAMA. 1983; 249:627-32.

6.1 May WE. Consensus or coercion. JAMA 1985;254:1077.

62 McDonald CJ. Hui SL. Smith DM. Tierney WM, Cohen SJ, Weinberger M, McCabe GP. Remindeis to physicians from an introspective computer medical record (a two-year randomized trial). Ann Intern med 1984;100:130-138

63 Meneely GR, Paul O. Dorn HF. Harrison TR. Cardiopulmonary semantics. JAMA 1960:174:1628-1629.

64 Middleton B, Shwe MA, Heckerman DE, Henrion M, Horvitz EJ, Lehmann HP, Cooper GF. Probabilistic diagnosis using a reformulation of the INTERNIST-1/QMR knowledge base. II Evaluation of diagnostic performance. Meth Inform Med 1991;30:256-267.

6.5 Musen MA, Rohn JA, Fagan LM, Shortliffe EH. Knowledge engineering for a clinical trial advice system: uncovering errors in protocol specification. Bull Cancer Paris 1987:74:291-296.

66 Nolan J. McNair P. Brender J. Factors influencing the transferability of medicail decision support systems. Int J Biomed Comput 1991:27:7-26.

67 North of England Study of Standards and Performance in General Practice. Medical audit in generat pratice. IEffects on doctors clinical behaviour for common childhood conditions. BMJ 1992;304: 1480-1484

68 Oliver MF. Consensus or nonsensus conferences on coronary heart disease. Lancer $1985 ; 1: 1087-1089$

69 Park RE, Fink A Brook RH, ot al. Physician ratings of appropriate indications for six medical and surgical procedures. Arn J Public Health 1986;76:766-772.

70 Pearson SD, Margolis CZ, Davis S. Schreier LK. Gottlieb LK. The clinical algorithm nosology: a method for camparing algorithmic guidelines. Med Decis Making 1992:12:123-131.

71 Perrin JM, Homer CJ. Berwick OM, Woolf AD, Freeman $\pi$, Wennberg JE Variations in rates of hespitalization of children in three urban communities. New Engl J Med 1989;320:1183-1187.

72 Falffa H. Decision analysis. Introductory lectures on choices under uncertainty. 1968. Reading. MA: Addison-Wesley.

73 Reggia JA, Tuhrim S, ed. 1985. Computer-assisted medical decision making Volume. I. New York:Springer-Verlag.

74 Rennie D. Consensus statements. New Engl J Med 1981:304:665-566.

75 Riet ter G. Kleijnen d. Knipschild P. Accupuncture and chronic pain: a criteria-based metaanalysis. J Clin Epidemiol 1990:43:1191-1199

76 Rind DM, Safran C. Phillips RS, Slack WV, Calkins DR, Delbanco TL, Bleich HL. The effect of computer-based reminders on the management of hospitalized patients with worsening renal function. Proc16th SCAMC. 1992:28-32

77 Schioler T. Talmon J, Nolan J. McNair P. Information technology factors in transferability of knowledge based sỵstems in medicine. Art Intell Med 1994:6:189-201.

78 Shono H, Oga M, Shimomura K. Yamasaki M, Ito Y, Muro M. Sugimori H. Application of fuzzy logic to the apgar scoring system. Int I Biomed Comp. 1992;30:113-123.

79 Sikrabanek. P. Nonsensus consensus. Lancet 1990;335:1446-1447

80 Sheft DJ, Jones MD. Brown RF, Ross SE. Screening of chest roentgenograms by advanced roentgen technologists. Radiology 1970;94:427-429.

81 Shoemaker WC, Hopkins JA, Greenfieid S, Chang PC, Umof P, Shabot MM, Spenler CW, State 
D. Resuscitation algorithm for management of acute emergencies. JACEP 1978;7:361-367.

82 Shortiffe EH. Axline SG, Buchanan BG Mengan TC. Cohen SN. An artificial intelligence program to advise physicians regarding antimicrobial therapy. Comp Biomed Res 1973;6:544560 .

83. Shortliffe EH. Computer programs to support medical decision making. JAMA 1987:258:61. 66.

84 Sox HC, Sox. CH, Tompkins RK. The training of physician's assistants; the use of a clinical algorithm system for patient care, audit of performance and education. $N$ Engl J Med $1973: 288: 818-824$

85 Teach RL. Shortliffe EH. An analysis of physician attitudes regarding computer-based clinical consultation systems. Comp Biomed Res 1981;14:542-558.

86 Tielens VCL. Standaarden: het gezicht van de huisarts. Huisarts en wetenschap 1989:32:3.

87 Thacker SB. Meta-analysis: a quantitative approach to research integration. JAMA 1988:259:1685-1689.

88 Thornton JG, Lilford RJ, Johnson $N$. Decision analysis in medicine. Brit Med J 1992;304:1099-1103.

89. Tuddenham WJ. The use of logical flow charts as an aid in teaching roentgen diagnosis. A.JP 1968:102:797.803.

90 Tunis SR, Hayward RSA, Wilson MC, Rubin HR', Bass EB, Johnston M, Steinberg EP. Internists' attitudes about clinical practice guidelines. Ann Intern Med 1994;120:956-963.

91 Vang $J$. The consensus development conference and the European experience. Int J Tech Assess Health Care 1986:2:65-76.

92 Walker RD, Howard MO, Lambert MD, Suchinsky R. Medical practice guidelines. West J Med $1994: 161: 39 \cdot 44$

93 Waki $R$, Clayton $P$, Jensen $R$, Yanowitz F, Liddle $H$. Patient specifice medical decision anaiysis using the HELP system. In Proc Fifth Ann Symp on Comp Applic in Med Care IEEE, 1981:237. 242.

94 Wennberg J, Gittelsohn A. Small area variations in health care delivery. Science, 1973;182:1102-1108.

95 Wennberg JE, Gittelsohn A. Health care delivery in Maine I: Patterns of use of common surgical procedures. Maine medical association 1975:66:123-130,149.

96 Wennberg JE, Freeman JL, Culp WJ. Are hospital services rationed in New Haven or over. -utilised in Boston? Lancet 1987;1:1185-1189.

97 Wennberg JE. Unwanted variations in the rules of practice. JAMA 1991;265:1306-1307.

98 Wensing M, Grol R.Single and combined strategies for implementing changes in primary care: a literature review. Int J Qual Health Care 1994;6:115-132.

99 Williams BT. Computer aids to clinical decisions, volume I. CRC press, Boca Raton, Florida (1982).

100 Winkens RAG, Pop P. Grol RPTM, Kester ADM, Knottnerus JA. Effect of feedback on test ordering behaviour of general practitioners. Brit Med J 1992:304:1093-1096.

101 Winkens RAG, Pop P. Bugter-Maessen AMA, Grol RPTM, Kester ADM, Beusmans GHMI. Knottnerus JA. Randomised controlled trial of routine individual feedback to improve rationality and reduce numbers of test requests. The Lancet 1995;345:498-502.

102 Wirtschafter D, Carpenter JT. Mesel E. A Consultant-Extender system for breast cancer adjuvant chemotherapy. Ann Intern Med 1979;90:396-401.

103 Wirtschafter DD. Scalise M. Henke C. Gams RA. Do information systems improve the quality of clinical research? Results of a randomized trial in a cooperative multi-institutional cancer group. Comp Biomed Res 1981:14:78-90.

104 Woolf SH. Practice guidelines: a new reality in medicine. I. Recent developments. Arch Intern Med 1990:150:1811-1818.

105 Woolf SH. Practice guidelines, a new reality in medicine. II. Methods of developing guidelines. Arch Intern Med 1992;152:946-952.

106 Wyatt J, Spiegelhalter D. Field trials of medical decision-aids: potential problems and solutions. 
Proc 15th SCAMC 1991:3-7.

107 Wyat JC. Clinical data systems, part 3: development; and evaluation, Lancet 1994; 344:1682-1688.

108 Young DW. Doctors attitudes to a computer based Clinical Information System. Meth Inform Med 1981;20:196-200.

109 Zadeh LA. Making computers think like people. IEEE. Spectrum 1984;21:26-32.

110 Zagoria R, Reggia J. Transferability of medical decision support systems based on Bayesian classification. Med Decis Making 1983:3:501-509.

111 Zoltie N, Horrocks J, de Dombal F. Computer-assisted diagnosis of dyspepsia-report on transferability of a system, with emphasis on early diagnosis of gastric ancer. Meth Inform Med 1977:16:89-92. 
Chapter 3

Selection and development of research protocols 


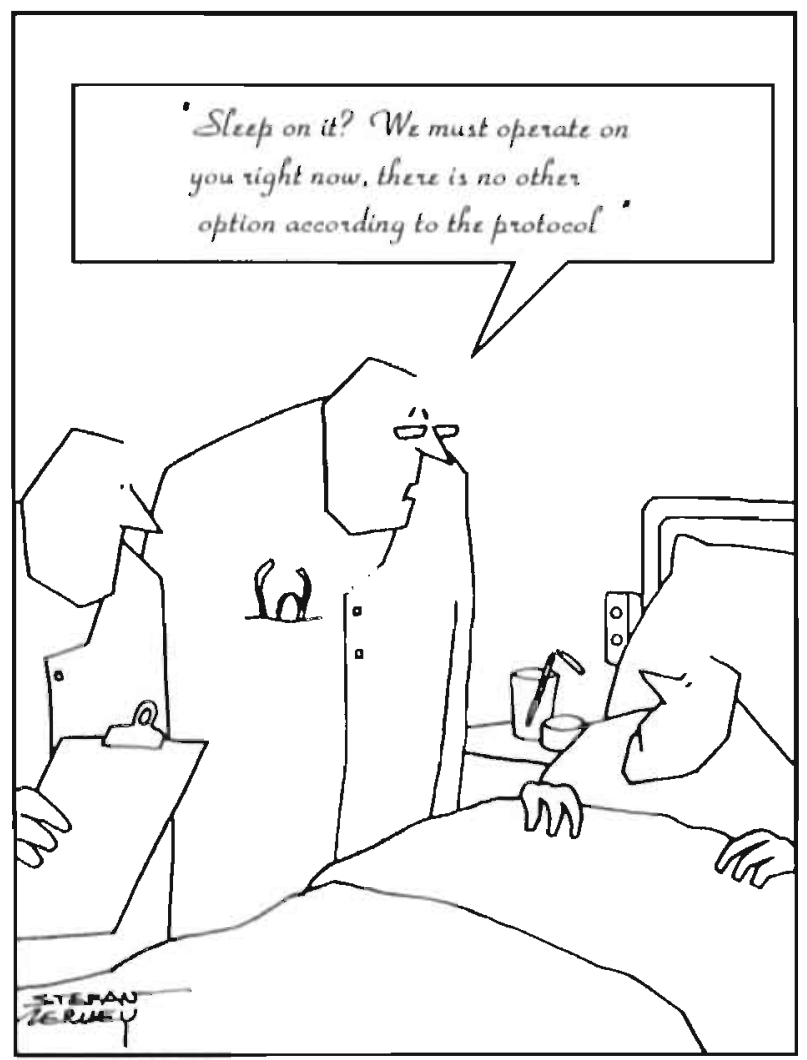

About rigidity... 


\section{Introduction}

In this chapter we present two surgical domains, traumatology and obstructive jaundice. in which we investigated several aspects of diagnostic and therapeutic protocol usage. The characteristics of the surgical domains, the origin of the protocols, previous research and the objectives of the investigations are discussed. In each section the first paragraph is about traumatology, whereas the second is about obstructive jaundice.

\section{Characteristics of the surgical domains}

\subsection{Management of fractures in the Accident and Emergency department}

At the Accident and Emergency (A \& E) department, very often, appropriate decisions have to be made quickly while, especially in academic hospitals, this department is mainly staffed by relatively inexperienced residents. Furthermore, experienced residents are replaced by inexperienced ones regularly. Finally, patients are often treated by various physicians during their follow-up visits which requires uniformity of treatment. These residents encounter many situations they are not familiar with. The commonest way to deal with uncertainty is to ask the opinion of colleagues ${ }^{2 n}$. Especially at evening and night time, however, experienced colleagues are not available. Then residents work more or less on their own while previous research has shown that residents are scarcely prepared for their task in the $\mathrm{A} \& \mathrm{E}$ department ${ }^{20,29}$.

\section{2 Diagnosis and management of obstructive jaundice}

Obstructive jaundice is a medical problem not frequently seen. It is a complex medical problem mainly dealt with by experienced physicians. The diagnostic process involves the cooperation of several disciplines (radiology. gastroenterology and surgery) and may consist of severa! diagnostic investigations. Fast changing medical insights and divergent preferences among the participating disciplines make it difficult to achieve a uniform workup strategy of high standard which limits costs and inconvenience for the patient as much as possible. Despite these obstacles, a diagnosis has to be established within the shortest possible time since obstructive jaundice is a severe medical condition.

\section{Review of the literature}

\subsection{Traumatology}

Not many studies can be found in the literature concerning protocol support for simple common medical problems at the A \& E department. Only two studies ${ }^{3 . *}$ could be retrieved about protocol usage in skull radiography in patients with head injuries. Both studies evaluated protocols in the A \& E departments. The studies were included in a review study ${ }^{12}$ examining whether protocols can change the behaviour of health care professionals. Both studies investigated the effect on process, as measured by adherence to the protocols, while effects on patient outcome were not measured. The study by Fowkes et al." used nationally developed protocols while the study of Clarke and Adams used locally devel- 
oped protocols. Both studies showed a significant improvement of adherence to the protocols' recommendations. However "both studies made use of a 'before and after' controlled design, generally considered less valid than randomized (crossover) trials ${ }^{12}$.

\subsection{Obstructive jaundice}

Already in the sixties and seventies computer programs were developed to support physicians in the diagnostic process of jaundice. These programs predicted whether the obstruction was intra- or extra-hepatic based upon dozens of indicators from history, physical examination and biochemical data (clinical evaluation) ${ }^{1,4,10,11}$. Afterwards, subsequent computer programs could predict the location of obstruction more accurately using fewer indicators $^{2,15}$. These programs however, do not perform better than trained clinicians ${ }^{3,17.18 .25}$ but can be of help for inexperienced physicians.

Clinical evaluation is followed by the diagnostic work-up which attempts to confirm the suspected diagnosis making use of several diagnostic imaging techniques. In order to make optimal choices from the large number of available techniques accurate decision support would be very helpful. Until now, a few computerized decision support systems such as the expert systems HEPAR ${ }^{13}$ and DXcon ${ }^{26}$, have been developed to support the diagnostic work-up of jaundice. The working strategy supported by these systems is based upon a local consensus process indicating the lack of a generally accepted protocol for the best working strategy. Particularly in the work-up of obstructive jaundice this might be attributed to the numerous changes that occurred in the improvement of existing imaging techniques and the development of new ones in the past 10 years. Still, many studies deal with comparisons of several imaging techniques ${ }^{16,19,21}$. Several contradicting strategies have been proposed by different authors ${ }^{7,14.22}$. In 1989 the committee of the American Gastroenterology Association formulated a protocol for the work-up of jaundiced patients based upon a consensus conference".

\section{Protocol support at the local level}

\subsection{Traumatology}

In the past. trauma protocois were developed to educate and support inexperienced residents working in the $A \bar{E}$ department of University Hospital in Nijmegen. The trauma protocols (to be used in chapters 5-7) were the result of informal consensus ${ }^{27}$ among local surgeons. The protocols contained information about the management of common isolated fractures. The structure of the protocol is simple and straightforward. For each fracture type the protocol prescribes a treatment plan such as: the immobilisation material to be used, the duration of immobilisation and the follow-up schedule. The protocols consisted of 106 different protocol treatments for 120 fracture types (some protocol treatments are used for several fracture types). The protocols hardly contain any information about the diagnosis of fractures which is based upon physical and $x$-ray examination only. The protocols were collected in an easy-to-carry pocket book and subsequently distributed among the physicians concerned. Figure ! displays such a protocol in its pocket book format. 


\section{Eracture of forearm benes}

Fractures of both of the forearm bones is common in children (mostly greenstick. fractures) which can be treated conservatively after manipulative reduction. In adults open reduction with internal fixation is often required. Only fractures without angulation, rotary deformity or shortening will be treated conservatively as follows:

Manipulative reduction carried out under general anaesthesia; the elbow, forearm, wrist and hand are then immobilized (proximal fractures in supination, mid-fractures in mid-position and distal fractures in pronation) for 6 weeks.

Follow-up: 1 day (check plaster), 1 week (check reduction of displacement), 6 weeks, 10 weeks.

\section{Colles' fractures ifractura radii typical}

Fractures of the distal radius localized at the former epiphyses. Dorsal and radiair displacement of the distal fragment leads to a typical deformity which reșembies a bayonet and diner fork.

Conservative treatment:

Nondisplaced fractures: the forearm should be immobilized for 5 weeks.

Follow-up: 1 day (check plaster), 1 week, 5 weeks. (remove plaster and start exercises).

Displaced fractures: reduction funder local anaesthesia. Inject $1 \%$ Lidocaine into the haematoma surrounding the fracture). Reduction should be as adequate as possible: The forearm should be immobilized in a position of slight supination or mid-position with the wrist in $15^{\circ}$ of flexion and with $20^{\circ}$ of ulnar deviation for 6 weeks.

Follow-up: 1 day (check plaster and obtain $X$-ray to check proper positioning), 1 week (obtain $\mathrm{X}$-ray to check proper positioning), 6 weeks (remove plaster and start exercises). In case $X$-ray reveals displacement after 1 day or 1 week, reduction should be repeated. Reduction should be followed by internal or external fixation. Again an $X$-ray should be obtained after 1 week.

Figure 1 Part of the paper based fracture protocols.

\section{2 Prolocols to support diagnosis and treatment of obstructive jaundice}

In 1992, an informal consensus conference ${ }^{27}$ about the diagnostic work-up of obstructed jaundice for patients suspected of a malignancy was held in the Netherlands. Participants were 4 surgeons, 5 radiologists and 6 gastroenterologists working in 4 different University Hospitals. A number of general guidelines and recommendations concerning the diagnostic work-up and treatment of obstructive jaundice resulted from this meeting ${ }^{21}$. Figure 2 displays - in a flow chart - the recommended working strategy which was based upon the experiences and knowledge of experts. Since a local protocol for the work-up and management of obstructive jaundice was not available at the University Hospital of Maastricht, a local surgeon adapted the national protocol. The protocol was extended to be used for all patients with obstructive jaundice and modified for locally available resources (see chapter 8). Protocols serve different purposes in the diagnostic and therapeutic process. Therefore, we chose two different surgical working environments with completely different characteristics to investigate several aspects of protocol usage. The differences are listed in Table 1. 


\section{Suspicion of Malignant Distal Bile Duct Obstruction}

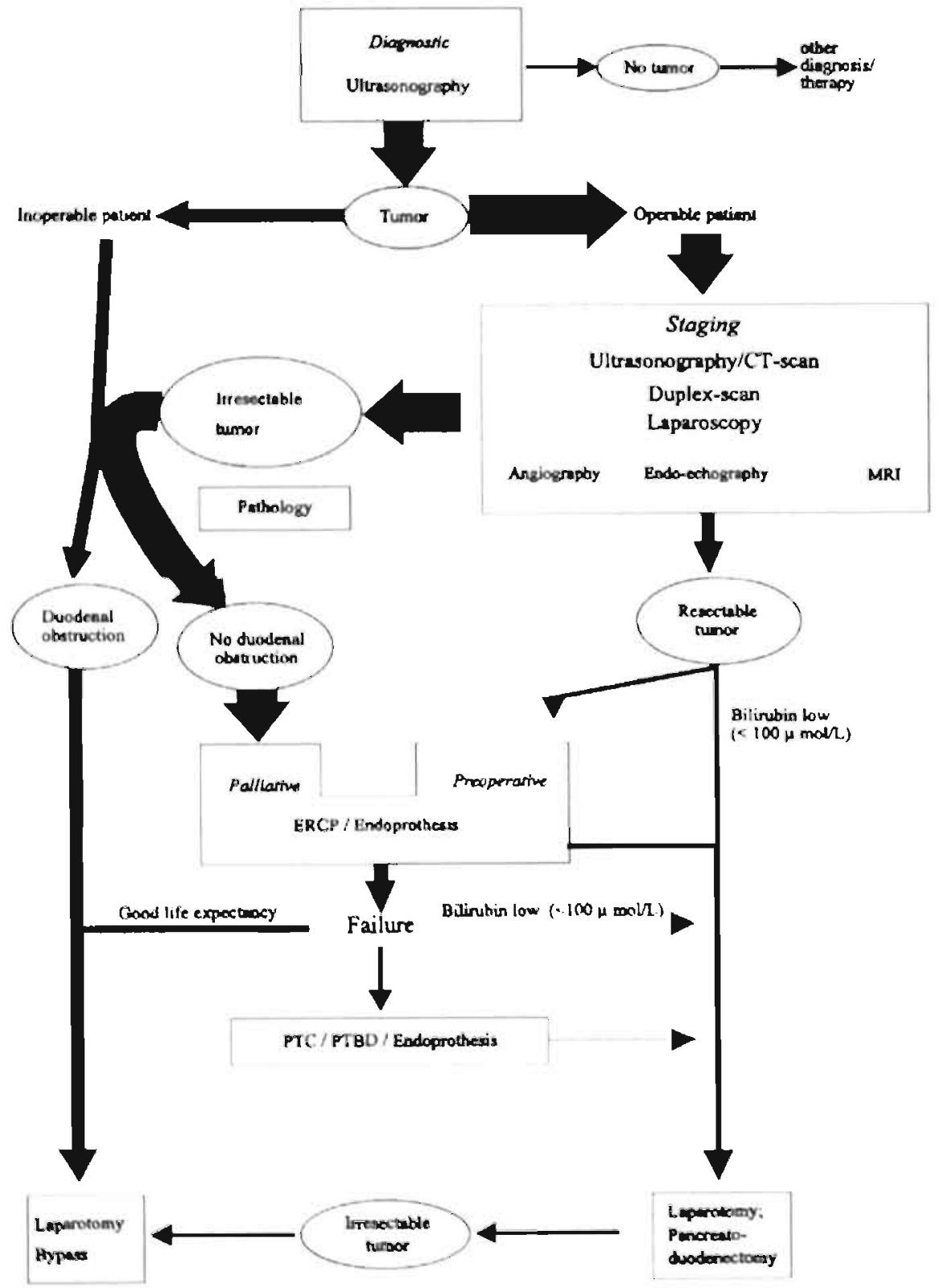

Figure 2 National protocol for the work.up of patients with obstructive jaundice suspected of a malignancy. 
Table 1 Characteristics of the surgical domains studied

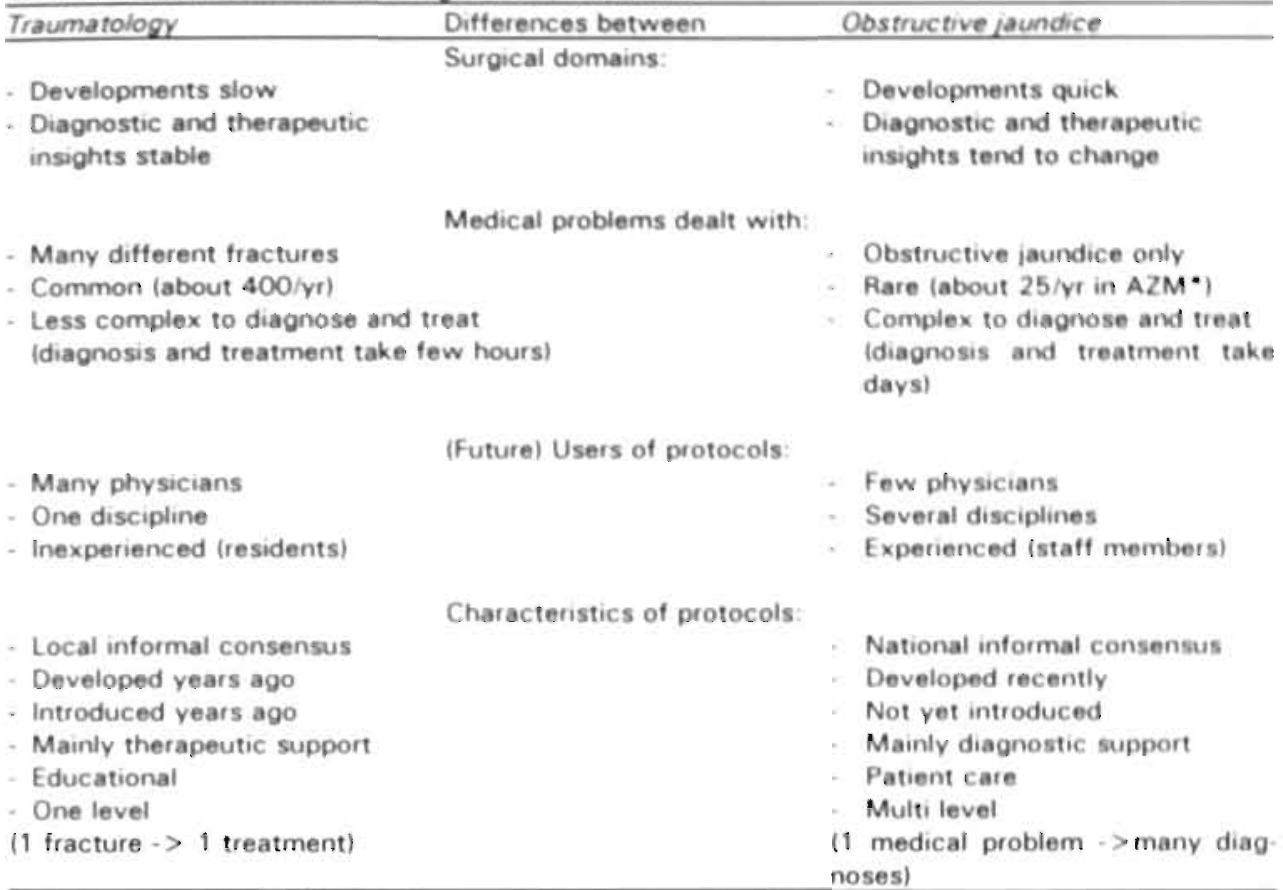

- University Hospital of Maastricht

\section{Study objectives}

\section{1 Traumatology}

Although the situation at the A \& E department seemed to call for protocol support, the developed protocols were infrequently consulted after they became available. A preliminary survey showed that only $27 \%$ of the A \& E patients with fractures, joint luxation or joint ligament lesions were treated in complete accordance with the protocol.

Some reasons for poor protocol adherence might be considered. First, residents want to loose as little time as possible when looking for information since decisions have often to be made quickly. Conversations (often by telephone) with colleagues or supervisor are experienced as fast and easy ${ }^{2 \pi}$. Moreover, it is safe to rely on advice of supervisors when physicians are not certain about medical decisions. Consulting protocols should therefore be just as fast as making a phone call.

\section{2 Obstructive jaundice}

As outlined previously, obstructive jaundice is a complex medical problem which requires good cooperation between several disciplines. To optimally streamline the diagnostic process, a protocol must be available at any location in the hospital any time. Due to the complexity and extensiveness of the medical problem, physicians should be provided with protocol information in a structured way. On the other hand, physicians should be able to 
retrieve background information relevant for their discipline without drowning in the information. The diagnosis of obstructive jaundice takes several days, diagnostic decisions previously made must be available. Finally, developments in this field require fast and regular updating of the protocols. A computer system might be very useful in overcoming the limitations of paper protocols. Furthermore, patient data can be stored and information can be retrieved any time.

Therefore, our research focuses on the development, implementation, and evaluation of an automated protocol processing system to solve some problems and limitations of paper based protocols.

The main purpose was to design an interface that presents protocols in a convenient and user friendly way.

Specific questions to be answered were:

1 Is the system transparent enough for the user to find the correct information?

2 How often is the system used correctly (consulted before final treatment decisions were made)?

3 To what extent is consultation of the system time consuming?

4 To what extent is the system experienced as a useful information source by the users?

5 What are the benefits of such a system in daily practice in terms of correct of use of the system, time consumption, providing useful information?

We do not expect that a flexible information system will be the ultimate stimulus to change physicians' behaviour. Other aspects play a role in this process too. Previous research has shown that especially less experienced physicians appeared to overestimate the certainty of their initial diagnostic impressions ${ }^{24}$. Therefore, we may doubt whether physicians will be able to decide when they need to consult the information system in routine circumstances. It is interesting to know the relation between protocol consultation and the confidence physicians have in the correctness of their medical decisions.

We therefore investigated the effect of mandatory and optional protocol consultation on protocol adherence and trearment using an automated protocol processing system.

Specific questions to be answered were:

1 What information sources are used in routine circumstances?

2 To what extent physicians are able to decide whether they need to consult the protocols?

3 To what extent does mandatory protocol consultation lead to improved protocol adherence and better treatment?

The nationally developed protocol for the work-up and management of obstructive jaundice was extended and adapted by a local expert to be used at the surgical, internal and 
radiology departments of the University Hospital in Maastricht. The modified protocol will be stored into ProtoVIEW and introduced into clinical practice. Since local expertise with available resources may differ from those reported in the literature (on which protocol recommendations are based), the validity of adapted national protocols can be doubted.

We therefore investigated to what exsent a nationally developed protocol can be transferred to a local situation.

Specific questions to be answered were:

1 What is the potential benefit of an adapted national protocol for local use by comparing its recommendations with the strategies actually followed in patients with obstructive jaundice.

2 How does local expertise with diagnostic and therapeutic procedures compare with expertise reported in the literature?

\section{References}

1 Burbank F. A computer diagnostic system for the diagnosis of prolonged undifferentiating liver disease. Am J Med 1969:46:401-415.

2 Begon F, Lockhart AM, Métreau JM, Dhumeaux D. A computer-aided system for the diagnosis of hepato-biliary diseases. A comparison with the performance of physicians. Med Inform $1979 ; 4: 35-42$.

3 Camma C, Garofalo G, Almasio P, Tine F, Craxi A, Palazzo U et al. A performance evaluation of the expert system 'Jaundice' in comparison with that of three hepatologists. 1991:13:279. 285

4 Cattaneo AD, Lucchelli PE, Rocca E, Mattioli F, Becchi G. Computer versus clinicall diagnosis of biliary tract diseases. J Abd Surg 1972;14:71-75.

5 Clarke JA, Adams JE. The application of clinical guidelines for skull radiography in the accident. and emergency department: theory and practice. Clin Radiol 1990:41:152-155.

6 Dessel PFHM, Hasman A, Linden CJ van der. ProtoVIEW: a workstation for the use of clinical algorithms In: Adlassnig KP, Grabner G, Bengtsson S, Hansen R, editors. Lecture Notes in Medical Informatics, 45. Springer Verlag, Berlin, 1991:233-237.

7 Eyre-Brook IA, Ross B, Johnson AG. Should surgeons operate on the evidence of ultrasound alone in jaundiced patients? Br J Surg 1983;70:587-589.

8 Fowkes FGR, Evans RC. Williams LA, Gehlbach SH, Cooke BRB, Roberts CJ. Implementation of guidelines for the use of skull radiographs in patients with head injuries. Lancet 1984;ii:795. 797.

9 Frank BB. Clinical evaluation of jaundice. A guideline of the patient care cammittee of the american gastroenterological association. JAMA 1989;262:3031-3034.

10 Fraser PM, Baron DN. Computer-assisted classification and diagnosis of liver disease. Proc R Soc. Med 1966;59:776 779.

11 Fraser PM. Franklin D. Mathematical models for the diagnosis of liver disease. Ouart J Med 1974 43:73-88.

12 Grimshaw J, Freemantle N, Wallace S, Russell I, Hurwitz B, Watt I, Long A, Sheldon T. Devel. opment and implementing clinical practice guidelines. Oual Health Care 1995:4:55-64 .

13 Lucas P.JF, Segaar RW, Janssens AR. HEPAR, an expert system for the diagnosis of disorders of the liver and biliary tract. Liver 1989:9:266-275.

14 Lunderquist A. The radiology of jaundice. Baill Clin Gastroenterol 1989;3:387-405.

15 Malchow-Meller A. Thomsen C, Matzen P. Mindeholm L. Bjerregaard B. Bryant S et al. Com- 
puter diagnosis in jaundice. Bayes' rule founded on 1002 consecutive cases.J Hepatol 1986;3:154-163.

16 Malchow-Møller A, Grønvall S, Milden J: Juhl E: Lassen A, Matzen P et al. Utrasound examina. tion in jaundiced patients. Is computer-assisted preclassification helpful? J Hepatol 1991:12:321-326.

17 Matzen P. Diagnosis in jaundice: a contemporary approach. Dig Dis 1986:4:220-230.

18 Matzen P. Malchow-Maller A. Use of computers in diagnosis off jaundice. Baill Clin Gastroenterol 1989;3:407:421.

19 Matzen P. Malchow-Møtter A, Brun B, Grønvall S, Haubek A, Henriksen JH et al. Uitrasonography, computed tomography, and cholescintigraphy in suspected obstructive jaundice- a prospective comparative study. Gastoenterol 1983;84:1492-1497.

20 Morris F. Cope A, Hawes S. Training in accident and emergency: views of senior house officers. BMJ 1990; 300:165-166.

21 Obertop H, Leeuwen DJ, Leeuwen MS. Het gebruik van afbeeldingstechnieken voor diag. nostiek en therapie bij icterus met het vermoeden van maligne obstructie van de distale galwegen. Ned Tijdschr Geneeskd i 992:136:1450-1458.

22 Olen R. Pickleman J. Freeark RJ. Less is better. The diagnostic workup of the patient with obstructive jaundice. Arch Surg 1989:124:791-795.

23 Pasanen PA, Partanen K. Pikkarainen P. Alhava E. Pirinen A, Janatuinen E. Diagnostic accuracy of ultrasound, computed tomography, and endoscopic retrograde cholangiopancreatography in the detection of obstructive jaundice. Scand J Gastroentero 1991:26:1157-1164.

24 Sklar DP. Hauswald M, Johnson DR. Medical problem solving an uncertainty in the emergency department. Ann Emerg Med 1991;20;987-991.

25 Stern RB, Knill-Jones RP. Williams R. Clinician versus computer in the choice of 11 differential diagnoses of jaundice based on formalised data. Meth Inform Med 1974; 13:79-82.

26 Swett HA, Rothschild M. Weltin GG, Fisher PR, Miller PL. Optimizing radiologic workup: an artificial intelligence approach. J Dig Imag 1989;2:15-20.

27 Woolf SH. Practice guidelines, a new reality in medicine. II. Methods of developing guidelines. Arch intern Med 1992:152:946-952.

28 Wyatt J. Use and sources of medical knowledge. Lancet 1991:338:1368-1373.

29 Yates DW. Wakeford R. The training of junior doctors for accident and emergency work: a case for urgent treatment? Injury 1985:14:456-460. 
Chapter 4

Development, implementation and a first evaluation of a protocol

processing system (ProtoVIEW)

\author{
Vissers $\mathrm{MC}^{!}$ \\ Hasman $\mathrm{A}^{1}$ \\ Donkers HHLM ${ }^{1}$ \\ van der Linden $\mathrm{CJ}^{2}$
}

'Department of Medical Informatics, University of Limburg, Maastricht

${ }^{2}$ Department of Surgery, University of Nijmegen, The Netherlands 


\section{Abstract}

In this contribution the protocol information system ProtoVIEW is presented. The system provides the necessary information to physicians about diagnostic procedures and therapies. It is implemented as a stand alone system. The design criteria are discussed and the results of a first evaluation presented. It appears that interns can easily find the required information with the help of the system. The time that they need for accessing the relevant information is relatively short (about 1 minute). The users expressed the opinion that the system is easy to use and does support them in the management of their patients. On the basis of this evaluation and evaluations reported elsewhere it is concluded (a) that standalone protocol systems can support daily patient management in a positive way and (b) that the design criteria for a protocol information system as presented in this paper are useful for prospective protocol information system developers. 


\section{Introduction}

Computer systems are ideally suited for providing decision support. Several types of systems can be distinguished. Reference systems provide decision support by allowing access to large knowledge bases, usually stored in the form of free text, sometimes with graphical additions. Procedural decision support systems contain the domain knowledge in their procedures. Decision making is performed in an algorithmic way. The user has to enter the necessary data and the system. then determines the solution. Finally knowledge based systems contain the knowledge separately from the procedures. The procedures, also collectively called inference mechanism, can reason with the knowledge stored in a knowledge base. The knowledge in this case is often represented in a declarative form. Contrary to procedural decision support systems such systems are easier to maintain: when the knowledge is incorporated in the procedures, changes in the knowledge of one procedure can have unforeseen consequences for other procedures. Knowledge based. systems and procedural decision support systems have been proven to support medical decision making in well defined limited domains. On the basis of information voluntecred by the user the system provides valuable diagnostic or therapeutic suggestions.

Knowledge based systems and to a lesser extent procedural decision support systems can justify their decisions. Such systems are active systems in the sense that they reason with the knowledge they possess. The user has a more passive role and only supplies the facts that are needed by the system to reason with its knowledge base. This type of approach has been called the Greek oracle approach. Some knowledge based systems exploit the knowledge of the user. An example of such a cooperative system is QMR ${ }^{15}$.

Decision support systems can also be discerned by the way they provide advice. Solicited advice systems provide advice on the request of the user. In this case the user is usually asked by the system for data. Unsolicited advice systems react on the data that have been entered by the user through another registration system (e.g. a clinical information system). In this case the system has to be integrated with the registration system.

The ultimate intention of decison support systems is to support and improve the decision making process. Several computerized information systems have proven their value in surgical decision support ${ }^{2,13,18}$. The type of system to be used in a certain medical domain should be chosen carefully in order to fill up existing gaps without creating other obstacles. An area suitable for computer support seems to be diagnostic and therapeutic protocols. Protocols make it possible to introduce uniform guidelines in a clinical department. Although the use of printed copies of the algorithms proved to be valuable ${ }^{6,8,10}$, paper protocols seem to suffer from several limitations. One of the problems is that when protocols become larger they are more difficult to access. Furthermore, paper protocols are too static to keep rapidly changing protocols up to date. A computer system might be very useful in overcoming these limitations.

A research project was started with the main objective of designing and implementing a prototype information system providing protocol information for diagnostic and therapeutic purposes. The developed system is used as a research instrument in order to study the 
effects of such a system on the management of patients. The research project. had to answer the following questions:

(1) What should the design criteria be of a computer based system that can overcome limitations of paper protocols? (2) What are the benefus of such a system in daily practice? Is the system easy to use and does it lead to a better protocol adherence? (3) Will the system be useful as a stand-alone system or should it be integrated with an electronic medical record system in order to be really useful?

This paper describes the developed protocol information system, ProtoVIEW, that is predominantly passive, has the characteristics of a reference system and provides solicited advice when working in the active mode. It enables users to access a large number of protocols. In the active mode the system guides the user through the protocol. As such it also has the characteristics of a cooperative system.

It might be argued that such a system should be integrated with a clinical information system but this was not possible in our case. This situation occurs in many hospitals where it is not possible to enter clinical data in an existing hospital information system. The HELP system and the Regenstrief system are exceptions , $^{3,14}$. Since personal computers are on the desk of many physicians it was assumed that the protocol system described here could fill an existing gap.

In this contribution the design criteria of the system are emphasized and the results of a first evaluation study concerning user acceptance are reported. The other aspects of the research project will be presented in forthcoming papers.

\section{Design criteria}

\section{1 Protocol usage}

The process via which the expert gains expertise in diagnosis and therapy ultimately results in the construction of a mental model of the structure of a problem domain ${ }^{16,16}$. By writing a clinical algorithm the expert makes this mental model explicit and therefore accessible to other physicians. Expressed in this way clinical algorithms effectively portray the complex branching structure of therapeutic and diagnostic strategies and the expert's opinion regarding the method of solving specific problems. Algorithms make it possible to introduce uniform guidelines in a clinical department. Protocols can be of help for less experienced physicians in selecting the right therapeutic or diagnostic action from the vast amount of possibilities. Protocols allow clinicians to transfer knowledge about diagnostic and therapeutic procedures to other persons or institutions $s^{1,12}$, which makes it possible to reach global consensus on the number of diagnostic steps and the optimal treatment of specific diseases. Thus, by taking full advantage of these improved communication facilities, clinical algorithms can aid in optimizing clinical care.

\section{2 limitations of paper protocols}

Until now the standard procedure was to publish protocols in a book which was subsequentiy distributed among the physicians concerned. Paper protocols however seem. to suffer from several limitations. As clinical problems become more complex protocols tend 
to grow larger. This makes it harder to interpret the information contained therein and the accessibility of the information will degrade. Furthermore, paper protocols prove to be too static a medium to keep rapidly changing protocols concerning - in our case - surgical problems up to date 4 . Last but not least, because of the ever increasing complexity of the problems algorithms, are dealing with, the resulting protocols might be less evident for the non-expert physicians since they lack the background knowledge on which the protocol decisions are based. The more flexible way of presenting algorithms with the help of a computer system might be very useful in overcoming these limitations.

\section{3 system requirements}

Since physicians are not all experienced computer users it was evident that the information system had to be user-friendly. Users should be able to familiarize themselves with the system in a short time. Limited data input by keyboard and an easy to control user interface should enhance the acceptability of the system ${ }^{17}$.

Limitations in their capability of fast and easy updating of protocol information make paper protocols unreliable soon after their release. Therefore the system should enable physicians to create and update protocols easily.

Protocols are often presented in a simplified way by means of a flowchart supplied with limited textual information. Despite this structuring and the restrictions in textual information, it still takes time to find the right protocol information especially when protocols are larger and more complex. Moreover, less specialized physicians may need more background information than experts.

Therefore, the protocol information system should be able to present protocols in various ways (graphical and textual) with the possibility of switching easily between them. Furthermore the information system should provide adequate searching facilities allowing users to obtain the additional information they wish to view.

The diagnostic and therapeutic process often covers several days. Therefore, when consulting the system in different stages of this process the results of earlier diagnostic and therapeutic choices should be available. Therefore, all actions performed during the consultation of the information system have to be recorded.

\subsection{System considerations}

Protocols may be suitable for implementation as knowledge based systems. ONCOCIN is an example of such a system?. In ONCOCIN a general treatment plan is generated that is subsequently refined using inferential knowledge. ONCOCIN supports a large number of protocols dedicated to oncology. In our situation the protocols cannot be described by a general framework that can be refined depending on the circumstances. So the approach used in ONCOCIN was not considered feasible in our case. Part of the protocols (clinical algorithms) can be viewed as rules that could be appropriate for implementation as a rule based system. It is our experience however that it is not always very easy to translate free text protocol information in formal rules that can be used in a rule based system. The free text descriptions of the clinical algorithms often contain information that a human will understand but that cannot be used in the same way by an expert system; for example 
certain information may be implicit in the protocol descriptions. We therefore decided to store the information contained in the protocols as free text. The branching character of clinical protocols does not pose problems. Connections between different parts of protocols or with background information can be obtained via a hypertext approach. Another reason we chose a more passive approach is that clinicians more readily accept computer systems meant to support clinical practice than computer systems that automate clinical activities traditionally performed by clinicians ${ }^{9.17}$.

\section{Description of ProtoVIEW}

\section{1 Hardware specifications and program languages}

The protocol information system was developed for implementation on IBM compatible stand-alone PCs. The system was programmed in Turbo Pascal 6.0 making use of Hyperpas, a home-made object-oriented toolbox with which a graphical user interface similar to Microsoft Windows or the Macintosh interface can be built. This toolbox provides among others full mouse support, both stacked and resizable windows, icons, buttons, entry fields, pull-down menus and both normal text and hypertext windows.

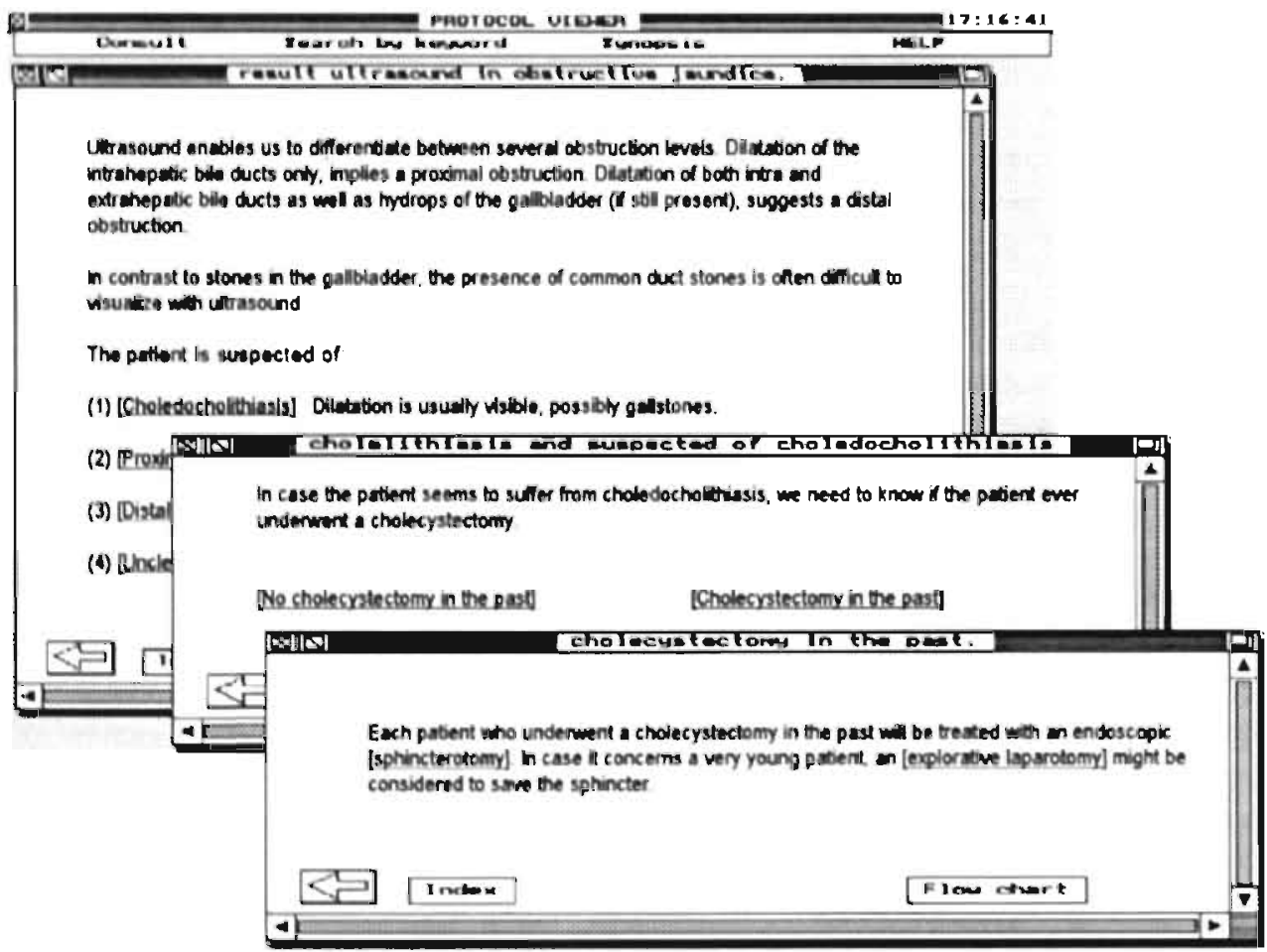

Figure 1 Text-browse windows containing protocol information. 
Since the acceptance of MS-Windows 3.1 as the defacto standard PC-graphical environment, the maintenance of Hyperpas as windowing environment was discontinued. Only small adaptations for specific applications are carried out. Btrieve is used as record manager. Btrieve is a memory-resident record manager program that manages, reads, updates, and inserts records in database files. For example, it supports sophisticated indexing, variable record length and record and file locking, etc. Btrieve routines can be invoked by a Turbo Pascal program by calling an interrupt address. An interface to Btrieve providing programmer friendly routines was available' and used in the development of ProtoVIEW.

\subsection{The user interface}

The user interface - the protocol viewer - makes use of a number of different window types (text-browse windows, tree windows and a summary window) and has a main menu from which these windows can be called. The main menu contains four pull down menus. The corresponding four options are the following. The first option concerns either the entry of patient demographic data when a new patient is seen or the retrieval of existing patient demographic data. The second option allows the search for information via keywords. This search procedure uses both exact, partial and phonetic methods for matching the entered keyword with information in the system.
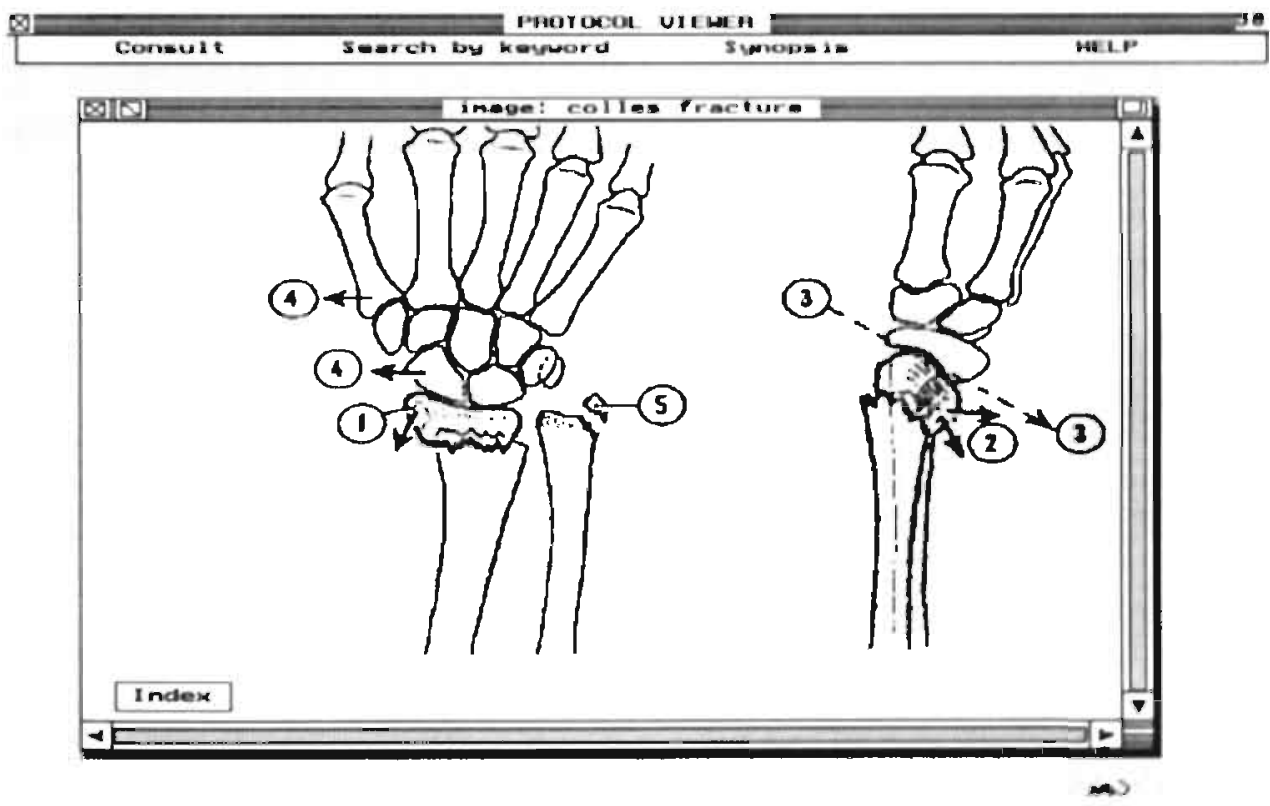

Figure 2 Text-browse window containing an image.

With the third option a summary is presented of the available patient medical data such as test results and actions taken. A printout of this summary can be obtained. The fourth 
option is a help function with which general information about the use of the program can be obtained.

\subsection{Text-browse window}

A text-browse window contains text, e.g. the text of a protocol (Figure 1), and may contain images (Figure 2). Images are stored as bitmaps in BMP format in a library outside Btrieve. Each text-browse window is assigned a unique number and a window title. The number is used as a primary key by Btrieve. The window title describes the contents of the window.

All significant words contained in window titles are stored in an index. When the user of the system wants to retrieve information about a certain term mentioned in the text he can click on this term after which the system will search the index for this term. All matching window titles are displayed and a title can be selected by clicking on one of them. The selected window is then presented. Underlined words or phrases in the text signify that specific background information about these subjects is available which can be selected by clicking on it.

When the protocol contains branching logic, each branching point signifies a decision point or a diagnostic or therapeutic action combined with explanatory text. Steps in the protocol are presented to the physician as separate pieces of text that explain which therapeutic or diagnostic actions should be undertaken and why. When the surgeon clicks on the words or phrases in the text that apply to the patient, the system presents the next step in the protocol.

Furthermore the text-browse window contains three buttons: the backward arrow button, the index button and the flowchart button. The backward arrow button enables the user to go back to the previously displayed window. When clicking on the index button a window is displayed containing a list box with alphabetically sorted window titles out of which the user can select the relevant ones. With this facility the user can search for information about subjects that are not mentioned in the current window.

After clicking on the flowchart button a graphical display of the protocol is presented.

It will be apparent from the above description that the text-browse window enables the user to browse in a natural and associative way through both the algorithmic information or the background information on which the decision tree is based.

Texi-browse windows are divided into a number of types depending on their role.

Discussion: It contains information about the current status and about how to proceed in the decision making process (e.g. referral for ultrasound when obstructive jaundice is evident, ERCP referral after CT).

Questions: questions that have to be answered by the user (e.g. the results of tests, condition of the patient) in order to proceed to the next protocol step. By selecting one of the provided options the user is guided to the next part of the protocol as displayed in the next window.

Actions: description of actions that can be performed (e.g. a surgical technique).

Information: this window type provides background information (e.g. the sensitivity and 
protocol. Background information is indicated by underlined words or phrases in the text.

\subsection{Tree window}

The tree window allows the user to visualize the flowchart. The flowchart is displayed as a network containing nodes (corresponding to text browse windows) connected by arrows that indicate how a certain node is linked to other windows (Figure 3). Nodes are either presented as small coloured squares without text (coarse mode) or as rectangles containing text (detail mode; the text is a short hand version of the corresponding window title). In the coarse mode this short hand version of the window title can be obtained for a given node by clicking on it. When clicking on a node also all links with its neighbouring nodes are highlighted. In this way the user gets a better impression of the local structure of the flowchart. By double clicking on a node the corresponding window is displayed.

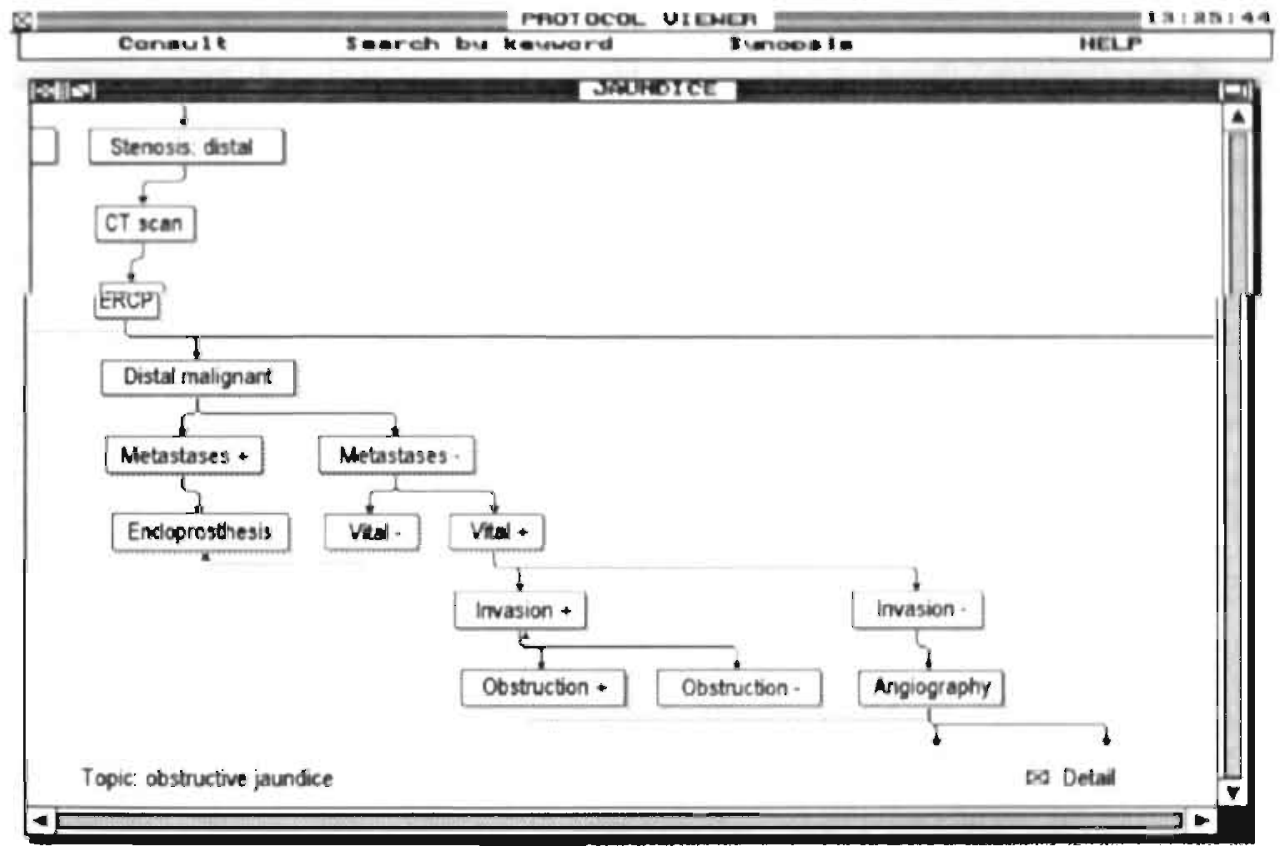

Figure 3 Tree window containing part of a flowchart.

For display purposes the flowchart, which is a network instead of a tree, is converted into a tree. Although the actions theoretically can be represented by a tree sometimes it is necessary to backtrack to an earlier node: e.g. a test may have to be repeated when test results are contradictory, etc. For display purposes the width of the tree is determined in a recursive way: the width of the root of the tree is equal to the sum of the widths of its children nodes, the width of which is again equal to the sum of the widths of their children's nodes, etc. The width of each node is either determined by the amount of text that has to be displayed in the node (in the detail mode) or by the width of the node itself (in the coarse mode). After the width of the tree is determined the tree is displayed by 
(in the coarse mode). After the width of the tree is determined the tree is displayed by following pointers to windows further down that are included in each record corresponding to a window. The missing links are added during a second pass through the data. Links are displayed in one of two colours depending on their direction (down (the usual way of proceeding) or up (when some action has to be repeated)). The rectangles or the squares in the flowchart are coloured. The colour indicates what type of window the rectangle refers to (Discussion window, etc; Information windows are not displayed because they are not part of the protocol).

\subsection{The summary window}

A summary window contains summary information. This information can only be viewed or printed. While consulting the system for the management of a specific patient, the user will enter patient data. These data are copied to the summary window. Diagnostic and therapeutic decisions made are subsequently stored automatically in the summary window. A summary window therefore presents an overview of the diagnostic and therapeutic choices made in the current and preceding consultation sessions. A summary window is obtained via the main menu.

\subsection{Editing the protocols}

Protocols can easily be defined or updated by physicians with the help of WordPerfect. The authors of protocols can use several macros especially developed for this purpose.

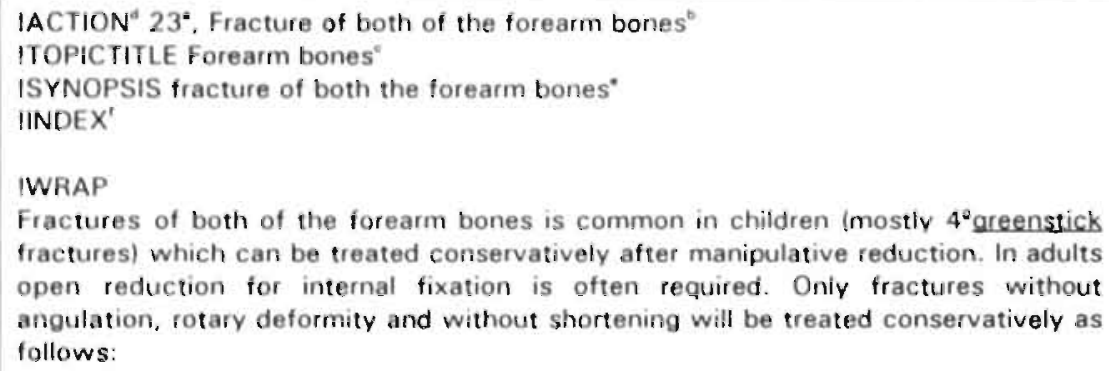
fractures) which can be treated conservatively after manipulative reduction. In adults open reduction for internal fixation is often required. Oniy fractures without angulation, fotary deformity and without shortening will be treated conservatively as follows:

Manipulative reduction carried out under general anaesthesia, the elbow, forearm. wrist and hand are then immobilized (proximal fractures in supination, mid-fractures in mid-position and distal fiactures in pronation) for 6: weeks.

Follow-up:

1 day (check plaster), 1 week (check reduction of displacement), 6, weeks, 10 weeks.

\section{MAGE: FRACTURE OF SHAFTS OF THE FOREARM BONES}

Figure 4 The WP protocol text document which contains a text segments together with window header information. The superscripts are referred to in the text.

Apart from the text that has to be presented in the window the author must provide additional information about the window. This latter information constitutes the so-called 
window header and contains the following information (Figue 4; the superscript letters are explained below): a unique window number (a) and window title (b); text to be presented in the rectangles of the flowchart (c) when this window is connected to a tree window; the kind of window information it contains (d) (Discussion, etc.); the text that has to be stored in the summary window (e) after this window has been visited; whether or not the words in the window title should be included in the index $(f)$; in case the window contains an image the image filename. The supportive macro to define window headers obtains the relevant information from the author by means of a dialogue.

The ProtoVIEW user is able to browse through the protocol (or to retrieve background information) by pointing on underlined phrases in the text using a mouse. All underlined phrases are linked to the appropriate window. While editing the protocol in WordPerfect this linkage has to be specified by the author. To this end the author has to underline the relevant phrase and enter the window number of the window containing the appropriate text segment immediately before the underlined phrase (Figure $4 \mathrm{~g}$ ). To support the author in the determination of the correct window number a macro has been developed that presents the existing window titles together with their window numbers. Also a macro has been developed which enables the author to browse through the protocol in WordPerfect in the same way as the user of ProtoVIEW does. Updating or extending the protocols can be done in the same way using the same macros.

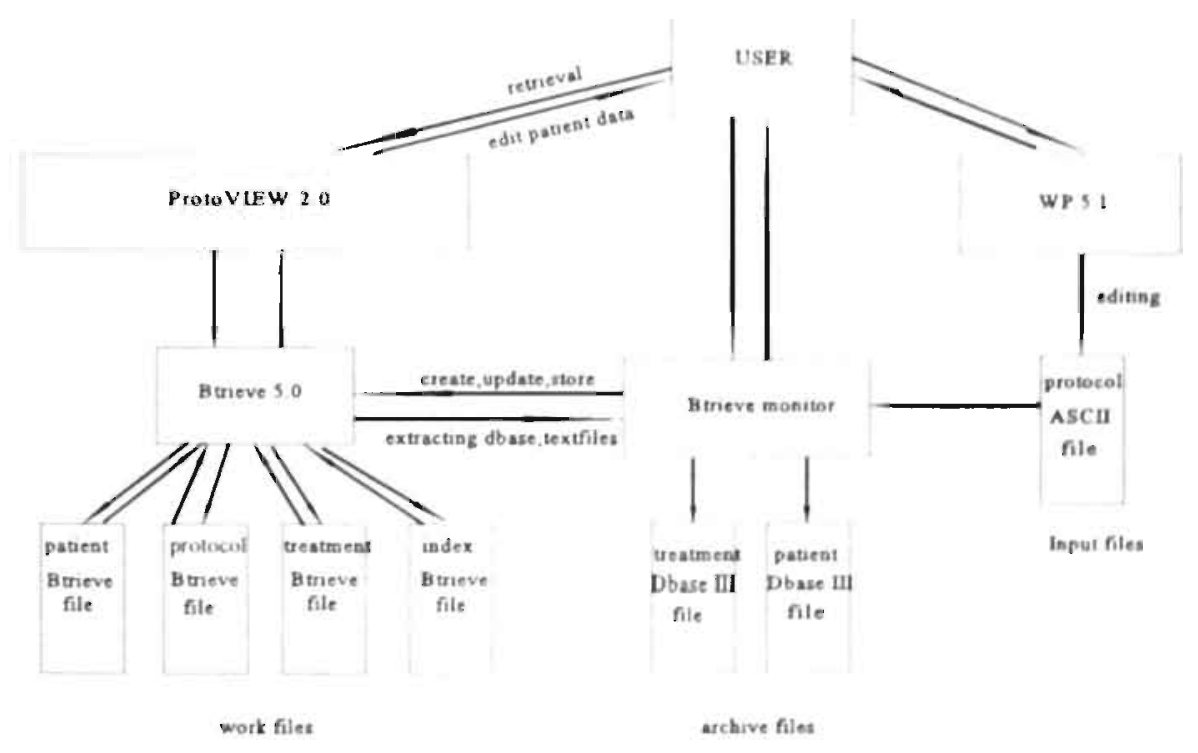

Figure 5 Overview of the protocol information system

The resulting. WordPerfect protocol text document contains a sequence of text segments together with window header information which is converted by a program (called Btrieve monitor) into a number of Btrieve files (Figure 5). In the protocol file each record contains 
the text of one window. In this record also the record numbers are stored of those windows that can be reached from the window corresponding to the current record. Identifying data about the patient are stored in the patient file. In the treatment file the summary of the treatment is stored. The treatment file also stores the patient identification number, physician name and the date and time of all actions performed when working with ProtoVIEW. In an author file author names and author codes are stored. The protocolauthor file stores information about each protocol and contains the code of the author, the name of the protocol, the creation date of the protocol and an expiration date indicating when the information within the protocol should be checked. For research purposes the Btrieve monitor program also converts Btrieve files (the patient file and the treatment file) into ABASE files later on. The dBASE files are used for research purposes.

\section{Evaluation}

ProtoVIEW was first evaluated on a small scale before it was used in the study about the impact of a protocol information system on medical practice. The consultation behaviour of physicians using the system was again evaluated during that study ${ }^{19}$.

The main objective of the first evaluation was to answer the following questions. (1) Is it easy to learn how to use the system? (2) Is usage of ProtoVIEW time consuming? and (3) Is the system accepted as a user friendly information source?

\section{1 Design and methodology}

Eight case histories about which in total 13 questions were asked were given to interns. The questions concemed the surgical policy relevant for the respective cases.

Six interns, divided into three groups of two, were invited to solve the case histories with and without the aid of the information system. One group of 2 interns used a desktop 486IBM compatible computer connected to a VGA colour monitor while the two other groups used a notebook with a built in LCD screen. Firstly, a brief tutorial instruction about ProtoVIEW was given. Next the interns were asked to answer the questions about the eight case histories without the aid of computerized protocols. The interns subsequently had to use the information system and again had to answer the same questions.

Evaluation of the interaction between user and information system took place by 'event logging' which means that the information system registered ali actions of the user in order to be able to analyze the searching behaviour of the interns afterwards. Finally the participants were supplied with an evaluation form in order to evaluate various user interface aspects of the information system such as the appropriateness of hypertext for presentation of protocols and about the searching facilities the information system offered. Furthermore the impact the information system might have on their clinical behaviour was estimated.

\subsection{Evaluation results}

One of the initial six participants was removed from the analysis since the intern had not been present during the introductory tutorial. Eventually, in total 24 case histories were 
solved by the three groups of interns with and without the help of ProtoVIEW. Table I shows the evaluation results. ProtoVIEW consultation took on average 2:37 minutes per case of which on average 1:38 minutes were spent looking at the relevant window.

Table 1 Results of the case histories solved by interns; before and after the use of the protocol information system (ProtoVIEW)

\begin{tabular}{|c|c|c|c|c|c|c|c|c|c|}
\hline & \multirow[t]{2}{*}{$\begin{array}{l}\text { avg no of } \\
\text { windows } \\
\text { retrieved. }\end{array}$} & \multirow{2}{*}{$\begin{array}{l}\text { avg } \\
\text { consultation } \\
\text { time } \\
\text { mss }\end{array}$} & \multirow{2}{*}{$\begin{array}{l}\text { avg tume } \\
\text { relevant window } \\
\text { viewed } \\
\text { miss }\end{array}$} & \multicolumn{3}{|c|}{$\begin{array}{l}\text { frequency of score } \\
\text { before ProtoVIEW } \\
\text { consultation. }\end{array}$} & \multicolumn{3}{|c|}{$\begin{array}{l}\text { frequency of score } \\
\text { after ProtoVIEW } \\
\text { consultation. }\end{array}$} \\
\hline & & & & 1 & 2 & 3 & 1 & 2 & 3 \\
\hline Case $1^{*}$ & 9 & $4 \cdot 48$ & 3.11 & 0 & 2 & 4 & 4 & 2 & 0 \\
\hline Case $2^{*}$ & 3 & $1: 45$ & $1: 17$ & 0 & 0 & 6 & 6 & 0 & 0 \\
\hline Case $3^{\circ}$ & 4 & $2: 36$ & $1: 29$ & 4 & 2 & 0 & 5 & 1 & 0 \\
\hline Case $4^{\prime \prime}$ & 7 & $3: 50$ & $2: 53$ & 0 & 3 & 0 & 2 & 1 & 0 \\
\hline Case 5: & 3 & $1: 53$ & 1.05 & 2 & 3 & 1 & 6 & 0 & 0 \\
\hline Case $6^{\circ}$ & 2 & 1.43 & $1: 28$ & 0 & 2 & 1 & 2 & 1 & 0 \\
\hline Case $7^{*}$ & 2 & 0.52 & $0: 45$ & 5 & 0 & 1 & 6 & 0 & 0 \\
\hline Case $8^{\circ}$ & 4 & $3: 27$ & 0.53 & 1 & 1 & 1 & 2 & 0 & 1 \\
\hline Total & 4 & 237 & 138 & 12 & 13 & 14 & 33 & 3 & 3 \\
\hline
\end{tabular}

* 1, correct; 2, incomplete, 3, wrong:

"case contains one question. " case contains two questions.

We defined a relevant window as a text-browse window containing the protocol information necessary to answer the question. The relevant window was retrieved in all but one case. Search of the relevant window via a keyword was used in 12 of the 24 cases. The search resulted in the retrieval of the relevant window in 8 of the 12 cases. In 3 of the 4 unsuccessful cases a window was retrieved containing protocol information highly related to the information contained in the relevant window. In the remaining case, one group of interns could not find the required information. Besides keyword search, interns navigated through the protocols retrieving an average of 4 (median 3.5) text-browse windows during each case. An average of 2.7 windows (median 2.5) had to be retrieved to reach the relevant text-browse window in these cases.

Table 2 Acceptance and attitude towards ProtoVIEW as a useful information source

\begin{tabular}{lllllll}
\hline Question & Frequency of scores & Median score \\
\hline & 1 & 2 & 3 & 4 & 5 \\
\hline The stepwise presentation of protocols is useful & 0 & 0 & 1 & 0 & 4 & 5.0 \\
ProtoVIEW is easy to operate with the help of a mouse & 0 & 2 & 0 & 0 & 3 & 5.0 \\
The windows are easy to handle & 0 & 0 & 1 & 1 & 3 & 5.0 \\
The speed of ProtoVIEW is, acceptable & 0 & 1 & 0 & 1 & 3 & 5.0 \\
The searching facilities provided are easy to use & 0 & 0 & 1 & 0 & 4 & 5.0 \\
The searching facility provides enough keywotds. & 0 & 2 & 0 & 1 & 2 & 4.0 \\
I think I know how to navigate through the protocols & 0 & 0 & 0 & 1 & 4 & 5.0 \\
ProtoVIEW contains useful information for me & 0 & 0 & 0 & 1 & 4 & 5.0 \\
I perform better with the help of ProtoVIEW & 1 & 0 & 0 & 2 & 2 & 4.0 \\
I would use the system when available in daily practice & 0 & 1 & 1 & 0 & 3 & 5.0 \\
I think I will be able to use a system like ProtoVIEW in & 0 & 0 & 1 & 1 & 3 & 5.0 \\
practice & & & & &
\end{tabular}

Scores: 1, strongly disagree; 2 , disagree: 3, no opinion: 4, agree: 5 , strongly agree 
Each given answer was compared with the 'official' guidelines provided by ProtoVIEW and judged as either correct, incomplete or wrong. Interns answered 12 out of 39 questions correctly without and 33 out of 39 questions correctly with the aid of computerized protocols. Five of the remaining six questions were incompletely answered because interns probably did not copy all required information correctly from the relevant window onto their registration form.

In the remaining case the interns could not find the relevant window as already mentioned before. For each of the statements on the evaluation form interns had to assign a value ranging from 1 (strongly disagree) to 5 (strongly agree). Each of the statements about the user friendliness of the system and the expected 'clinical' value were on average judged positively (Table 2). The two residents who used the desktop computer judged all statements about the user interface aspects more positively than the notebook users which can be attributed to the less comfortable LCD screens.

\section{Discussion}

In this contribution the protocol information system ProtoVIEW is presented. This system was designed for research purposes. The study had different goals. One of the goals was to investigate the usefulness of the developed design criteria of such a system. The evaluation results are presented here. The first part of this evaluation concerned the performance of interns in solving cases with and without computer support. The second part of the evaluation is concerned with the user's opinion about the user-friendliness of the system.

It was determined that the cases were answered much better when interns received help of the system. The interns used the system for the first time and received only a brief tutorial instruction about the use of ProtoVIEW. Nevertheless they did not experience any problems with the use of the system. Consultation of the system for obtaining the solution for each case took on average 2:37 minutes of which on average 1:38 minutes were spent reading the relevant information. Since interns were not familiar with the system, consultation time can be expected to fall when used routinely and can therefore hardly be experienced as time consuming. Afterwards, during a clinical trial, consultation time indeed dropped to 1:30 minutes of which 1 minute was spent reading the relevant information ${ }^{19}$. From the monitored information we verified that interns as a group found the relevant window in 23 of the 24 cases and answered 33 of the 39 questions correctly after consulting the system. Only 1 of the 6 incorrectly or incompletely answered questions could be attributed to an unsuccessful search.

From this evaluation it can be concluded that the time needed to find relevant information in ProtoVIEW is acceptable and that interns find their way through the system easily after a bricf tutorial instruction. It can be concluded from the results of the questionnaire that interns rate the system positively both with respect to user friendliness and the expected 'clinical' value.

From this study it can be concluded that a protocol information system that supports a user mainly in a passive way is an acceptable tool for supporting clinicians in their daily work. 
The remaining objectives of this study were to investigate the benefits of such a system in daily practice and the usefulness of the system as a stand-alone device.

This was investigated by means of a randomised clinical trial. The trial investigated the consultation behaviour of residents, the protocol adherence level of surgical residents supported with or without ProtoVIEW, quality of treatment eventually received by patients treated by residents with or without computer support. The main result of the trial was that the use of ProtoVIEW in daily practice leads to a better protocol adherence. The entire results of this trial will be presented in the forthcoming papers.

\section{References}

1 Abendroth TW. Greenes. RA, Joyce EA. Investigations in the use of clinical algorithms to organize medical knowledge. Proceedings of the Twelfth Annual Symposium on Computer Applications in Medical Care, New York: 1988.90-95

2 Adams ID, Clifford P. Cooke. WM, Dallos V, DeDombal FT, Edwards MH et al. Computer aided diagnosis of acute abdominal pain : a multicentre study. Brit Med J 1986;293:800-804

3 Cannon SR, Gardner RM. Experience with a computerized interactive protocol system using HELP. Comp Biomed Res 1980:13:399-409.

4 Dessel PFHM, Hasman A, Linden van der CJ. ProtoVIEW: a workstation for the use of clinical algorithms In: Adlassnig X.P. Grabner G, Bengtsson S. Hansen R, editors. Lecture Notes in Medical Informatics, 45. Springer Verlag, Berlin. 1991,233-237

5 Donkers HHLM, Hasman A. Using object oriented turbo pascal 5.5. In: Timmers T, Blum Bi, editors. Software Engineering in Medica! Informatics. North-Holland, Amsterdam 1991:323-337.

6 Grimm RH, Shimoni K, Harlan WR, Estes EH. Evaluation of patient care protocol use by various providers. N Engl J Med 1975;292:507-511.

7 Hickam DH, Shortliffe EH, Bischoff MB, Scott AC, Jacobs CD. The treatment advice of a computer-based cancer chemotherapy protocol advisor. Ann Intern Med 1985;103:928-936.

8 Hopkins JA, Shoemaker WC. Greenfield S, Chang DC, McAuliffe T, Sproat R. Treatment of surgical emergencies with and without an algorithm. Arch Surg 1980;115:745-750.

9 Kidd A.L. What do users ask? Some thoughts on diagnostic advice. In: Merry M, editor. Expert Systems '85. Proc Fifth Tech Conf Br Comp Soc Spec Group on Expert systems. Cambridge University Press. New York 1985:9-19.

10 Komaroff AL, Black WI. Flatley M. Knopp RH, Reifen B. Sherman H. Protocols for physician assistants - management of diabetes and hypertension. N Engl J Med 1974:290:307-312.

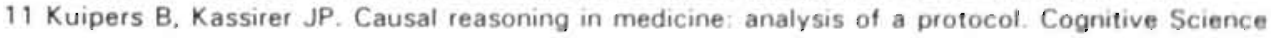
1984;8:363-385.

12 Margolis CZ. Uses of clinical algorithms. JAMA. 1983:249:627-32.

13 McAlister NH. Covvey HD, Tong C. Lee A. Wigle ED. Randomised controlted triat of computer assisted management of hypertension in primary care. Brit Med J 1986:293:670-674.

14 McDonald CJ, Hui SL, Smith DM, Tierney WM, Cohen SJ, Weinberger M, Mccabe GP. Reminders to physicians from an Introspective computer medical record la two-year randomized trial). Ann Intern Med 1984;100:130-138

15. Middleton B, Shwe ME, Heckerman DE, Henrion M. Horvitz EJ, Lehmann HP. Cooper GF. Probabilistic diagnosis using a reformulation of the INTERNIST-1/OMR Knowledge Base II Evaluation of diagnostic performance. Method Inform Med 1991:30:256-267.

16. Patel VL, Evans DA, Groen GJ. Biomedical knowledge and clinical reasoning. In: Evans DA. Patel VL, editors. Cognitive Science in Medicine; Biomedical modelling. MIT Press, Cambridge 1989 !

17 Teach RL, Shortliffe EH. An analysis of physician attitudes regarding computer-based clinical consultation systems. Comp Biomed Res 1981:14:542-558.

18 Vingroft S, Fugisang-frederiksen A, Ronager F, Petrera J, Stigsby B, Willison RG et al. KANDID- 
an EMG decision support system- evaluated in a european multicenter trial. Muscle Nerve 1993:16:520-529.

19 Vissers MC, Hasman A, van defi Linden CJ. Consultation behaviour of residents supported with a protoco! processing system (ProtoVIEW) at the emergency ward. Int J Biomed Comp 1995:38:181-187. 
Chapter 5

Consultation behaviour of residents supported with a protocol processing system (ProtoVIEW) at the $A \& E$ department

Vissers $\mathrm{MC}^{1}$

Hasman $A^{\prime}$

van der Linden $\mathrm{CJ}^{2}$

'Department of Medical Informatics, University of Limburg, Maastricht

${ }^{2}$ Department of Surgery, University' of Nijmegen. The Netherlands 


\section{Abstract}

We evaluated the consultation behaviour of residents using a protocol processing system in routine clinical practice. A total of 125 consecutive patients, of age 16 years or older with an isolated fracture without concomitant lesions, were treated with computer support between October 13, 1992 and June 9, 1993. All 8 surgical residents who worked at the emergency ward of the University Hospital in Nijmegen, The Netherlands participated. The mean consultancy time, method of information retrieval, number of correct protocols found, number of windows retrieved and attitude towards ProtoVIEW as a useful information source were estimated. Main results are: a mean consultancy time of $1 \frac{1 / 2}{2}$ minutes per case, residents browsed through the protocol information more often than using keyword search. The correct protocols were found in $98 \%$ of the cases while on average a minimum number of text-browse windows was retrieved. Residents were positive about the way protocols were presented and about the information supplied by ProtoVIEW. From this study we may conclude that ProtoVIEW consultation is hardly time consuming, and easy to use. Since keyword search was hardly used, expanding the number of synonyms may stimulate searching by keyword more often. 


\section{Introduction}

In the past 25 years many computer-aided decision support systems have been developed. Considering the role of the user we can distinguish several type of systems. In active knowledge based systems (such as the abdominal pain program from Leeds first reported in $1972^{4}$ ) the system asks the user for patient: data and derives case specific advice from this and its own knowledge. However, typing in information takes time and then the user has to wait for the results. Critiquing systems such as The HELP system' and the medical record system CARE ${ }^{\circ}$, also active systems, generate case specific advice based upon patient data stored in a database. Such a system does not directly interact with the user to obtain information. The user is provided with advice not specifically asked for. Critiquing systems were evaluated in routine clinical practice and proved to be effective 0.11 . These systems need to be integrated with an electronic medical record. In contrast to active systems, passive systems such as DeSyGNER ? contain knowledge that has to be searched by the user. Passive systems should be easy to use since the user must be able to navigate through the system without getting lost. QMR ${ }^{10}$ and DXplain" are mixtures of passive and active decision support. The user can take the initiative and ask for information, but QMR and DXplain can also provide information derived from the the information supplied by the user.

Most decision support systems are not used routinely. Many reasons have been given why medical decision aids are hardly used in daily clinical practice. Some reasons are related to the human-computer interface. Typing and waiting for the advice can be time consuming. Using a computer should be as easy as using a telephones. Computers should also support rather than replace physicians ${ }^{8,12}$. Furthermore, the doctor has to maintain responsibility for the patient from the legal point of view ${ }^{2}$.

A passive protocol processing system. (ProtoVIEW) was developed by us, to support physicians working at the Accident and Emergency (A\&E) department. With this system the user him- or herself can retrieve knowledge and navigate through the protocols. This paper discusses the use of ProtoVIEW. The following questions were investigated. (1) Is the system transparent enough for the user to find the correct therapy when he or she diagnosed the cases correctly? (2) Is ProtoVIEW consultation time consuming? (3) Was the system used correctly? (4) Is the system experienced as a useful information source by the residents?

\section{Materials and methods}

\section{7 Study design}

Consecutive patients who entered the A \& E department, of age 16 years or older with an isolated fracture without concomitant lesions were admitted to the study. All eight residents who regularly worked at the A \& E department participated and were divided into two groups. The first group used the system the first 16 weeks and the second group used the system for the following 16 weeks. For each eligible patient, residents had to record their proposed diagnosis and proposed treatment plan (based on the patient's X-ray and physical 
examination) before computer intervention, and a final diagnosis and final treatment plan after computer intervention. Each resident was instructed personally about the use of the system. In order to be able to investigate the consultation behaviour of the residents, all actions taken by the residents while consulting ProtoVIEW were logged.

Resident's acceptance and attitude towards ProtoVIEW were assessed by means of a questionnaire. Each question could be answered with a score ranging from 1 (low) to 5 (high).

\section{2 ProtoVIEW}

ProtoVIEW enables physicians to store and retrieve protocol knowledge and patient data. The protocols can be created or updated easily by physicians. Information can be retrieved using an index, by keyword searching, or via browsing through the protocol. A physician can also point on any word in the protocol text. The computer will then search the database for additional information concerning that particular topic, if available. ProtoVIEW has a flow chart window which provides a graphical representation of the protocol. ProtoVIEW can be consulted using only a mouse.

ProtoVIEW has been programmed in an object oriented way in TURBO PASCAL 6.0 making use of HYPERPAS, a home-made toolbox ${ }^{6}$ providing objects and an environment to build a graphical user interface similar to Microsoft Windows or the Macintosh interface. Protocols, patient data and treatment plans are stored in Btrieve, a record management system $^{12}$.

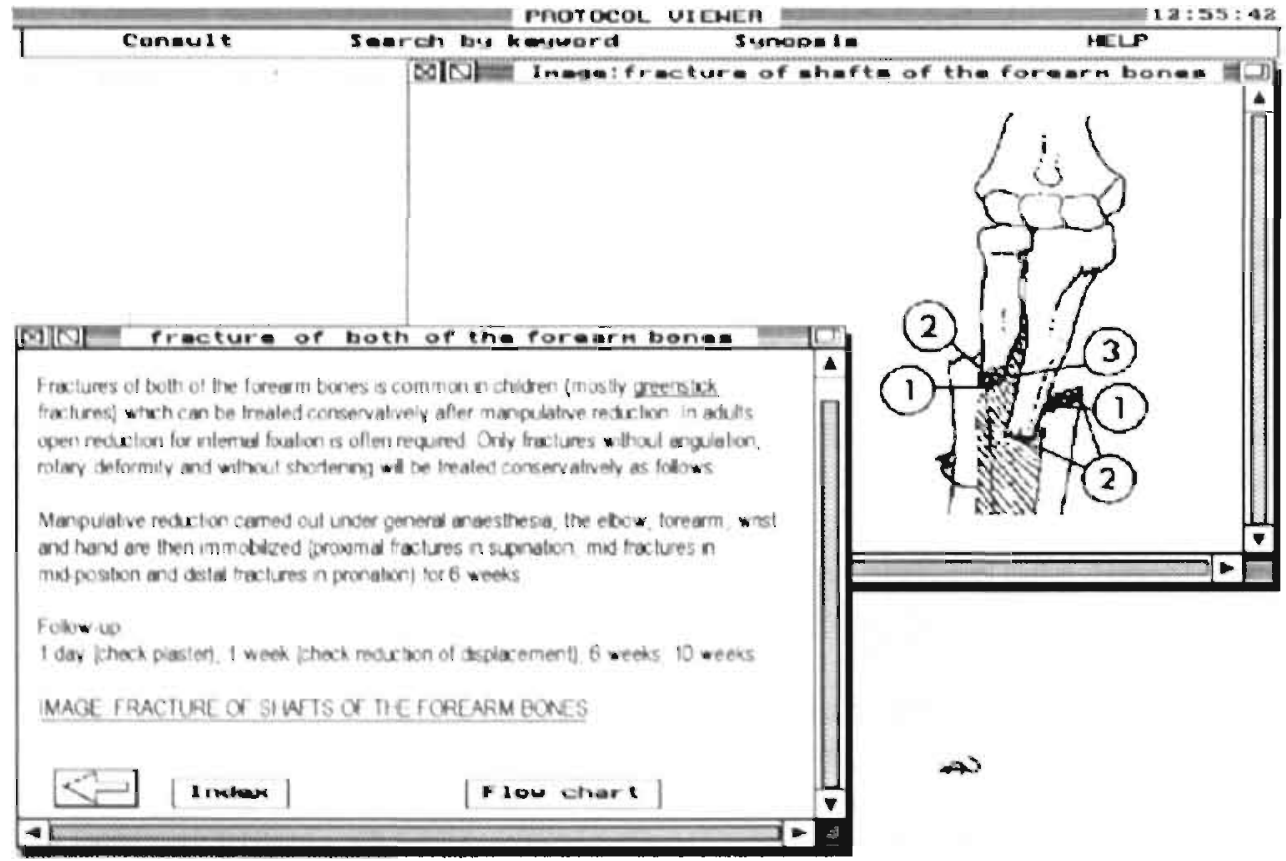

Figure 1 Text-browse windows containing protocol information and an image. 
The protocol viewer provides text-browse windows (containing textual protocol information or images (Figure 1)), tree windows (to display a graphical overview of the protocol) and a summary window (presents an overview of the therapeutic choices made during ProtoVIEW consultation) and has a main menu from which these windows can be called. Each text-browse window is assigned a unique number and a window title. The window title provides information about the contents of the window. All significant words contained in window titles may be stored in an index. This allows later retrieval of information related to the keywords.

ProtoVIEW was installed on a stand alone 486-1BM compatible computer which was available $24 \mathrm{~h} /$ day and located in a room next to the A \& E department.

\subsection{Trauma protoco/s}

Except for some supportive diagnostic information, the computerized trauma protocols were identical to the paper protocols already available at the A \& E department. The protocols contained mainly therapeutic information about the management of common isolated fractures such as the immobilisation material to use, duration of immobilisation, and follow-up schedule (see figure 1). Since some protocol treatments are used for several fracture types, the protocols contained 106 different protocol treatments and 120 fracture types. Most windows contained one protocol treatment for one fracture type. Some windows contained several protocol treatments for several fracture types and some windows contained one protocol treatment for several fracture types.

\section{Results}

Between 13 October 1992 and 9 June 1993, 134 consecutive patients were admitted to the study. Because of hardware failures ProtoVIEW could not be consulted in 9 cases. These cases were removed from the analysis. The remaining 125 cases were analyzed. In 22 of these 125 cases the proposed treatment plan was changed after computer intervention. As the gold standard we used the diagnosis (and associated protocol treatment) provided by the emergency ward's supervisor after the completion of the study to judge the treatment plans of the residents.

\section{I Compliance towards correct Proto VIEW usage}

Date and time of a patient's arrival at the A \& E department were recorded by a nurse on a patient encounter form. To check whether residents consulted ProtoVIEW before final treatment decisions were made, the delay between a patient's arrival and ProtoVIEW consultation was measured. A delay shorter than $120 \mathrm{~min}$ was assumed to be acceptable given the time the patient has to wait at the A \& E department and the radiology department.

Patients were entered into the system within $2 \mathrm{~h}$ after arrival in $76 \%$ (95/125) of the cases. Mean delay of these 95 cases was 61 minutes (median, 62 min). In 17 instances patients were entered 2 or more h after arrival but within I day and 13 patients were entered into ProtoVIEW one or more days after arrival. We might assume that these latter 
30 patients were entered into the system when the patient had already left the A \& E department.

During evenings, night-time or weekends the compliance rate was $65 \%$ (37/57). Mean delay was $63 \mathrm{~min}$ (median, $67 \mathrm{~min}$ ). In 13 instances patients were entered 2 or more h after arrival and seven patients were entered 1 day after arrival. The lower compliance rate might be attributed to a longer waiting time (resident and radiographer have to be called).

\subsection{Information retrieval}

Of all searching facilities available to them, residents preferred browsing through the protocol. Residents retrieved a median of five text-browse windows during each ProtoVIEW consultation. This is about the minimum number of windows required to reach the relevant text-browse window. We define a relevant window as a text-browse window containing the protocol belonging to the proposed diagnosis while we define an adequate window as a text-browse window containing the correct protocol according to the gold standard. Search by keyword was used in only 17 of the 125 cases. The search resulted in the retrieval of the adequate window in 12 of the 17 cases. Despite this success rate and the fact that a keyword search would have saved time, residents kept browsing through the protocol. The five cases in which keyword search was not successful might be attributed to the limited number of synonyms provided by the system.

Overall, the adequate text-browse window was retrieved in $66 \%(83 / 125)$ of the cases, the adequate text-browse windows was not retrieved in $21 \%(26 / 125)$ of the cases and shortcuts were made through the system in $13 \%(16 / 125)$ of the cases. This low proportion of adequate text-browse windows retrieved can be explained by the high proportion of incorrect proposed diagnoses established.

When correct diagnoses were made, the adequate window was retrieved in $92 \%(65 / 71)$ of the cases. In three of the remaining six cases, it could be deduced that residents were obviously not looking for the protocol belonging to the proposed diagnosis but just browsing through the protocol. They were apparently sure about the treatment to apply which was indeed entered correctly. In the other three cases residents viewed a text-browse window containing a protocol belonging to a diagnosis which highly resembled their proposed diagnosis. In those cases the diagnostic terminology used by the resident probably did not match the terminology used in the protocol.

When incorrect proposed diagnoses were made, the adequate window was not retrieved in $33 \%(18 / 54)$ of the cases. In these cases residents viewed, a relevant window (15 cases) or a relevant window belonging to a diagnosis which highly resembled their incorrect proposed diagnosis (three cases). In the remaining 36 cases the adequate window was retrieved because these text-browse windows contained several protocol treatments (including both the one belonging to the correct and the incorrect diagnosis). Thus, in $98 \%(122 / 125)$ of the cases residents found the relevant window. Residents however, stated that they found the required protocol information in $56 \%(70 / 125)$ of the cases, more or less found the required information in $25 \%(31 / 125)$ of the cases and did not find suitable protocol information in $19 \%(24 / 125)$ of the cases. In 10 cases residents stated in free text what information was lacking (table 1). Since the lacking information was present in ProtoVIEW 
in eight of the 10 cases and the relevant window was retrieved by the residents in seven of the 10 cases, residents were probably looking for information other than that provided by ProtoVIEW. Also, the terminology used by the resident might not have matched the terminology used in the protocol.

\section{3 Consultancy time}

ProtoVIEW consultation could. hardly be experienced as time consuming by the residents since consultation took on average $90 \mathrm{~s}$ per case. In the 22 cases where treatment changes were made after ProtoVIEW consultation, the mean consultancy time was $102 \mathrm{~s}$ (S.D., 62.9 s) while this was 88 s (S.D. 56.5 s) in the 103 cases where no changes were made ( $95 \%$ confidence interval of difference; -43.2 to +16.2 ).

Table 1 Lacking information in ProtoVIEW according to residents

\begin{tabular}{|c|c|c|c|}
\hline Fracture concerned & Lacking information & ProtoVIEW information under & $\begin{array}{l}\text { Relevant } \\
\text { window } \\
\text { tound }\end{array}$ \\
\hline Phalanges & Avulsion fractures (twice) & Fracture of the phalanges & $\mathrm{Y}, \mathrm{N}$ \\
\hline Femural & Femural condyles & Intra-articular femural fractures & Y \\
\hline Neck of the femur & Impacted fractures & Fractures of the neck of femur & 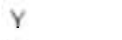 \\
\hline Comminuted & Not found at all & For each fracture separate & $N$ \\
\hline Fibular & Due to direct violence & Isolated fibular tracture & $\gamma$ \\
\hline Ankle & Tri-malleolar fracture & Several ankle fractures & $\mathbf{N}$ \\
\hline Metacarpal $V$ & Plaster information & Limited information available & Y \\
\hline Left sided rib & Rib tractures causing spleen lesion & Information not present & $\checkmark$ \\
\hline Phalanges, avulsion & Different plaster can be used & Information not present & Y \\
\hline
\end{tabular}

When the adequate window was retrieved, residents spent the extra consultation time looking at the protocol information, especially when treatment changes were made. The mean viewing time of the adequate window was $60 \mathrm{~s}$ (S.D. $42.4 \mathrm{~s}$ ) when treatment changes were made while this was 43 seconds (S.D. 30.2 s) when no treatment changes were made ( $95 \%{ }^{1}$ confidence interval of difference: -39.5 to +6.1 ).

\subsection{Effect of Proto VIEW on decision making}

After each ProtoVIEW consultation residents were asked to record whether they intended to change their proposed treatment plan and whether this was due to ProtoVIEV, discussion with colleagues or both. Since residents hardly answered this question, answering was made compulsory in the final 36 ProtoVIEW consultations. Residents intended to change their treatments in $58 \%(21 / 36)$ of the cases of which $39 \%(14 / 36)$ were due to ProtoVIEW. However, when each proposed and final treatment plan was compared with the gold standard treatment, treatment changes were identified in only $25 \%$ (9/36) of the cases of which 19\% (7/36) were due to ProtoVIEW. Of the 12 unidentified cases it could be deduced that minor changes were made in four cases, the diagnosis was changed instead of the treatment in one case, the proposed change was not supported by the supervisor in two cases and an explanation was lacking why the proposed treatment change was not carried

t-test, independent samples 
out in the final five cases. Since the supervisor was consulted in the five latter cases, we might assume that he did not agree with the treatment changes.

\subsection{Attitude}

Questionnaires were given to the residents when their computer supported period terminated.

Table 2 Acceptance and attitude towards. ProtoVIEW as a useful information source

\begin{tabular}{|c|c|c|c|c|c|c|c|c|}
\hline \multirow[t]{2}{*}{ Question } & \multicolumn{5}{|c|}{ Fiequency of scores } & $\begin{array}{l}\text { Median } \\
\text { score }\end{array}$ & $\begin{array}{l}\text { Median } \\
1<1 \text { yr exp })\end{array}$ & \multirow{2}{*}{$\begin{array}{l}\text { Median } \\
(>1 \text { yr exp) }\end{array}$} \\
\hline & 1 & 2 & 3 & 4 & 5 & & & \\
\hline Previous experience with computers & 0 & 0 & 2 & 1 & 4 & 5.0 & 3.5 & 5.0 \\
\hline $\begin{array}{l}\text { Computer support might be useful in } \\
\text { clinical decision making }\end{array}$ & 0 & 1 & 1 & 2 & 3 & 4.0 & 4.5 & 4.0 \\
\hline ProtoVIEW is easy to use & 0 & 1 & 1 & 3 & 2 & 4.0 & 4.0 & 3.0 \\
\hline Clear and convenient presentation & 0 & 0 & 1 & 4 & 2 & 4.0 & 4.0 & 4.0 \\
\hline $\begin{array}{l}\text { Appropriate information for most pat- } \\
\text { ients }\end{array}$ & 0 & 0 & 3 & 3 & 1 & 4.0 & 3.5 & 4.0 \\
\hline Slower than other information sources & 0 & 2 & 2 & 2 & 1 & 3.0 & 2.5 & 4.0 \\
\hline Less discussions with colleagues & 1 & 1 & 4 & 1 & 0 & 3.0 & 3.0 & 3.0 \\
\hline $\begin{array}{l}\text { Diagnostic and/or therapeutic delay } \\
\text { shorter }\end{array}$ & 1 & 4 & 1 & 1 & 0 & 2.0 & 2.0 & 2.0 \\
\hline $\begin{array}{l}\text { ProtoVIEW serves as a useful training } \\
\text { source }\end{array}$ & 0 & 0 & 1 & 3 & 3 & 4.0 & 5.0 & 4.0 \\
\hline Would use system in daily practice & 1 & 2. & 0 & 3 & 1 & 4.0 & 4.0 & 2.0 \\
\hline Performance increases & 2 & 1 & 3 & 1 & 0 & 3.0 & 3.0 & 1.0 \\
\hline
\end{tabular}

Scores: 1, strongly disagree; 2 , disagree; 3 , no opinion; 4, agree; 5 , strongly agree.

Seven residents filled out the questionnaire. The questions about the appropriateness of the protocol, the user friendliness and the potential training effect of the system, were judged positively. The residents doubted whether usage of the information system would lead to a decrease of supervisor consultation. Especially more experienced residents did not believe that they performed better with the help of ProtoVIEW nor that it would be faster than consultation of other information sources. The residents that had less than 1 year experience with the trauma cases thought that they would use it in daily practice (table 2).

\section{Discussion}

In this study we evaluated the use of a protocol processing system (ProtoVIEW) in routine clinical practice. In a passive information system like ProtoVIEW the user should be: able to find his or her way easily without wasting time. Since ProtoVIEW consultation took on average $1 \frac{1}{2} \mathrm{~min}$, it is probably faster than making a telephone call. It can therefore hardly be experienced as time consuming. When treatment changes were made, ProtoVIEW consultation was only $14 \mathrm{~s}$ longer because residents spent this extra time looking at the protocol information. Some residents however, doubted whether the usage of ProtoVIEW would be faster than consultation of other information sources.

looking at the way residents retrieved information from the system, residents did not use keyword search very often, even though this would have saved them. time. Despite 
keyword search was successful in most cases, residents continued browsing through the protocol information. Increasing the success rate by expanding the number of synonyms might stimulate the residents to search by keyword more often. We may consider two other reasons why residents preferred browsing. First, after entering the patient data, the first text-browse window is retrieved automatically. This might have encouraged them to start to browse. Second, residents did not have difficulties in finding the shortest path to the relevant window which took them about half a minute. The results of the questionnaire also showed that residents were positive about the way protocols were presented and that they found the system easy to use. When we assessed the reactions on the information that was provided by ProtoVIEW, residents were positive about the information supplied by it. From the monitored information we verified that residents found the relevant window in $98 \%$ of the cases. However, residents stated that they could not find the required information in $19 \%$ of the cases and more or less found the information in $25 \%$ of the cases. From the few recorded comments about the lacking information we concluded that residents were looking for more additional information. Since proposed diagnoses were incorrect in almost half of the cases, it might be worthwhile to provide physicians with additional diagnostic information also. When diagnostic accuracy improves, protocol adherence is likely to be affected positively.

We expected that computer support would be needed more when residents worked more or less on their own. Yet, compliance was found to be better during daytime than comparing to evenings, nights or weekends. Since consecutive cases were treated instead of selected complex cases, most cases are probably seen frequently by the residents so that computer consultation will not be crucial for treating most patients satisfactorily. Most of the information contained in the protocol might already be known or might be known after a few months of working at the A \& E department. This explains also that most residents doubted whether ProtoVIEW would increase their clinical performance and that physicians with less than 1 years' experience expressed the view that they liked ProtoVIEW as a useful training source and stated that they would use the system in daily practice. Residents intended to change their treatments due to ProtoVIEW in $39 \%$ of the cases while this was $19 \%$ when measured by objective standards. This difference could be attributed in most. cases to minor changes made which were not identified, using the objective standards.

\section{References}

1 Barnett GO, Cimino JJ, Hupp JA, Họffer EP. DXplain: an evolving diagnostic decision-support system. JAMA 1987:258:67-74.

2 Brahams D, Wyatt J. Decision aids, and the law Lancet 1989, . 632-634.

3 Cannon SR, Gardner RM. Experience with a computerized interactive protocol system using HELP. Comp Biom Res 1980:13:399-409.

4 De Dombal FT, Leaper DJ, Staniland JR, McCann AP. Horrocks JC. Computer-aided diagnosis of acute abdominal pain. BMJ 1972:2:9-13.

5 De Dombal FT. Computer-aided decision support-glittering prospects, practical problems, and Pandora's box. Baillière Clin Ob Gy 1990:4:841.849.

6 Donkers HHLM. Hasman A. Using object oriented turbo pascal 5.5. In: Timmers T. Blum BI, editors. Software Engineering in Medical Informatics. North-Holland. Arnsterdarn 1991:323337. 
7 Greenes RA. A "building block" approach to application development for education and decision support in radiology: implications for integrated clinical information systems environments. J Digit Imaging 1991:4 213-225.

8 Kidd AL. What do users ask? some thoughts on diagnostic advice. Proceedings of the Fifth Technical Conference of the British Computer Society Specialist Group on Expert Systems; 1985: 9-19.

9 McDonald CJ, Hui SL, Smith DM, Tierney WM, Cohen SJ, Weinberger M, McCabe GP. Reminders to physicians from an introspective computer medical record. Ann Intern med 1984; 100:130-138

10. Middleton B, Shwe MA, Heckerman DE, Henrion M, Horvitz EJ, Lehnnann HP, Cooper GF. Probabilistic diagnosis using a reformulation of the INTERNIST-1/QMR knowledge base. I Evaluation of diagnostic performance. Meth Inform Med 1991;30:256-267.

11 Rind DM, Safran C, Phillips RS, Slack WV, Calkins DR, Delbanco TL et al. The effect of computer-based reminders on the management of hospitalized patients with worsening renal function. Proceedings of the Sixteenth Annual Symposium on Computer Applications in Medical Care 1992;28-32.

12 Teach RL, Shortliffe EH. An analysis of physician attitudes regarding computer-based clinical consultation systems. Comp Biomed Res 1981;14:542-558.

13 Vissers MC, Hasman A, Donkers. HHLM, Linden van de CJ. Development, implementation and a first evaluation of a protocol processing system (ProtoVIEW). Comp Meth Prog Biomed 1995:47:81-92. 
Chapter 6

Effects of a protocol display system (ProtoVIEW) on clinical behaviour of residents in the Accident \& Emergency department

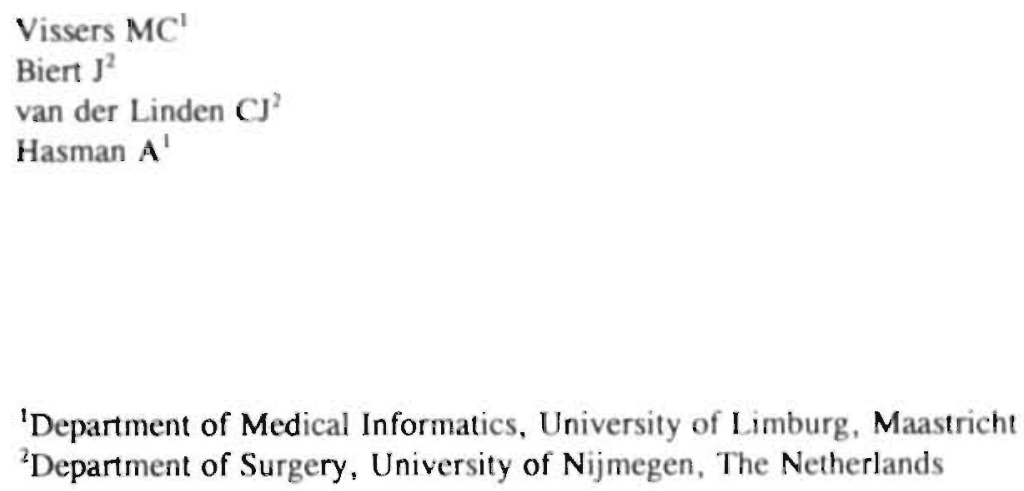

'Department of Medical Informatics, University of Limburg, Maastricht

${ }^{2}$ Department of Surgery, University of Nijmegen, The Netherlands 


\section{Abstract}

Objective - To assess what the impact is of (mandatory) consultation of a protocol for the. management of isolated traumas on treatment decisions of residents.

Design - A randomized two period crossover trial.

Intervention - The management protocol was available on computer (using ProtoVIEW) during experimental periods and on paper during control periods.

Setting - The accident \& emergency (A\&E) department of the University Hospital in Nijmegen (the Netherlands)

Patients - All patients who entered the A \& E department between October 13, 1992 and June 9, 1993, of age 16 years or older with an isolated fracture without concomitant. lesions.

Subjects - Eight surgical residents who regularly worked in the A \& E department.

Main measurements - Treatment adjustments made by residents (after consulting different, information sources), and their opinion about ProtoVIEW as an information source assessed by means of a questionnaire.

Results - When protocol consultation was mandatory, residents changed their treatments almost 4 times more often towards the protocol than during the control periods $(p=0.01$ Chi-square test). Most residents found ProtoVIEW easy to use, liked it as a useful training source while half of them said they would use the system in daily clinical practice.

Conclusions - Mandatory protocol consultation using ProtoVIEW influenced protocol adherence positively. 


\section{Introduction}

Several studies ${ }^{0.5}$ have shown that clinical protocols can aid in optimizing patient care. A situation which calls for protocol support is the Accident \& Emergency (A \& E) department where relatively inexperienced residents regularly work more or less independently. especially outside office hours. In many hospitals therapeutic trauma protocols based upon local consensus have been developed during the last decades to support physicians working at the A \& E department. However, paper protocols seem to be hardly consulted. In a preparatory study only $27 \%$ of the A \& E patients were treated in complete accordance with the protocol. For this reason we were interested in the effect of mandatory protocol consultation on therapeutic decision making in daily practice.

The lack of voluntary protocol usage might be caused by limitations related to paper protocols. Paper protocols appear to be too static to keep rapidly changing protocols, such as treatment algorithms in surgery, up to date'. Furthermore, concise paper protocols might not be comprehensible for those physicians who lack the background knowledge on which the protocol decisions are based. Presenting protocols in a more flexible way (such as easy retrieval of additional information, several ways to search for information) with the help of a computer system might be useful in overcoming these limitations. Since clinicians more readily accept computer systems meant to support clinical practice than computer systems that automate clinical activities traditionally performed by clinicians ${ }^{149}$, we developed a protocol display system (ProtoVIEW) with which the user himself can retrieve protocols ${ }^{15}$. This 'passive approach.' contrasts with active knowledge based systems (such as INTERNIST-1/QMR ${ }^{12}$ and the abdominal pain program from Leeds first reported in 1972') which ask for patient data and on that basis generate case specific advice.

This paper reports the results of a randomized controlled trial in which we investigated the effect of mandatory protocol consultation (using ProtoVIEW) on treatment decisions of surgical residents in routine circumstances. In addition we investigated the usage of other information sources during the trial and the opinion of residents towards ProtoVIEW as an information source.

\section{Materials and methods}

\subsection{Study design}

The study had a two-period full crossover design and was performed at the A \& E department of the University hospital in Nijmegen. In the 6 weeks preceding randomization we recorded the baseline situation without computer assistance. Each consecutive patient, 16 years or older, with an isolated fracture without concomitant lesions was admitted to the study. Eight residents who regularly work in the A \& E department were randomly' divided into two groups, a control group starting without computer support and an

\footnotetext{
Eight folded pieces of paper containing the names of the residents were put in a bowl that was subsequently shaken. The first four names drawn from the bowl formed group. 1 while the last four names drawn formed group 2.
} 
experimental group starting with computer support. After 16 weeks the roles were reversed. Residents treated the patients they would have seen, had there been no study. Data collection forms were used during the baseline and control periods while during the experimental periods residents entered data into the computer. To avoid a check-list effect ${ }^{20}$, the same data were collected in the same order in both situations. Computer consultation was mandatory for each eligible patient treated by computer supported residents. Residents were free to reject the advice given by ProtoVIEW. During the control period residents proceeded as in the baseline situation.

\subsection{Intervention}

ProtoVIE,W enables physicians to retrieve protocol knowledge and to enter patient data. Information can be retrieved using an index, by keyword searching, or via browsing through the protocol. ProtoVIEW contains a flow chart window which provides a graphical representation of the protocol ${ }^{15}$. ProtoVIEW was installed on a stand alone 486-IBM compatible computer which was availabie 24 hours a day and located in a room next to the A \& E department. To prevent control group residents from consulting ProtoVIEW a screen saver was installed. A password had to be entered to reactivate the system. The password was changed in the second trial period. Each resident was instructed personally about the usage of the system.

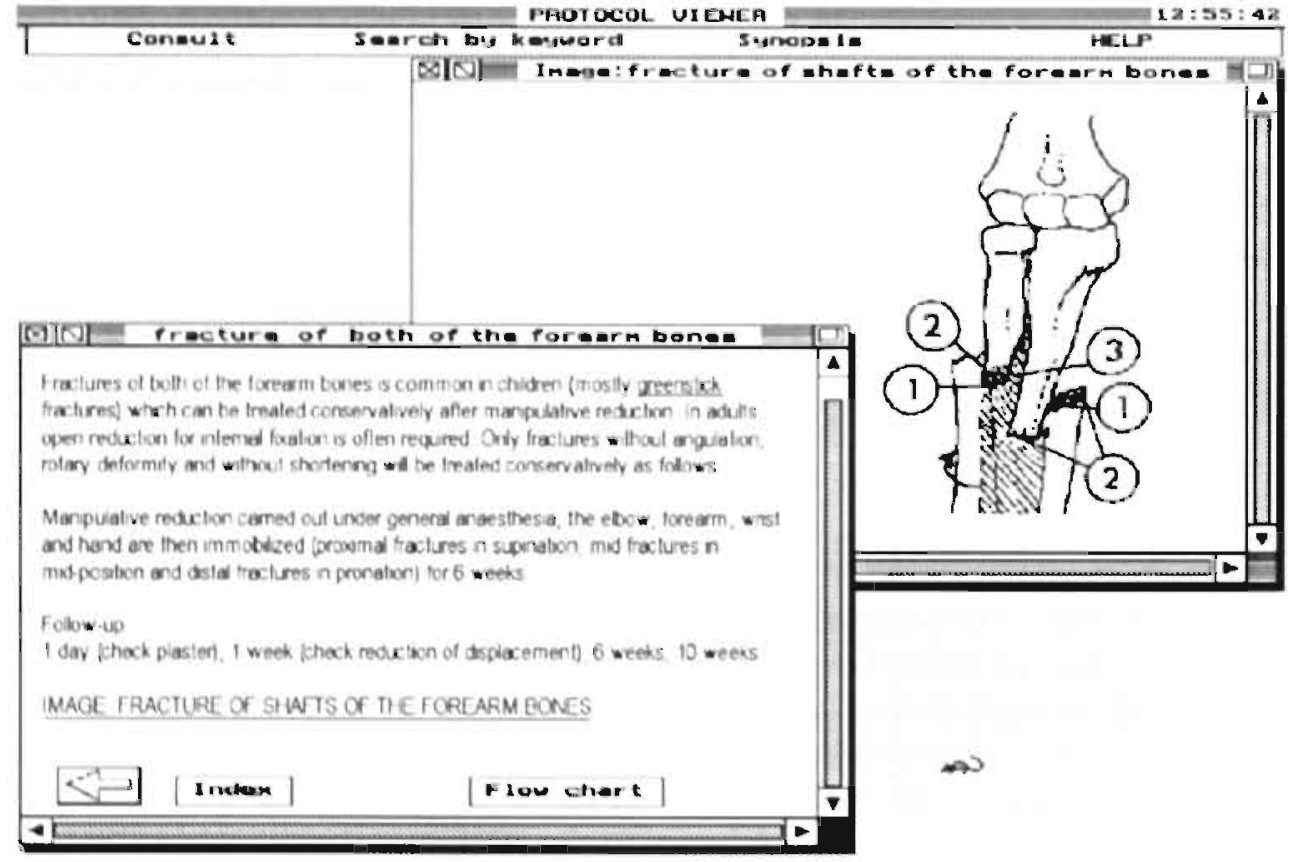

Figure 1 Text-browse windows containing protocol information and an image.

Except for some supportive diagnostic information (such as: supportive images of different fracture types, $X$-ray angles required to diagnose certain fractures, and reminders 
about potentially coexisting lesions), the actual information in the computerized protocols were identical to the pre-existing paper protocols. The protocols contained mainly therapeutic information about the management of common isolated fractures such as: the immobilisation material to be used, the duration of immobilisation and the follow-up schedule (see figure 1). The protocols consist of 106 different. protocol treatments for 120 fracture types (some protocol treatments are used for several fracture types).

For each eligible patient, residents had to register their proposed diagnosis (PD) and proposed treatment plan (PTP, including therapy and follow-up schedule), based on the patient's X-ray and physical examination, before consulting any information source. Furthermore, they were asked to indicate their confidence in the correctness of their proposed treatment plan by a score ranging from 1 (low) to 5 (high). After consulting the available information sources (conversation with colleagues, textbooks, literature, and either paper protocols or ProtoVIEW) a final diagnosis (FD) was established and a final treatment plan (FTP) was registered and subsequently applied to the patient. After the completion of the study the FD and FTP were obtained from the patient record, computerized and subsequently judged by the investigator who was unaware whether patients were treated with or without computer support.

The residents' acceptance and attitude towards ProtoVIEW were assessed with a questionnaire. Questionnaires were given to the residents when their computer supported period terminated. Each question could be answered with a score ranging from 1 (low) to 5 (high).

\subsection{Measurements}

As the gold standard, the 'working diagnoses' (and associated protocol treatment), provided by the A \& E department's supervisor were used to judge each residents' PTPs and FTPs. The working diagnoses were established independently from the residents' diagnoses, 6 months after randomization.

For each PTP and FTP, given by the residents, the level of protocol adherence was established, Each treatment was compared with the protocol treatment (gold standard) and judged as either:

1) Identical: complete match with the protocol treatment.

2) Imprecise: partly identical with the protocol treatment.

3) Different: no match at all with the protocol treatment.

Adjustments made after the registration of the proposed treatment plan leading to a final treatment plan were defined as:

1) Change away from the protocol: changed treatment leading to a lower level of protocol adherence (from 'identical' to either 'imprecise' or 'different', or from 'imprecise' to 'different')

2) Change towards protocol: changed treatment leading to a higher level of protocol adherence. (from 'different' to 'imprecise.' or 'identical', or from 'imprecise' to 
'identical')

3) Miscellaneous: obviously changed treatment but not leading to a different level of protocol adherence (both judged as: 'identical', 'imprecise' or 'different')

The statistical analysis was performed using SPSS version 6.0.1. Comparisons of protocol adherence level of PTP FTP and type of treatment changes during intervention and control periods were performed using chi-square test.

When we took the residents as the unit of analysis, the Wilcoxon signed ranks test was used to compare PTPs and FTPs. For each resident separately the proportions of PTPs and FTPs in complete accordance with the protocol treatment were calcutated (from the cases treated by this resident). The difference between these two proportions provided the individual results which were used to apply the Wilcoxon signed ranks test.

To compare correctness of diagnoses, the use of information sources during intervention and control periods difference are reported with their $95 \%$ Confidence intervals (CI).

\section{Results}

Belween October 13, 1992 and June 9, 1993246 consecutive patients were admitted to the $A$ \& E department. A gold standard could not be obtained in 13 cases (patients whose $X$-ray could not be retrieved because the follow-up was performed in another hospital) and they were removed from the analysis. Patients diagnosed by the residents as having a fracture although no fracture was present according to the 'working diagnosis' as well as nine cases in which ProtoVIEW could not be consulted because of hardware failures were not removed from the analysis. The data of 233 patients were analyzed. One hundred thirty-four (134) cases were treated by the residents during the periods with computer support and 99 cases were treated during the periods without computer support. Thirty-nine patients were treated during the baseline period and the results were almost the same as those in the control periods.

\section{1 Impact on protocol adherence}

Table 1 shows the protocol adherence level of proposed treatment plans (PTPs) registered before, and final treatment plans (FIPs) registered after intervention. It can be concluded that there are no significant differences in protocol adherence when PTPs are considered $(p=0.520)$. After intervention the protocol adherence is significantly better $(p=0.013)$ in the experimental group. Overall, the intervention leads to a $19 \%$ difference in complete protocol adherence in favour of the computer supported group. Table 2 shows how often and in what direction treatment changes were made. Only changes leading to a different level of protocol adherence were included. Overalt, computer supported residents did not change their treatments significantly more often than residents without computer support. Considering the direction of changes however, during the computer supported periods residents changed their treatment towards the protocol almost four times more often than residents without computer support. This resulted in a more uniform working strategy and thus improved protocol adherence for computer supported residents (table 1). 
In order to generalize the results as much as possible we also took the residents as the unit of analysis ${ }^{17}$. Although in this way the number of degrees of freedom is reduced drastically, we could still show that (applying the Wilcoxon signed ranks test) protocol adherence improved significantly $(p=0.043$ two-tailed) from PTP to FTP during the experimental periods and did not differ significantly $(p=0.422$ two-tailed) during the control periods.

Miscellaneous changes (not leading to a different level of protocol adherence) were made in $3 \%$ of the cases during both experimental and control periods. $p=0.01$ Chi-Square test ( $p=0.23$ comparing baseline period with control periods).

Table 1 Protocol adherence level of Proposed Treatment Plans(PTP) and Finat Treatment Plans (FTP)

\begin{tabular}{|c|c|c|c|c|c|}
\hline & \multicolumn{2}{|c|}{ Experimental periods } & \multicolumn{2}{|c|}{ Control periods } & \\
\hline & $\mathrm{Nr}$ & $\%$ & $\mathrm{Nr}$ & $\%$ & \\
\hline \multicolumn{6}{|c|}{ Proposed Treatment Plan } \\
\hline Identical & 53 & $40 \%$ & 34. & $34 \%$ & \multirow{4}{*}{ - } \\
\hline Imprecise & 55 & $41 \%$ & 40 & $40 \%$ & \\
\hline Differens & 26 & $19 \%$ & 25 & $25 \%$ & \\
\hline Total & 134 & & 99 & & \\
\hline \multicolumn{6}{|c|}{ Final Treatment Plan } \\
\hline Identical & 66 & $49 \%$ & 30 & $30 \%$ & \multirow{4}{*}{1} \\
\hline Imprecise & 48 & $36 \%$ & 46 & $46 \%$ & \\
\hline Different & 20 & $15 \%$ & 23 & $23 \%$ & \\
\hline Total & 134 & & 99 & & \\
\hline
\end{tabular}

- $p=0.52$ Chi-Square test $(p=0.28$ comparing resuits of baseline period with control periods)

$\dagger p=0.013$ Chi-Square test $(p=0.64$ comparing results of baseline period with control periodsi)

Residents felt very confident about their proposed diagnoses and treatments. In $99 \%$ of the cases, with and without computer support, residents stated that they were sure or very sure about their proposed diagnoses and in $92 \%$ of the cases about their treatment (both therapy and follow-up schedule).

Table 2 Adjusted treatments from Proposed treatment plan (PTP) to final treatment plan (FTP), overall and individual results

\begin{tabular}{|c|c|c|c|c|c|c|}
\hline & \multicolumn{3}{|c|}{ Experimental periods } & \multicolumn{3}{|c|}{ Control periods } \\
\hline & \multirow{3}{*}{$\begin{array}{l}\text { Change } \\
\text { towards: } \\
\text { protocol }\end{array}$} & \multirow{3}{*}{$\begin{array}{l}\text { Change } \\
\text { away from } \\
\text { protocol }\end{array}$} & \multirow{3}{*}{$\begin{array}{l}\text { No } \\
\text { Change }\end{array}$} & \multirow{3}{*}{$\begin{array}{l}\text { Change } \\
\text { towards } \\
\text { protocol }\end{array}$} & \multirow{3}{*}{$\begin{array}{l}\text { Change } \\
\text { away from } \\
\text { pratocol }\end{array}$} & \multirow{3}{*}{$\begin{array}{l}\text { Nọ } \\
\text { Change }\end{array}$} \\
\hline & & & & & & \\
\hline & & & & & & \\
\hline & Nr $(\%)$ & $\mathrm{Nr} \quad(\%)$ & $\mathrm{Nr} \quad(\%)$ & Ni $\quad(\%)$ & $\mathrm{Nr} \quad(\%)$ & Nr $(\%)$ \\
\hline Total * & $19(14)$ & $3 \quad(2)$ & $112(84)$ & (4) & (7) & $88 \quad(89)$ \\
\hline \multicolumn{7}{|c|}{ Indiviđuaì resuits: } \\
\hline resident 1 & 1 & 1 & 9 & 1 & 0 & 12 \\
\hline resident 2 & - & . & . & 1 & 1 & 19 \\
\hline resident 3 & 3 & 0 & 15 & 0 & 0 & 14 \\
\hline resident 4 & 3 & 0 & 29 & 0 & 2 & 24 \\
\hline resident 5 & 4 & 1 & 24 & 0 & 2 & 12 \\
\hline resident 6 & 6 & 1 & 20 & 2 & 2 & 3 \\
\hline resident 7 & 0 & 0 & 8 & - & $\cdot$ & - \\
\hline resident 8 & 2 & 0 & 7 & 0 & 0 & 4 \\
\hline
\end{tabular}


Since a correct diagnosis increases the probability of applying a correct protocol treatment, diagnostic accuracy was estimated. A correct proposed diagnosis was established in $58 \%$ of the cases during the periods with computer support and in $55 \%$ of the cases during the periods without computer support $(95 \% \mathrm{CI}$ for difference: $-9.8 ;+15.8)$. Since ProtoVIEW did not provide much diagnostic information, residents did not revise their proposed diagnosis more often during the computer supported periods. A correct final diagnosis was established in $69 \%$ of the cases diring the periods with computer support and in $65 \%$ of the cases during the periods without computer support ( $95 \% \mathrm{CI}$ for difference:

$-8.1 ;+16.1$ ). However, in cases where correct diagnoses were made, complete protocol adherence was much higher and complete protocol non adherence was much lower compared with cases diagnosed incorrectly (see Appendix).

\section{2 Altifude}

Seven residents filled out the questionnaire. The results are listed in table 3. The questions about the user friendliness of the system and the appropriateness of the protocol were answered positively. Most residents doubted whether the usage of ProtoVIEW would be faster than consultation of other information sources or would lead to a decrease of supervisor consultation. Most residents did not believe that they performed better or saved time when using the information system. Most residents liked it as a useful training source but only half of them would use it in daily practice. Finally, residents thought that computer support in general might be useful in clinical decision making. Aspects concerning the consultation behaviour of residents using the system were investigated also and were published elsewhere ${ }^{16}$.

Table 3 Acceptance and attitude towards ProtoVIEW as a useful information source

\begin{tabular}{llllllll}
\hline Question & \multicolumn{3}{c}{ Frequency of scores } & \multicolumn{1}{c}{ Median score } \\
\hline & 1 & 2 & 3 & 4 & 5 & \\
\hline Previous experiance with computers & 0 & 0 & 2 & 1 & 4 & & 5.0 \\
Computer support might be useful in clinical deci- & 0 & 1 & 1 & 2 & 3 & & 4.0 \\
sion making & & & & & & \\
ProtoVIEW is easy to use & 0 & 1 & 1 & 3 & 2 & 4.0 \\
Clear and convenient presentation & 0 & 0 & 1 & 4 & 2 & 4.0 \\
Appropriate information for most patients & 0 & 0 & 3 & 3 & 1 & 4.0 \\
Slower than other information sources & 0 & 2 & 2 & 2 & 1 & 3.0 \\
Less discussion with colleagues & 1 & 1 & 4 & 1 & 0 & 3.0 \\
Diagnostic and/or therapeutic delay shorter & 1 & 4 & 1 & 1 & 0 & 2.0 \\
ProtoviEW serves as a useful training source & 0 & 0 & 1 & 3 & 3 & 4.0 \\
Would use system in daily practice & 1 & 2 & 0 & 3 & 1 & 4.0 \\
Performance increases & 2 & 1 & 3 & 1 & 0 & 3.0
\end{tabular}

Scores: $1=$ strongly disagree 2 =disagree $3=$ no opinion $4=$ agree $5=$ strongly agree

\section{3 Use of resources}

Discussion with colleagues (mostly supervisor) was the most important information source used. The supervisor was consulted in $40 \%(54 / 134)$ of the cases during the computer supported periods and $32 \%(32 / 99)$ of the cases during the control periods. The differences were not statistically significant ( $p=0.13$, chi-square test; $95 \% \mathrm{CI}$ for difference: $4.4 ;+20.4)$. 
Diagnostic accuracy of both proposed and final diagnoses was about $17 \%$ better without supervisor involvement during both experimental and control periods, probably because supervisor consultation was mainly requested in the more difficult cases.

Other information sources were hardly used. During all periods, literature, textbooks or both were consulted in only $3 \%(7 / 233)$ of the cases. Residents without computer support recorded the use of paper protocols in only $2 \%(2 / 99)$ of the cases.

Computer supported residents stated that they found all the required information in ProtoVIEW in $56 \%(70 / 125)$ of the cases, more or less found the required information in $25 \%(31 / 125)$ of the cases and did not find appropriate protocol information in $19 \%$ $(24 / 125)$ of the cases. ProtoVIEW was not consulted in $7 \%(9 / 134)$ cases because of hardware failures.

\section{Discussion}

From this study it can be concluded that mandatory protocol consultation (with the freedom to reject the advised treatment) resulted in a $19 \%$ higher level of complete protocol adherence. This could be shown for a population containing consecutive patients with relatively simple common isolated fractures instead of rare complex cases. II was shown that even under these routine circumstances residents' proposed ireatment plans (PTP's) deviated from the protocol quite often. Computer supported physicians changed their treatment lowards the protocol treatment almost four times more often than physicians in the conventional situation, supplied with paper protocols. When the physician is taken as the unit of analysis there is a significant difference in protocol adherence between computer supported and non-computer supported physicians.

A crossover design was chosen to counter an overestimation of the true effects ${ }^{6}$ since residents randomized to mandatory ProtoVIEW consuitation may be subject to a greater Hawthorne effect (the beneficial effect on performance of taking part in research) than controls.

Our finding that ProtoVIEW improves the level of protocol adherence is in accerdance with other studies evaluating computerized protocols ${ }^{8,1,3,19,10}$.

One can doubt whether the beneficial effect would remain when computer consultation becomes optional. Firstly, most residents doubted whether ProtoVIEW would increase their clinical performance. Secondly, residents stated that they were sure or very sure about the correctness of their PTPS in $92 \%$ of the cases in this study. Since physicians will use the system only when they are uncertain about the protocol treatment "it is unlikely that they would have used the system in the current cases. Yet in $20 \%$ of these cases their FTP was 'different' from the protocol treatment and in $39 \%$ it was 'imprecise'.

It has been stated before that one of the major stumbling blocks to the introduction of computer-aided decision support is that doctors believe their clinical performance to be better than it actually is ${ }^{4}$. Therefore, ProtoVIEW could serve as an instrument for medical audit. Evaluating the working strategy of physicians regularly and providing feedback to the physicians concerned increases awareness of their actual performance ${ }^{i x}$. Providing 
physicians with feedback immediately when their treatment deviates from the protocol can be another solution. In this case ProtoVIEW should not be used as a stand alone device but should be integrated with an electronic medical record system. Critiquing systems of various types have already been shown to be successful in daily clinical practice ${ }^{13.11}$. Since proposed diagnoses were incorrect in almost. half of the cases, it might be worthwhile to provide physicians with additional diagnostic information also. When diagnostic accuracy improves, protocol adherence is likely to be affected positively ${ }^{16}$.

When we assessed their reactions on the information that was provided by ProtoVIEW, residents were positive about the information supplied by it and the way protocols were presented and they found the system easy to use.

In concordance with previous studies ${ }^{2,21}$ we found that conversation with colleagues is the information source most frequently used. Although the majority of medical problems discussed during. these conversations concern diagnostic uncertainty and treatment strategies $^{2}$ (the kind of information provided by ProtoViEW), we did not find a decrease but a slight increase of supervisor consultations during the computer supported periods. This increase of supervisor consultations could not explain the improved protocol adherence since supervisor consultation did take place as often in cases where residents changed their treatment lowards the protocol advice as in cases where no changes or changes away from the protocol were made.

Summarizing we may say that a randomized controlled trial conducted in a relatively easy clinical setting revealed that 1) despite residents' belief that their treatment was correct in most cases, they deviated from the protocol treatment in a substantial number of cases, and 2) despite residents' doubt whether ProtoVIEW would increase their clinical performance, mandatory consultation of the trauma protocols using ProtoVIEW induced a more uniform working strategy. It was shown that protocol adherence was $19 \%$ better during the computer supported periods. In an attempt to reduce the gap between subjective feelings and objective findings, residents should be provided with continuous feedback about their actual performance. Integrating. ProtoVIEW with an electronic medical record system could be useful to realize continuous reedback and maintain the ProtoVIEW effect in daily clinical practice.

Besides the evaluation of physicians' diagnostic and therapeutic performances, results in terms of patient outcome should also be evaluated ${ }^{4}$. At the moment a follow-up study is being carried out to investigate whether patient outcome improved as a result of the more uniform working strategy.

\section{References}

I Cannon ST, Gardner RM. Experience with a computerized interactive protocol system using HELP. Comp Biom Res. 1980; 13:399-409.

2. Covell DG, Uman GC. Manning PR. Information needs in office practice: are they being met? Ann Intern med 1985; 103:596-599.

3 De Dombal FT, Leaper DJ, Staniland JR, McCann AP, Horrocks JC. Computet-aided diagnosis of acute abdominal pain. Brit Med J 1972:2:9-13. 
4 De Dombal FT. Computer-aided decision support-glittering prospects, practical problems, and Pandora's box. Bailliere Clin Ob Gy 1990:4:841-849.

5 Dessel PFHM, Hasman A, Linden CJ van der. ProtoVIEW: a workstation for the use of clinical algorithms In: Adlassnig KP. Grabner G, Bengtsson S, Hansen R, editors. Lecture Notes in Medical Informatics, 45. Springer Verlag, Berlin. 1991:233-237.

6 Grimshaw JM, Russell IT. Effect of clinical guidelines on medical practice: a systematic review of rigorous evaluations. Lancet 1993:342:1317-1322.

7 Henderson S, Crapo RO, Wallace CJ, East TD, Morris AH, Gardner RM. Performance of computerized clinical protocols for management of arterial oxygenation in an intensive care unit. Int J Clin Monit Comp 1992:8:271-280.

8 Johnston ME, Langton KB, Haynes RB, Mathieu A. Effects of computer-based clinical decision support systems on clinician performance and patient outcome. Ann Intern Med 1994:120:135. 142.

9 Kidd AL. What do users ask? Some thoughts on diagnostic advice. In: Merry M, editor. Expert Systems '85. Proceedings of the Fifth Technical Conference of the British Computer Society Specialist Group on Expert Systems. Cambridge University Press, New York, 1985:9-19.

10 McAlister NH, Covvey HD, Tong C, Lee A, Wigle ED. Randomised controlled trial of computer assisted management of hypertension in primary care. Brit Med J 1986;293:670-674.

11 McDonald CJ, Hui SL, Smith DM, Teirney WM, Cohen SJ, Weinberger M. McCabe GP Reminders to physicians from an introspective computer medical record. Ann Intern Med; 1984:100:130-138.

12 Middleton B, Shwe MA, Heckerman DE, Henrion M, Horvitz EJ, Lehmann HP, Cooper GF. Probabilistic diagnosis using a reformulation of the INTERNIST-1/OMR knowledge base. II. Evaluation of diagnostic performance. Meth Inform Med 1991:30:256-267.

13 Rind DM, Safran C, Philips RS, Slack WV, Calkins DR, Delbanco TL, Bleich HL. The effect of computer-based reminders on the management of hospitalized patients with worsening renal functions. Proc Annu Symp Comput Appl Med Care 1991:28-32.

14 Teach RL, Shortliffe EH. An analysis of physician attitudes regarding computer-based clinical consultation systems. Comp Biomed Res 1981;14:542-558.

15 Vissers MC, Hasman A, Donkers HHLM, van der Linden CJ. Development, implementation and a first evaluation of a protocol processing system (ProtoVIEW). Comp Meth Prog Biomed 1995:47:81-92.

16 Vissers MC, Hasman A, van der Linden CJ. Consultation behaviour of residents supported with a frotocol processing system (PratciVIEW) at the emergency; ward. Int I Biomed Comp 1995; $38: 181-187$.

17 Whiting-O'Keefe QE, Henke C. Simborg DW. Choossing the correct unit of analysis in medical care experiments. Med Care 1984:22:1101-1113.

18 Winkens RAG, Pop P, Grol RPTM, Kester ADM, Knottnerus JA. Effect of feedback on test ordering behaviour of general practitioners. Brit Med J 1992;304:1093-1096.

19 Wirtschafter DD, Scalise M, Henke C, Gams RA. Do information systems improve the quality of clinical research? Results of a randomized trial in a cooperative multi-institutional cancer group. Comp Biom Res 1981;14:78-90.

20 Wyatt J, Spiegelhalter D. Evaluating medical expert systems: what to test and how? Medical Informatics 1990; 15:205-217.

21. Wyatt J. Use and sources of medical knowledge Lancet 1991:338:1368-1373. 


\section{Appendix: Diagnostic accuracy}

Because ProtoVIEW also contains some diagnostic information, the diagnostic accuracy of proposed and final diagnoses was estimated to investigate whether residents using ProtoVIEW reached a better diagnosis. We compared each proposed and final diagnosis with the 'working diagnosis' and judged them according to the following criteria:

1) Correct: Diagnosis identical with 'working diagnosis'.

2) Incomplete: identical to the 'working diagnosis' but essential part(s) missing.

3) Different: partly or totally incompatible with the 'working diagnosis'.

Diagnostic accuracy of proposed (before) and final (after consulting any information source) diagnoses did not differ much between experimental and control periods (table I). ProtoVIEW usage did therefore not affect the diagnostic accuracy. Furthermore diagnostic accuracy did not change with the experience level of the residents.

Comparing protocol adherence between cases where the proposed diagnosis was correct and cases where the proposed diagnosis was different from the working diagnosis, we found that protocol adherence of correctly and incorrectly diagnosed cases was statistically different from the overall protocol adherence ( $\mathrm{p}=0.0006$ Kruskal-Wallis test). Complete protocol adherence was higher for cases diagnosed correctly $(59 \%$ with and $26 \%$ without computer support) than cases diagnosed incorrectly (35\% with and $24 \%$ without computer support). Complete protocol non adherence was lower for cases diagnosed correctly (8\% with and $7 \%$ without computer support) than cases diagnosed incorrectly (35\% with and $48 \%$ without computer support).

Table I Diagnostic accuracy of proposed diagnoses and final diagnoses

\begin{tabular}{|c|c|c|c|c|c|}
\hline \multirow{2}{*}{ Proposed diagnosis } & \multirow{2}{*}{$\begin{array}{l}\text { Experimental periods } \\
\mathrm{Ni} \%\end{array}$} & \multicolumn{2}{|c|}{ Control periods } & \multirow{2}{*}{\multicolumn{2}{|c|}{ Difference $(95 \% \mathrm{Cl})$}} \\
\hline & & $\mathrm{Nr}$ & $\%$ & & \\
\hline Correct & $7858 \%$ & 54 & $55 \%$ & $3 \%$ & $(-9.8 ;+15.8)$ \\
\hline Partly correct & $35.26 \%$ & 24 & $24 \%$ & $2 \%$ & $(-8.4 ;+12.4)$ \\
\hline Different & $2116 \%$ & 21 & $21 \%$ & $-5 \%$ & $(-15.0 ;+5.0)$ \\
\hline Total & 134 & 99 & & & \\
\hline \multicolumn{6}{|l|}{ Final diagnosis } \\
\hline Correct & 92. $69 \%$ & 65 & $65 \%$ & $4 \%$ & $(-8.1 ;+16.1)$ \\
\hline Partly correct & $20 \quad 15 \%$ & 12 & $12 \%$ & $2 \%$ & $(-6.8 ;+10.8)$ \\
\hline Different & 22. $16 \%$ & 22 & $22 \%$ & $-4 \%$ & $(-12.8 ;+4.8)$ \\
\hline Total & 134 & 99 & & & \\
\hline
\end{tabular}


Chapter 7

Influence of computer support on treatment of isolated fractures; results of a follow-up study

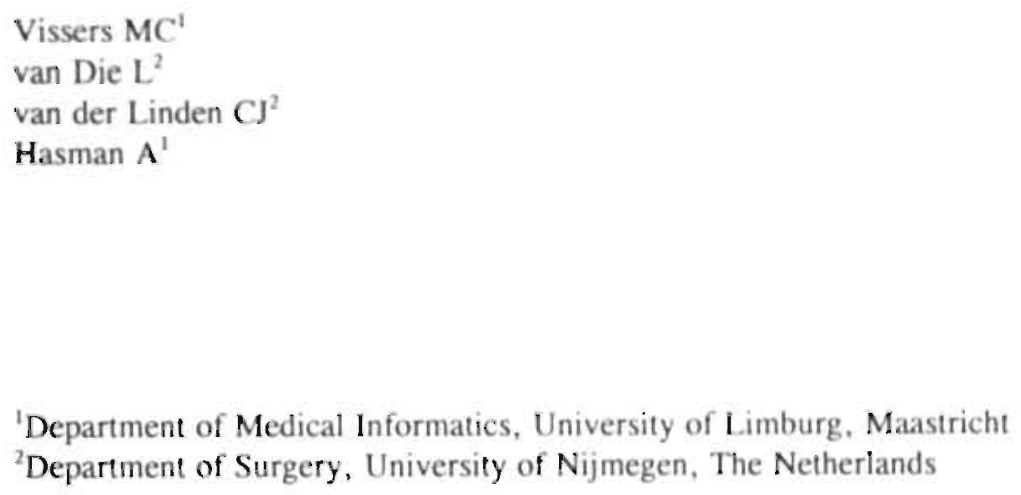

'Department of Medical Informatics, University of Limburg. Maastricht ${ }^{2}$ Department of Surgery, University of Nijmegen, The Netherlands 


\section{Abstract}

Objective - To investigate the influence of computerized trauma protocols on fracture treatment.

Design - A randomized cross-over trial. Residents, supported with either computerized or paper trauma protocols, treated patients with isolated fractures. Twelve months after the first emergency room visit patient records were reviewed in a blind fashion.

Setting - The Accident \& Emergency department of the University Hospital in Nijmegen (the Netherlands).

Subjects - 221 patients with an isolated fracture.

Main outcome measures - Number of treatment revisions performed after the initiation of the treatment, number of complications developed during healing, treatment duration and number of follow-up visits.

Results - Overall, computerized trauma protocols did not influence treatment. A subgroup, restricted to cases where residents read the correct protocol treatment, revealed slight differences indicating that treatment had been improved by computer support.

Conclusions - Our data indicate that computerized trauma protocols do not improve treatment for patients with isolated fractures unless additional support is given to ensure that residents are confronted with the correct protocol treatment. This hypothesis needs further research. 


\section{Introduction}

Numerous studies have shown that computerized clinical protocols can improve diagnostic and therapeutic performances of physicians and improve results in terms of patient care ${ }^{4,6}$. A suitable setting for protocol support is the Accident \& Emergency (A \& E) department . Residents who start to work in the A \& E department seem to be scarcely prepared for their $\operatorname{task}^{10,18}$ while existing paper protocols seemed to be hardly consulted. We investigated the impact of computerized trauma protocols on treatment decisions of residents and on quality of treatment received by patients. A randomized crossover trial was performed at an A \& E department supported with protocols for isolated traumas. Here, we report the treatment results of 221 patients who participated the trial.

Previous studies $2.13 .121,7.11 \times 10$ have shown that uftimate outcome variables such as residual deformity and restricted mobility correlate largely with the quality of reduction. Since these measures assess physicians.' skills rather than assess the effect of applying a correct protocol, we did not use these ultimate outcome measures. Instead we chose number of complications that developed during the healing process, treatment duration, number of follow-up visits and number of treatment revisions made after the first emergency room visit as proxies for quality of treatment. The hypothesis was tested that treatment was better for patients treated by residents supported with computerized trauma protocols during the first emergency room visit as compared to residents not supported.

\section{Materials and methods}

The trial had a two-period full crossover design and was performed at the A \& E department of the University Hospital in Nijmegen, the Netherlands. For a period of 7 months the protocol information system (ProtoVIEW) containing therapeutic information about 120 common isolated traumas (fractures and dislocations in particular) ${ }^{14}$ was used at the A \& E department. Consecutive patients, of age 16 years or older with: an isolated fracture were admitted to the study. Eight residents who regularly worked at the A \& E department participated and were randomly divided into two groups, an experimental group with and a control group without computer support. Four out of eight residents first served as the experimental group and later as control group. The remaining four physicians took these roles in reverse order. Computer consultation was compulsory for experimental residents while consultation of paper protocols was optional for control residents. For each eligible patient, residents registered in the patient record their (initial) diagnosis and (initial) treatment. Patients were either hospitalized or treated in an outpatient department. Of 233 eligible patients with an isolated fracture, 1.34 were treated by residents with computer support and 99 were treated without computer support during the first emergency room visit.

\section{1 Follow-up}

Patients who were not hospitalized visited the outpatient department for follow-up at regular intervals. Whether the patient was treated with or without computer support during 
the first emergency room visit was not stated in the patient record and was therefore not known by the physicians during follow-up. Based on the patient data described in the patient record and the findings of physical and $\mathrm{X}$-ray examination during follow-up, the initiated treatment was continued or treatment revisions were made.

\section{2 Patient record analysis}

The patient records were analyzed 12 months after the first emergency room visit. For each eligible patient, the following data was collected from the patient record: demographic data, the initial diagnosis and initial treatment registered during the first emergency room visit. In addition the following treatment variables were registered: complications developed during healing, surplus treatment duration, surplus follow-up visits and treatment revisions made after the first emergency room visit'.

The patient records were reviewed by the investigator who was blinded with regard to the patients' ProtoVIEW exposure status.

\subsection{Analysis}

A comparison was made between patients treated by residents with computer support during the first emergency room visit (referred to as experimental patients) and patients treated by residents without computer support during the first emergency room visit (reterfed io as control patients).

Since the trauma protocols gave mainly therapeutic support residents had to establish a diagnosis first, and then find the corresponding protocol treatment in ProtoVIEW or in the paper protocols. As a consequence ProtoVIEW could influence patient care only when residents considered the correct protocol treatment. We therefore decided to perform a subgroup analysis restricted to correctly diagnosed cases. Since some protocol treatments correspond with more than one diagnosis, we also included those cases whose (incorrect) diagnosis corresponded with a protocol treatment matching the correct diagnosis.

As the gold standard we used the protocol treatment corresponding with the diagnosis provided by an independent radiologist.

\section{4 Statistical methods}

The statistical analysis was performed using SPSS version 6.0.1. The chi-square test was applied when analysing complications and treatment revisions but when the numbers were too small Fisher's exact test was used. The t-test for independent samples was applied for surplus follow-up and surplus treatment duration. The study had a power of $77 \%$ when a $10 \%$ difference in complications (3\% in experimental and $13 \%$ in the control patients) was considered to be relevant ( $\alpha=0.05$ two sided). In the subgroup we found a. power of $73 \%$ when a $15 \%$ difference in treatment revisions $(5 \%$ in experimental and $20 \%$ in control patients) was considered to be relevant ( $\alpha=0.05$ two sided). 


\section{Results}

Of 233 patients who participated in the trial, 7 experimental patients and 5 control patients were lost to follow-up. Patient records were reviewed for the remaining 221 cases consisting of 126 experimental patients and 95 control patients. Treatments were known to be completed in $96 \%$ of the cases 12 months after the first emergency room visit.

Table 1 Results of all patients and operated and non-operated patients separately

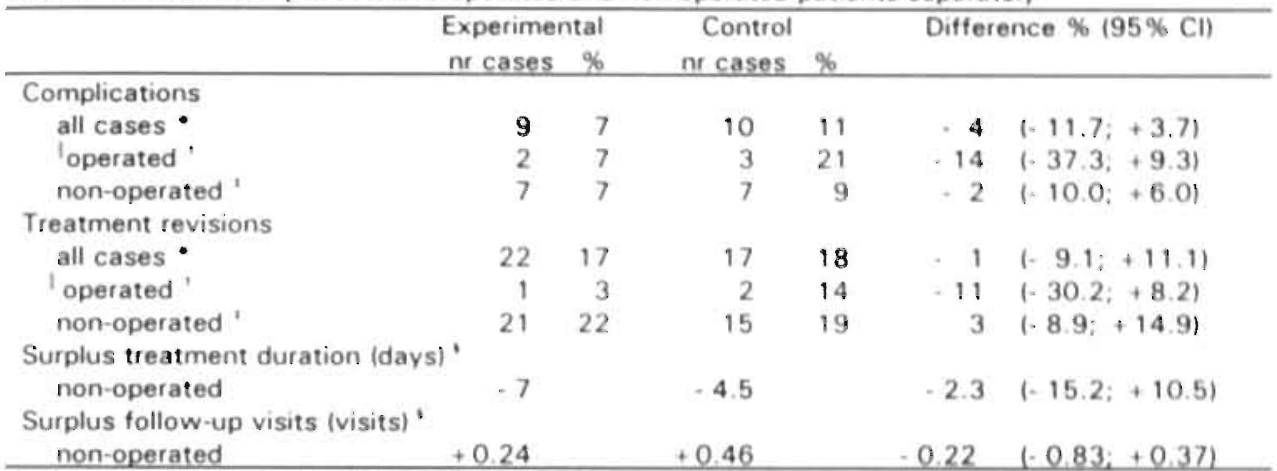

5 Surplus treatment duration and surplus follow-up visits were measured for 89 experimenta! patients and 71 control patients who were not operated and visited the outpatient department at: least once.

| Fisher's exact test was used. - The group consisted of 126 experimental patients and 95 control patients.

1 Operated patients consisted of 29 experimental patients and 14 control patients.

1 Non-operated patients consisted of 97 experimental and 81 control patients.

\subsection{Overall analysis}

The overall analysis included 221 patients. Table I shows that, treatment was not better for experimental patients as compared to control patients. The frequency of complications. did not differ between experimental patients and controls for either operated and nonoperated patients. Treatment duration was only a few days less for experimental patients while the number of follow-up visits and the proportion of revised treatments in the nonoperated group were similar in the experimental and control groups.

\section{2 Subgroup analyses}

In 137 cases the diagnosis established by the resident corresponded with the gold standard protocol treatment. Table. 2 shows that a subgroup analysis revealed fewer complications and shorter treatment duration for experimental patients as compared to controls.

Surplus follow-up and treatment revisions showed similar results as compared with the. overall results. Due to many incorrect and incomplete diagnoses, adherence to the system's advice does not seem optimal in our study ${ }^{15}$. A second subgroup analysis therefore assessed the maximum obtainable potential benefits of protocol adherence. 
Table 2 Results of a subgroup analysis restricted to patients treated by residents who established a diagnosis matching the gold standard treatment

\begin{tabular}{|c|c|c|c|c|c|c|}
\hline \multirow[b]{2}{*}{ Complications } & \multicolumn{2}{|c|}{$\begin{array}{c}\text { Experimental } \\
\text { nr cases \% }\end{array}$} & \multicolumn{2}{|c|}{$\begin{array}{c}\text { Control } \\
\text { nr cases \% }\end{array}$} & \multicolumn{2}{|c|}{ Difference $\%(95 \% \mathrm{Cl})$} \\
\hline & & & & & & \\
\hline I all cases & 2 & 3 & 8 & 13 & .10 & $(=19.3 ;-0.7)$ \\
\hline ' operated' & 1 & 6 & 3 & 33 & .27 & $(-59.6 ;+5.6)$ \\
\hline ' non-operated ' & 1 & 2 & 5 & 10 & -8 & $(-17.0 ;+1.0)$ \\
\hline \multicolumn{7}{|l|}{ Treatment revisions } \\
\hline all cases * & 11 & 14 & 8 & 13 & +1 & $\{-10.5 ;+12.5\}$ \\
\hline ' operated ' & 1 & 6 & 1 & 11 & .5 & $(-28.2 ;+18.2)$ \\
\hline non-operated ' & 10 & 17 & 7 & 14 & +3 & $(-10.5 ;+16.5)$ \\
\hline \multicolumn{7}{|l|}{ Surplus treatment duration (days)' } \\
\hline non-operated & -14 & & -6 & & -7.8 & $(-22.6 i+6.93)$ \\
\hline \multicolumn{7}{|l|}{ Surplus follow-up (visits)' } \\
\hline non-operated & +0.13 & & +0.30 & & 0.17 & $(-0.80 ;+0.46)$ \\
\hline
\end{tabular}

5 Surplus treatment duration and surplus follow-up visits were measured for 59 experimental patients and 47 control patients who were not operated and visited the outpatient department at least once.

I Fisher's exact test was used.

- The group consisted of 77 experimental patients and 60 control patients.

1 Operated patients consisted of 18 experimental and 9 control patients.

I Non-operated patients consisted of 59 experimental and 51 control patients.

Patients whose treatment was initiated (during the first emergency room visit) in complete accordance with the protocols were compared with patients whose treatment was not initiated in complete accordance with the protocols. To keep the groups comparable we had to restrict this analysis to common, simple fractures for which the frequency of each fracture type was similar in both groups.

Table 3 Subgroup results adjusted for type of fracture (34\% of all fractures)

\begin{tabular}{|c|c|c|c|c|c|c|}
\hline & \multicolumn{2}{|c|}{$\begin{array}{c}\text { treated ICA } \\
\text { with the } \\
\text { protool } \\
N=38\end{array}$} & \multicolumn{2}{|c|}{$\begin{array}{l}\text { treated not ICA } \\
\text { with the } \\
\text { protocol } \\
N=41\end{array}$} & \multicolumn{2}{|c|}{ Difference $\%(95 \% \mathrm{Cl})$} \\
\hline & inr cases & $\%$ & $\mathrm{nr}$ cases & $\%$ & & \\
\hline Complications & 2 & 5 & 2 & 5 & 0 & $(-9.7 ;+9.7)$ \\
\hline Treatment revisions & 1 & 3 & 9 & 22 & -19 & $(-32.8 ;-5.2)$ \\
\hline Surplus treatment duration (days) & -3 & & -1 & & -2 & $(-25.4 ;+22.2)$ \\
\hline Surplus follow-up (visits) & +0.28 & & +0.84 & & -0.57 & $(-1.60 ;+0.46)$ \\
\hline
\end{tabular}

- ICA $=$ in complete accordance

Table 3 shows that when these simple common fractures were treated not in complete accordance with the protocol treatment, revisions were made in more than $20 \%$ of cases while no revisions were made when treated in complete accordance with the protocol. The remaining variables did not differ between the two groups. 


\section{Discussion}

Until now, evaluation of the effect of computerized decision support systems (CDSSs) on clinical practice is still not performed routinely and only a few studies assessed the effect on patient outcome ${ }^{\circ}$. This might be due to difficulties related to the rigorous evaluation of CDSSs as compared to pharmaceutical trials ${ }^{0.17}$. One major problem is that impact of CDSSs is measured at two levels, physicians and patients respectively. Depending on the number and kind of clinical conditions supported, large numbers of participants may be required to assess patient outcomé.

The present study attempted to measure the effect of computerized trauma protocols on treatment outcome. A problem we encountered was that the management of a wide range of isolated fractures was supported while the number of each particular fracture type treated was quite small. This precluded conclusions for each fracture type separately but the results of two more homogeneous patient groups, based on severity of fracture (operated versus non-operated), were presented also.

Furthermore, we may wonder whether optimal treatment results can be expected. Improved protocol adherence during the first emergency room visit might be a basis for optimal treatment but the lack of computer support during follow-up, reacting to sudden changes in the patient's clinical course and patient refusals may have interfered with carrying out the protocol treatment. In the future, more comprehensive trials, should assess these possibilities.

We found that treatment revisions were made in equal proportions in experimental and control patients. The fact that experimental patients were not treated more consistently than controls might be explained as follows. When residents deviated from the protocol, computer supported residents showed more minor protocol deviations while residents without computer support showed more major protocol deviations" ${ }^{15}$. Minor protocol deviations can be corrected more easily during follow-up visits than major protocol deviations. This leads to more treatment revisions but fewer complications and shorter treatment duration.

In a subgroup all residents could have considered the correct protocol treatment when they would have consulted them. However, only computer supported residents actually read the correct protocol treatment for each case (computer consultation was compulsory) while control residents hardly read the protocol treatment because they did not consult the paper protocols very often ${ }^{15}$. This might explain that experimental patients developed fewer complications and had a shorter treatment duration as compared to controls. Computer supported residents seemed therefore more capable to apply the most suitable treatment. Control residents on the other hand applied treatments based on other information sources such as their own or their colleagues' knowledge. Although one has to be cautious in interpreting subgroup results, they suggest that improvement of treatment, secondary to further improvement of protocol adherence, might be possible. If residents are provided with additional diagnostic support they will read the correct protocol treatment more often. 
When the impact of CDSSs on patients is assessed, patients in whom doctors ignored the CDSS's advice should not be excluded from the analysis. The study should be analyzed according to the 'intention to provide advice.17. Since further improvement of protocol adherence seems feasible in our setting we measured the benefit maximally obtainable of protocol adherence after all. It is interesting that the results showed hardly any treatment revisions when common simple fractures were treated in complete accordance with the protocol. Although treatment revisions are made in order to reach an optimal treatment result, a more consistent treatment might lead to a reduction of workload, costs and inconvenience for the patient.

Although a wide variation of clinical protocols has been evaluated, none involved the management of common fractures ${ }^{0.4}$. As a result we were unable to compare our results with other studies.

\section{Conclusion}

We could not show that the use of computerized trauma protocols, used during the first emergency visit only, influenced treatment positively. To demonstrate this, either a much larger trial, extending the trauma protocol with diagnostic information and providing residents with computer support during follow-up seems necessary.

\section{References}

1 Alberts KA, Jervaeus J. Factors predisposing to healing cornplications after internal fixation of fernoral neck fracture. A stepwise logistic regression analysis. Clin Orthop 1990:257:129-133.

2 Babst R, Simmen BR, Regazzoni P. Clinical significance and treatment concept of Lisfranc dislocation and dislocation fracture. Helv Chir Acta 1989:56:603-607.

3 Gellman H, Schwartz SD, Botte MJ. Feiwell L. Late treatment of a dorsal transscaphoid, transtriquetral perilunate wrist dislocation with avascular changes of the lunate. Clin Orthop 1989;237:196-203.

4 Grimshaw IM, Rusell IT. Effect of clinical guidelines on medica! practice: a systematic review of rigorous evaluations. Lancet 1993:342:1317-1322.

5 Hendrix RW, Rogers LF. Diagnostic imaging of fracture complications. Rad Clin North Am 1989:27:1023-1033.

6 Johnston ME, Langton KB. Haynes RB, Mathieu A. Effects of computer-based cliniçai dẹcișion support systems on clinician performance and patient outcome. Ann Intern Med 1994;120:135-142.

7 Kjaer-Petersen K, Langhafi D, Andersen K. Bennett's fracture. J Hand Surg Br 1990;15:58-61

8 Leeds $\mathrm{HC}$. Ehrlich MG. Instability of the distal tibiofibular syndesmosis after bimalleolar and primalleolar ankle fractures. J Bone Joint Surg Am 1984;66:490-503.

9 Monk HL. Fractures are never simple. RN 1993:56:30-35.

10 Morris F, Cope A, Hawes S. Training in accident and emergency: views of senior house officers. BMJ 1990;300:165-166.

11 Sternbach G. Abraham Colles: fracture of the carpal extremity of the radius. J Emerg Med $1985: 2: 447 \cdot 450$

12 Teeny SM, Wiss DA. Open reduction and internal fixation of tibial plafond fractures. Variables contributing to poor results and complications. Clin Orthop 1993;292:108-117.

13 Thurston A.J. Dempsey SM. Bennett's fracture: a medium to long-term review. Aust N-Z J Surg $1993 ; 63: 120-123$ 
14 Vissers MC, Hasman A, Donkers. HHLM, van der Linden CJ. Development, implementation and a first evaluation of a protocol processing system (ProtoVIEW). Comp Meth Prog Biomed 1995; 47:81-92.

15 Vissers M, Hasman A, van der Linden CJ. Protocol processing system (ProtoVIEW) to support residents at the emergency ward. In: Proc MIE'94:138-143. Eds: Barahona P, Veloso M, Bryant $J$ (Lisboa, Portugal).

16 Warren PJ, Ferris BD. Colles' fractures: the use of the metacarpal index as a prognostic indicator investigated. I R. Coll Surg Edinb 1993;38:373-375.

17 Wyatt: J. Field trials of medical decision-aids: potential problems and solutions. Proceedings SCAMC 1991:3-7.

18 Yates: DW. The training of junior doctors for accident and emergency work: a case for urgent treatment. Injury $1985 ; 14: 456-460$. 


\section{Appendix: the treatment variables}

Complications developed during healing. Although many complications occur as a consequence of the injury itself, complications also result from the treatment provided ${ }^{5.9}$. Possibly minor treatment problems, not worth mentioning in the patient record explicitly, lead to a longer duration of treatment and an increased number of follow-up visits. Therefore, treatment duration and follow-up visits served as proxies for these minor problems.

Surplus treament duration was measured as the difference between treatment duration advised by the protocol treatment and the actual total treatment duration ${ }^{2}$ (in days).

Surplus follow-up visits: was measured as the difference between number of follow-up visits advised by the protocol treatment and the number of follow-up visits carried out.

Treatment revisions made after the first emergency room visit. Treatment revision involved: operation in second instance or reoperation, extension or shortening of immobilisation period, (type of) immobilisation material changed, both change of immobilisation material and extension of immobilisation period, both change of immobilisation material and shortening of immobilisation period and miscellaneous changes.

2 Treatments were considered to be initiated on the first emergency room visit and to be completed when "discharge" was recorded in the patient record during the final follow-up. 
Chapter 8

The introduction of a computerized protocol in clinical practice; is there anything to gain?

\author{
Vissers $\mathbf{M C}^{1}$ \\ Greve $\mathrm{JWM}^{2}$ \\ Gouma $\mathrm{DJ}^{3}$ \\ van der Linden $\mathrm{CJ}^{4}$ \\ Hasman $\mathbf{A}^{\prime}$ \\ 'Department of Medical Informatics, University of Limburg, Maastricht \\ ${ }^{2}$ Department of Surgery, University Hospital of Maastricht \\ ${ }^{3}$ Department of Surgery, Academic Medical Center, Amsterdam \\ ${ }^{4}$ Department of Surgery, University of Nijmegen \\ The Netherlands
}




\section{Abstract}

Objectives - Before the introduction of an adapted national protocol for the diagnostic work-up and management of patients with obstructive jaundice, the potential benefit of this protocol was assessed by comparing its recommendations with the strategies actually followed in patients with obstructive jaundice. Furthermore local expertise with diagnostic and therapeutic procedures was compared with expertise reported in the literature.

Design - A retrospective patient record analysis.

Subjects - Forty=nine consecutive patients presenting at the departments of internal medicine and surgery of the University Hospital in Maastricht, the Netherlands with serum alkaline phosphatase levels $>125 \mu \mathrm{mol} / \mathrm{l}$, and serum bilirubin levels $>17 \mu \mathrm{mol} / \mathrm{l}$ between June 1990 and June 1992.

Main outcome measures - The proportions of diagnostic and therapeutic decisions that deviated from the recommendations, and the success rates of diagnostic and therapeutic procedures.

Results - In patients with bile duct stones the treatment strategies did not deviate from the protocol. In patients with a malignancy $30 \%$ of the diagnostic decisions and $11 \%$ of the therapeutic decisions deviated from the protocol. Success rates of all diagnostic investigations were comparable with those reported in the literature. Success rates of endoscopic Dhary erainage tenced to oe lower than those iound in the therature.

Conclusions - The introduction of a protocol for the diagnostic work-up of obstructive jaundice may reduce half of the superfluous diagnostic investigations and diagnostic omissions. Since local expertise of some therapeutic procedures seems not to be comparable with those reported in the literature it may be necessary to modify the protocol to fit local circumstances better. 


\section{Introduction}

National consensus conferences have become increasingly popular. In the past two decades many consensus statements concerning a wide range of subjects have been developed and disseminated ${ }^{1,13,15,19.38}$. However, those national protocols often failed to achieve change in medical practice ${ }^{19,23,18}$. Locally developed protocols on the other hand, seem to influence medical practice much more easily 28.31 . Since locally developed protocols are less likely to be scientifically valid", a solution could be to carefully embed national protocols in the local situation taking into account specific features of setting and resources ${ }^{12}$.

Whether physicians consult and act according to the protocols seems to be related also to the format, style and presentation of the protocols. Doctors are reluctant to use algorithms when they are complex or inflexible ${ }^{12}$. Therefore protocol information must be presented in a reader friendly and comprehensible ${ }^{10}$ way. A protocol display system (ProtoVIEW) ${ }^{40}$ was developed in which a wide range of protocols can be stored and retrieved. ProtoVIEW can present protocols concisely in a flow chart format and additional information can be provided on request. Moreover, protocols can be updated easily and patient data such as demographic data, diagnostic and therapeutic choices can be stored into ProtoVIEW. When ProtoVIEW, supplied with locally developed trauma protocols, was evaluated in clinical practice, physicians judged positively the way the protocols were presented ${ }^{41}$. To evaluate ProtoVIEW in more complex circumstances we wanted to provide physicians with a protocol supporting them in the diagnostic work-up of extrahepatic bile duct obstructions. Obstructive jaundice is a complex medical problem that requires good cooperation between several disciplines.

In 1992, in the Netherlands, a national consensus meeting was held on the diagnostic work-up and therapeutic interventions in patients suspected to have malignant distal bile duct obstruction. General recommendations and guidelines resulted from this meeting ${ }^{29}$. Since a local protocol was not available, a surgeon at the university hospital in Maastricht adapted these national recommendations for available resources, to fit the local circumstances. Imaging procedures play a prominent role in the diagnostic process of jaundiced patients and their diagnostic protential may vary between institutions because of variance in local expertise ${ }^{30,24}$. To develop an optimal local protocol, national recommendations based on reported expertise may also have to be adapted if local expertise differs from that found in the literature. It was therefore decided to determine - before the introduction of the computerized local protocol into clinical practice - the potential benefit of the local protocol by analysing the diagnostic work-up of patients with obstructive jaundice. Furthermore, local expertise with diagnostic and therapeutic procedures was compared with that reported in the literature to estimate what kind of changes are needed to adapt the protocol optimally. 


\section{Materials and methods}

\section{1 Consensus meeting and protocof development}

Consensus was based mainly upon the experiences and knowledge of experts from several disciplines (surgery, radiology and gastroenterology) working in different university hospitals in the Netherlands ${ }^{29}$.

National recommendations on the use of relatively new techniques such as duplex scanning, endoscopic ultrasonography, Magnetic Resonance Imaging (MR.I) and diagnostic laparoscopy were not adopted by the local protocol. Some of the new techniques were not yet available and for other procedures local expertise was assumed to be insufficient to apply routinely.

National recommendations about the use of noninvasive imaging techniques such as Ultrasound (US) and Computed Tomography (CT) were adopted by the local protocol as well as invasive imaging techniques such as Endoscopic Retrograde Cholangio-Pancreatography (ERCP), Percutaneous Transhepatic Cholangiography (PTC), and Angiography.

Figure I displays a schematic outline of the local protocol. It shows that US is recommended as the first diagnostic step for patients suspected of obstructive jaundice. If US indicates bile duct stones, the stone(s) should be removed, depending on presence of gallbladder and patients' age, during endoscopy (after sphincterotomy) or by surgery ${ }^{20.26}$.

If US suspects an unresectable malignant tumour or metastatic disease, further investigations should aim at confirmation of the diagnosis followed by an early and ef fective non surgical palliative treatment.

If US does not reveal distant metastases or clear ingrowth of tumour, further staging has to be performed. The next step is a CT followed by ERCP. For patients with severe jaundice (serum bilirubin $>100 \mu \mathrm{mol} / \mathrm{l}$ ) or cholangitis, ERCP may precede CT because immediate drainage is indicated. During ERCP the diagnosis may be confirmed by bile fluid cytology or biopsy of suspected lesions. For all patients the diagnostic endoscopic procedure is preferably followed by the insertion of an endoprosthesis 25.26 . This wiil be the final palliative procedure for most patients $s^{10,21}$. In case of unsuccessful endoscopic stent insertion a second attempe is made, endoscopically or percutaneously. In patients with proximal bile duct stenoses, percutaneous drainage is recommended if endoscopic stent insertion fails ${ }^{22}$ since the success of endoscopic stent insertion in these patients varies considerably $y^{21}$. In case successive attempts fail to establish internal drainage, external drainage is attempted during PTC.

If suspicious lesions are visible on US or CT, confirmation of diagnosis should be attempted (if not established yet) by percutaneous aspiration cytology ${ }^{6}$, except when curative resection is considered (to avoid the risk of seeding tumour cells $\mathrm{s}^{440}$ ).

If curative resection is considered and the patient is in a good condition a selective splanchnic angiography may be performed as a last diagnostic investigation before laparotomy. 


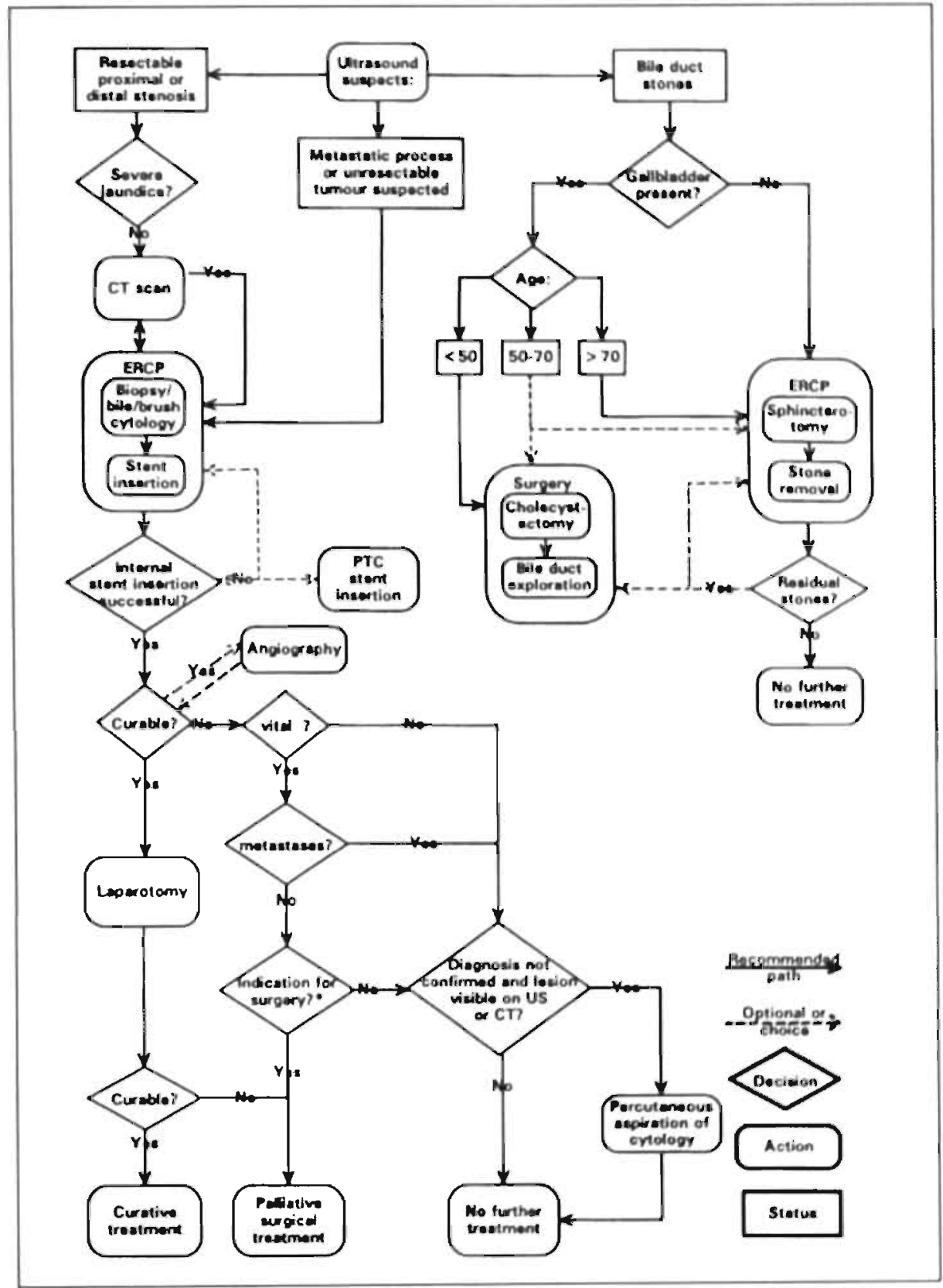

Figure 1 Dverview ofl the protocol for obstructive jaundice. * indications for surgery are: biliary drainage absen or long survival expected or duodenal obstruction. expected soon. 
If incurability is decided upon, palliative surgical treatment with biliodigestive bypass may be considered for patients in good condition withour signs of distant metastases ${ }^{4}$. For the remaining incurable patients treatment is limited to the already inserted endoprosthesis.

\section{2 Patients}

The patients were collected retrospectively from the departments of internal medicine and surgery of the University Hospital in Mastricht, the Netherlands. The records of all patients presenting with obstructive jaundice secondary to benign or malignant (proximal or distal) stenoses of the bile ducts between June ' 90 and June ' 92 were reviewed. All patients had a serum alkaline phosphatase $>125 \mu \mathrm{mol} / \mathrm{l}$ and a serum bilirubin level $>17 \mu \mathrm{mol} / \mathrm{l}$. Patients not diagnosed or treated entirely at the University Hospital of Maastricht were excluded from the study. A pathological diagnosis was sought whenever possible. If not available, a final diagnosis was based on a combination of clinical and radiological criteria.

\subsection{Outcome measures}

For each patient the diagnostic and therapeutic strategy was compared with the strategy suggested by the protocol. For patients with bile duct stones only treatment (endoscopy or surgery) was compared with the treatment recommended by the protocol.

For patients with a malignancy we compared i) the choice of each respective imaging technique, (after US), based upon previous work-up findings and 2) the decision to perform percutaneous punctions for cytology or biopsies with the recommendations from the protocol. For patients with proximal stenoses we investigated also 1) whether bile or brush cytology was performed in patients who underwent ERCP and 2) whether percutarieous stenting was chosen as the next procedure when the attempi to insert a prosthesis endoscopically had failed.

An endoscopic procedure was considered a diagnostic success if the bile ducts could be visualized and a therapeutic success if at least biliary drainage could be achieved, regardless of the number of investigations necessary to achieve this. PTC was considered a diagnostic success if the biliary tract could be visualized and introduction of a catheter resulted in a successful external drainage. Internal drainage was defined as successful if at least one drain showed to be radiologically positioned across the stricture, again regardless of the number of attempts.

For each diagnostic or therapeutic procedure a pooled success rate was calculated from several (review) studies. The differences are reported with their $95 \%$ Confidence Intervals (CI).

\section{Results}

Forty-nine patients were diagnosed with obstructive jaundice. Table 1 summarizes the paticmt characteristics, duration of hospital stay and the number of diagnoses confirmed pathologically. 
Table 1 Characteristics of 49 consecutive patients with obstructive jaundice presenting in the university hospital of Maastricht between June '90 - June '92. For continuous variables the median and (in parentheses) the 25 th and 75 th percentile is given

\begin{tabular}{|c|c|c|c|c|}
\hline & $\begin{array}{l}\text { Ductal } \\
\text { stones } \\
(n=12)\end{array}$ & $\begin{array}{l}\text { Proximal } \\
\text { stenosis } \\
(n=14)\end{array}$ & $\begin{array}{l}\text { Distal } \\
\text { stenosis } \\
(n=23)\end{array}$ & $\begin{array}{l}\text { Total } \\
(n=49)\end{array}$ \\
\hline Sex (male/female) & $3 / 9$ & $6 / 8$ & $11 / 12$ & $20 / 29$ \\
\hline Age (years) & $72 \quad(68 \cdot 76)$ & 64. (56- - 33$)$ & $72 \quad(63-83)$ & $71 \quad(63-78)$ \\
\hline Bilirubin (umol/1) & $92(40-103)$ & $97 \quad(32-120)$ & $102(35-241)$ & $97 \quad(43-161)$ \\
\hline Alk. phosph (umol/l) & $324\left(297^{\circ}-574\right)$ & $379(283-679)$ & $487(294-876)$ & $434(297-645)$ \\
\hline $\begin{array}{l}\text { Fever }\left(>38,{ }^{\circ} \mathrm{C}\right) \\
\text { Gallbladder }\end{array}$ & 2 & 0 & 1 & 3 \\
\hline $\begin{array}{l}\text { removed previously } \\
\text { Admission (days) }\end{array}$ & 4 & 2 & 0 & 6 \\
\hline $\begin{array}{l}\text { - Total } \\
\text { - Until diagnosis }\end{array}$ & $\begin{array}{ll}11 & (9-15) \\
3 & (2-4)\end{array}$ & $\begin{array}{ll}28 & (14-59) \\
16 & (12-29)\end{array}$ & $\begin{array}{ll}25 & (16-42) \\
10 & (4-12)\end{array}$ & $\begin{array}{ll}21 & (12-33) \\
10 & (4-14)\end{array}$ \\
\hline Diagnosis proved & & & & \\
\hline pathologically & - & 9 & 14 & 23 \\
\hline
\end{tabular}

- Surgery, biopsy, or combination of radiologic and clinical findings

In 12 patients bile duct stones were the cause of obstruction, in 14 patients a proximal bile duct stenosis was present ( 8 proximal bile duct carcinomas, 3 gallbladder carcinomas, 3 cases of hepatic location of metastases or primary carcinoma) and in 2.3 patients a distal stenosis was present ( 18 pancreatic and 5 ampullary carcinomas).

\section{1 Work-up and treatment in obstructive jaundice patients}

When bile duct stones are suspected on the basis of clinical evaluation and US, the recommended therapeutic strategy depends on age and the presence of the gallbladder. For all patients the strategy was carried out according to the protocol.

For patients suspected of a malignancy a total of 128 work-up decisions were compared with the strategy recommended by the protocol. The median number of analyzed work-up decisions was 5 in patients with a proximal stenosis and 3 in patients, with a distal stenosis. Thirty-eight of the $128(30 \%)$ analyzed work-up decisions deviated from the protocol in 10 of 14 patients $(71 \%)$ with a proximal stenosis and in 11 of 23 patients $(48 \%)$ with a distal stenosis. Table 2 presents the kind of protocol deviations observed while table 4 and 5 present details about the work-up and treatment of each patient with a malignant stenosis.

Protocol deviations can be characterized as superfluous diagnostic investigations (26\%), a change in sequence of ERCP and CT $(16 \%)$, diagnostic omissions such as biopsies, bile fluid cytology, punctions (39\%) and, finally, miscellaneous deviations (18\%) including the performance of MRI (a technique not adopted by the local protocol) in 1 patient and a second attempt to insert a stent endoscopically in 6 patients with a proximal stenosis.

The choice of treatment was not as recommended by the protocol in 4 patients $(11 \%)$. In these patients surgery was performed while the protocol recommended non-surgical palliative treatment. 
Table 2 Protocol deviations of 128 work-up and 37 treatment decisions evaluated in: 37 patients with obstructive jaundice

\begin{tabular}{|c|c|c|c|}
\hline Protocol deviations & $\begin{array}{l}\text { Proximal stenosis } \\
(n=64)\end{array}$ & $\begin{array}{l}\text { Distal stenosis } \\
(n=64)\end{array}$ & $\begin{array}{l}\text { Total } \\
\text { (n=128) }\end{array}$ \\
\hline \multicolumn{4}{|l|}{ Diagnostic excess } \\
\hline $\mathrm{CT}$ & 2 & 2 & 4 \\
\hline Angiography & 2 & 2 & 4 \\
\hline Pancreatic punction & 0 & 2 & 2 \\
\hline \multicolumn{4}{|l|}{ Sequence deviations } \\
\hline ERCP before CT & 2 & 4 & 6 \\
\hline \multicolumn{4}{|l|}{ Diagnostic omissions } \\
\hline Bile cytology & 9 & 0 & 9 \\
\hline Pancreatic punction & 1 & 5 & 6 \\
\hline Miscellaneous deviations & 7 & 0 & 7 \\
\hline Total nr of diagnostic deviations $(\%)$ & $23 \quad(36)$ & 15 (23) & $38,(30)$ \\
\hline Total $n$ r of treatment deviations (\%) & $2 \quad(14)$ & 2 (9) & $4(11)$ \\
\hline
\end{tabular}

\subsection{Success rates biopsies/punctions/cytology}

A total of 23 ampullary biopsies, percutaneous punctions, bile or ascitic fluid cytology were performed in 18 patients suspected of a malignancy. Of these investigations $11(48 \%)$ were positive (malignancy proven), $10(43 \%)$ were negative and in $2(8 \%)$ the material was inadequate for cytological assessment.

Table 3 Diagnostic and therapeutic results of ERCP and PTC in patients suspected of a malignancy

\begin{tabular}{|c|c|c|c|c|c|c|c|c|c|c|c|}
\hline \multirow[b]{2}{*}{ Diagnostic } & \multicolumn{2}{|c|}{$\begin{array}{l}\text { Proximal } \\
\text { stenosis } \\
\mathrm{Nr} \%\end{array}$} & \multicolumn{2}{|c|}{$\begin{array}{l}\text { Distal } \\
\text { stenosis } \\
\text { Nr \% }\end{array}$} & \multicolumn{2}{|c|}{$\begin{array}{l}\text { Total } \\
\text { Nr \% } \\
\end{array}$} & \multicolumn{2}{|c|}{$\begin{array}{l}\text { Literature } \\
\mathrm{Nr} \%\end{array}$} & \multicolumn{2}{|c|}{ Difference } & \multirow[t]{2}{*}{$\begin{array}{l}\text { Pooled } \\
\text { studies }\end{array}$} \\
\hline & & & & & & & & & & & \\
\hline Percutaneous punctions & \multicolumn{2}{|l|}{4} & \multicolumn{2}{|l|}{6} & \multicolumn{2}{|l|}{10} & & & \multirow{2}{*}{\multicolumn{2}{|c|}{$22(-9 ; 53)$}} & \multirow{2}{*}{5.0 .17} \\
\hline Nr successful & 2 & 50 & 4 & 67 & 6 & 60 & 108 & 82 & & & \\
\hline Brush/bile cytology & 3 & & 1 & & 4 & & & & & & \multirow[b]{2}{*}{7,39} \\
\hline Nr successful & 1 & 33 & 1 & 100 & 2 & 50 & 49 & 69 & 19 & $(-32 ; 70)$ & \\
\hline $\mathrm{Nr}$ of ERCPs intended & \multicolumn{2}{|c|}{11} & \multicolumn{2}{|l|}{22} & \multicolumn{2}{|l|}{33} & & & & & \multirow{2}{*}{$\begin{array}{l}3.8,14 \\
32,33,42\end{array}$} \\
\hline $\mathrm{Nr}$ successful & 9 & 82 & 19 & 86 & 28 & 85 & 872 & 91 & 6 & $(-6 ; 18)$ & \\
\hline $\mathrm{Nr}$ of PTCs intended & \multicolumn{2}{|l|}{7} & \multicolumn{2}{|c|}{5} & \multicolumn{2}{|l|}{13} & & & & & \multirow[b]{2}{*}{$21,34,9$} \\
\hline Nr successful & 6 & 86 & 5 & 100 & 12 & 92 & 128 & 95 & 3 & $(-12 ; 18)$ & \\
\hline \multicolumn{12}{|l|}{ Therapeutic } \\
\hline $\mathrm{Nr}$ of ERCPs intended & \multicolumn{2}{|c|}{11} & \multicolumn{2}{|l|}{20} & \multicolumn{2}{|l|}{31} & & & & & \multirow[b]{2}{*}{$27,37,21$} \\
\hline Nr biliary drainage & 7 & $64^{*}$ & 12 & $60^{\circ}$ & 19 & 61 & 2008 & 90 & 29 & $(12 ; 46)$ & \\
\hline $\mathrm{Nr}$ of PTCs intended & \multicolumn{2}{|l|}{7} & \multicolumn{2}{|l|}{6} & \multicolumn{2}{|l|}{13} & & & & & \multirow{2}{*}{$20,3 a$} \\
\hline Nr drainage & 6 & 86 & 6 & 100 & 12 & 92 & 128 & 95 & 4 & $(-11 ; 19)$ & \\
\hline Nr int drainage intended & \multicolumn{2}{|l|}{3} & \multicolumn{2}{|l|}{4} & \multicolumn{2}{|l|}{7} & & & & & \multirow{2}{*}{21.35 .9} \\
\hline $\mathrm{Nr}$ int drainage & 3 & 100 & 3 & 75 & 6. & 86 & 886 & 86 & 0 & $(-26 ; 26)$ & \\
\hline
\end{tabular}

a The success rate of proximal stenoses was comparable with the pooled success rate $(85 \%)$ reported in the literature (difference of $19 \%(\mathrm{Cl} ;-10 ; 48)$ ).

b The success rate of distal stenoses was significantly lower than the pooled success rate $(95 \%)$ reported in the literature (difference of $35 \%(\mathrm{Cl} ; 13 ; 57)$ ). 
Table 4. Diagnostic work-up and therapeutic intervention performed in 14 patients with proximal obstructive jaundice

\begin{tabular}{|c|c|c|c|c|c|c|c|c|c|c|}
\hline \multirow[t]{2}{*}{ Age } & \multicolumn{2}{|c|}{ Ulerasound } & \multicolumn{2}{|c|}{ Computer Tomography } & \multicolumn{2}{|c|}{ Biliary drainage } & \multirow{2}{*}{$\begin{array}{l}\text { Angiography } \\
\text { ingrowth? }\end{array}$} & \multirow{2}{*}{$\begin{array}{l}\text { Biopsyl } \\
\text { cytology" }\end{array}$} & \multirow[t]{2}{*}{ Treatment? } & \multirow{2}{*}{$\begin{array}{l}\text { Fina! } \\
\text { diagnosis" }\end{array}$} \\
\hline & mass & incurable? & mass' & incurable: & Internal ${ }^{3}$ & External & & & & \\
\hline \multicolumn{11}{|c|}{ Proximal stenosis diagnostic work-up and therapy according to the protocol } \\
\hline 65 & Gallbi & + & & & $n p$ & & & PAsC - & Nort-surgical & $\mathrm{PBD} \mathrm{ca}^{\dagger}+$ \\
\hline 53 & - & - & Liver & - & $n p$ & & + & P liver + & Non-surgica! & Liver \\
\hline 76 & - & - & & & + & & & & Incurable & Gallbl, + \\
\hline 65 & - & - & & & np & & & & Incurable: & Gallbl,t• \\
\hline \multicolumn{11}{|c|}{ Proximai stenosis, diagnostic work-up and therapy not according to the protocof } \\
\hline 60 & P' hepatis & + & - & + & + & & & $P$ liver + & Non-surgica! & Liver, $t$ \\
\hline 71 & Stomach & + & - & + & + & & $+1-$ & & Palliative & Liver \\
\hline 55 & - & - & - & + & - & + & - & C gall + & Incurable & PBD $\mathrm{ca}^{\dagger} \uparrow$ \\
\hline 82 & - & + & - & + & - & - & & $P$ liver - & Non-surgical & PBD ca \\
\hline 60 & - & - & - & - & + & & & $C$ gall - & Curable & PBD ca, $t^{*}$ \\
\hline 52 & - & - & $P$ hepatis & - & - & + & $?$ & & Incurable & PBD ca \\
\hline 71 & - & - & - & - & - & + & - & & Curable & PBD ca \\
\hline 78 & - & - & - & + & + & & & & Non-surgical & PBD ca,? \\
\hline 63 & - & - & $P$ hepatis & - & + & & & & Non-surgical & PBD ca $\uparrow$ \\
\hline 56 & - & - & - & - & - & $n p$ & MRI & C AsC - & Non-surgical & Liver, + \\
\hline
\end{tabular}

pancreas = mass: in pancreas $-=$ test performed but: no abnormalities visualized. gallbl = mass in gallbladder $\mathrm{P}$ hepatis $=$ mass in porta hepatic region $-\rightarrow$ test performed but no abnormalities visualized

$i+=$ metastases or focal ingrowth of tumour visualized $-=$ no signs of irresectability visualized

'Internal + = internal bilary drainage succeeded Internal - = internal biliary drainage failed Internal np = ERCP nor PTC. was performed

- External + = external biliary drainage succeeded External - = external biliary drainage failed External np = PTC was not performed

$+=$ ingrowth likely $+1-=$ ingrowth possible $-=$ no sign for ingrowth $?=$ report lost

P $\mathrm{P}=$ punction $\mathbf{B}=$ biopsy $\mathrm{C}=$ crtology $+=$ malignancy proved $-=$ malignancy not proved Asc $=$ Ascites

- Curable = curative resection intended and performed Incurable = curative resection intended but palliative surgery performed Palliative = palliative surgery intended and performed Non-surgical = internal or external biliary dtainage or no treatment:

- Pancr $=$ pancreas carcinoma Amp = ampullary carcinoma PBD ca = carcinoma of proximal bile ducts gallbl = gallbladder carcinoma Liver =liver. primary

of secundary (Lung, mamma) = other malignancy found simultaneously $t=$ patient died during follow-up. autopsy performed 
Table 5 Diagnostic work-up and therapeutic intervention performed in 23 patients with distal obstructive jaundice

\begin{tabular}{|c|c|c|c|c|c|c|c|c|c|c|}
\hline \multirow[t]{2}{*}{ Age } & \multicolumn{2}{|c|}{ Uitrasound } & \multicolumn{2}{|c|}{ Computer Tomography } & \multicolumn{2}{|c|}{ Biliary drainage } & \multirow{2}{*}{$\begin{array}{l}\text { Angiography } \\
\text { Ingrowth?" }\end{array}$} & \multirow{2}{*}{$\begin{array}{l}\text { Biopsy } \\
\text { cytology" }\end{array}$} & \multirow[t]{2}{*}{ Treatment' } & \multirow{2}{*}{$\begin{array}{l}\text { Final } \\
\text { diagnosis* }\end{array}$} \\
\hline & mass' inc & curable? $?^{2}$ & mass in & acurable? $?^{2}$ & Inte & External $^{2}$ & & & & \\
\hline \multicolumn{11}{|c|}{ Distal stenosis, diagnostic work-up and therapy according to the protocol } \\
\hline 65 & - & + & & & + & & & P liver + & Non-surgical & Pancr, $t^{\bullet}$ \\
\hline 71 & Pancreas & + & & & + & & & $\mathrm{B}$ duo + & Non-surgical & Pance \\
\hline 82 & Pancreas & + & & & - & $\mathrm{np}$ & & & Palliative & Pancr \\
\hline 72 & Pancreas & - & Pancreas & + & - & & & $\begin{array}{l}\text { P panc + } \\
\text { B. amp + }\end{array}$ & Non-surgical & Pancer \\
\hline 58 & - & - & - & - & - & $n p$ & - & & Curable & Amp \\
\hline 67 & - & - & - & - & - & $n p$ & & B amp - & Curable & Amp.t \\
\hline 80 & - & - & Pancreas & - & + & & & B duo - & Non-surgical & Pancr \\
\hline 72 & - & - & - & - & - & $n p$ & & & Curable & Amp \\
\hline 96 & - & - & & & + & & & & Non-surgical & Pancr \\
\hline 80 & - & - & & & - & $\mathrm{np}$ & & & Non-surgical & Panct, $t^{\bullet}$ \\
\hline 83 & - & - & & & np & & & B' amp - & Non-surgical & Amp, $\uparrow$ \\
\hline 63 & - & - & - & - & $n p$ & & & $P$ node - & Palliative & Pancr, $†$ \\
\hline \multicolumn{11}{|c|}{ Distal stenosis, diagnostic work-up and therapy not according to the protocol } \\
\hline 70 & - & + & Pancreas & + & - & + & & & Non-surgical & Pancr,t \\
\hline 73 & Pancreas & + & - & - & + & & $+1-$ & & Non-surgical & Panct, $t$ \\
\hline 47 & Pancreas & - & Pancreas & + & + & & + & P pancr + & Incurable & Pancr \\
\hline 53 & Pancreas & - & Pancreas & - & + & & + & P pancr - & Incurable & Panci \\
\hline 72 & - & - & - & - & + & & & & Non-surgical & Pancr,lung \\
\hline 63 & Pancreas & & Pancreas & - & - & + & & C gall + & Incurable & Pancr, $†$ \\
\hline 45 & Pancreas & - & Pancreas & - & - & + & $+1-$ & & Curable & Pancr \\
\hline 78 & - & - & - & - & + & & & B. $a m p+$ & Curabie & Amp \\
\hline 88 & Pancreas & - & & & + & & & & Non-surgical & Pancr \\
\hline 85 & Pancreas & - & & & + & & & & Non-surgical & Panc,mammat \\
\hline 84 & Pancreas & - & & & + & & & & Non-surgical & Pancr \\
\hline
\end{tabular}

Legends see table 4. 
Some patients underwent a test twice and a malignancy could eventually be proven in 9 out of 18 patients (overall sensitivity: $50 \%$ ). The investigations were positive in 6 out of $10(2$ were inadequate) pancreatic or liver punctions, 3 out of 6 ampullary biopsies, 2 out of 4 bile fluid cytology and none of the 3 ascitic fluid cytology.

The literature reports sensitivities of percutaneous punctions for cytology of 78-100\% $0.5,17$ and eytological brush of $57-71 \%$ respectively. Table 3 shows that the pooled sensitivities of these investigations did not differ significantly from the present study results. Specificities reported in these studies range from $87-100 \%$. $17,39.7$ for both percutaneous punctions for cytology and brush cytology.

\section{3 Success rates ERCP and PTC}

Table 3 shows the success rates of ERCP and PTC respectively. In patients with a malignancy, ERCP and PTC were diagnostically successful in $85 \%$ and $92 \%$ respectively. These success rates showed to be comparable with those reported in the literature. Internal biliary drainage was established by either endoscopic or percutaneous stenting in $91 \%$ proximal strictures and in $75 \%$ of distal strictures. Endoscopic biliary drainage was slighily more successful in patients with a proximal stenosis $(64 \%)$ than in patients with a distal stenosis $(60 \%)$. Of the 13 patients for whom endoscopic biliary drainage was not successful, percutaneous drainage was successfully performed in $12(92 \%)$. Of these 12 patients an internal stent could be successfully inserted in $50 \%$ of the patients with either a proximal or distal stenosis. Seven of the latter patients were subjected to non-surgical palliative treatment and as a result internal drainage was sought.

In these patients internal drainage was achieved in $6(86 \%)$ by either a percutaneous procedure or by a combination of percutaneous and endoscopic procedures.

Comparing the present study results with the results reported in the literature, it was found that the success rate of overall endoscopic biliary drainage of the present study was significantly lower than the pooled success rate.

Separating proximal from distal biliary drainage, the success rate of proximal biliary draiange did not differ significantly from the literature while the success rate of distal biliary drainage was significant lower as compared to the literature.

The success rate of overall percutaneous external and internal drainage did not differ significantly from the pooled success rate in the literature.

\section{Discussion}

Before the introduction of a computerized protocol into clinical practice the potential benefit of the protocol was estimated. In patients with bile duct stones, treatment strategies were in complete accordance with the protocol. Since introduction of the protocol will not change treatment strategies for patients with bile duct stones, improvement of treatment can therefore not be expected.

In $57 \%$ of the patients with a malignancy however, at least one of the work-up decisions deviated from the protocol. A total of 128 work-up decisions were analyzed of which $30 \%$ deviated from the protocol. Whether each of these deviations can be avoided with the 
introducing of the protocol is questionable. Diagnostic investigations that were superfluous - according to the protocol - may not always be possible to avoid. For instance, in young and fit patients suspected of a malignancy additional diagnostic investigations and surgery can be necessary to prove incurability with certainty. The performance of percutaneous punctions for cytology in patients considered for curative surgery, however, should be avoided since it exposes them to increased risks of seeding tumour cells. Moreover, the test result has no therapeutic consequences. A second attempt to insert a stent endoscopically in patients with proximal stenosis should also be avoided since endoscopic drainage fails more frequently in patients with proximal than distal stenosis. A percutaneous approach should be preferred as the next procedure.

Diagnostic omissions constituted $40 \%$ of all deviations. Also diagnostic omissions cannot always be avoided. For example, the protocol recommends confirmation of the suspected diagnosis by e.g. biopsy or percutaneous punctions for cytology. However, patients may refuse or physicians may decide not to subject patients over 80 years old with multiple metastases (suspected by CT) to inconvenient investigations with limited diagnostic reliability. In only $50 \%$ of the patients with a malignancy, percutaneous punctions could eventually confirm the diagnosis. The omissions to collect bile fluid for cytology during ERCP however, should be seen as a missed opportunity to obtain additional diagnostic information without any risk or inconvenience for the patient.

Deviations in the sequence of ERCP and CT constituted $16 \%$ of all deviations and may partly be altributed to logistic reasons such as a long waiting time for CT. Another reason might be that US could not visualize a mass or metastases in patients initially suspected of a malignancy. In this case bile duct stones could have been reconsidered since US often can not visualize bile duct stones. This justifies ERCP as the next diagnostic step.

Finally, the performance of surgical treatments instead of palliative non-surgical treatments (11\% of the patients) might be attributed to the younger age and condition of the patients.

Considering the observed differences between strategies performed in clinical practice and the strategy recommended by the protocol, it seems to be possible and desirable to avoid at least half of the future protocol deviations with the introduction of the protocol.

For the remaining (unavoidable) protocol deviations it may be worth while to investigate further whether these deviations were based upon individual patient indications or upon generally applicable indications. In the latter case it may be possible to generate new recommendations to be incorporated in the protocol. For instance: In case a malignancy is suspected bu US does reveal neither signs of a malignancy nor sones, then ERCP precedes $C T$ :

Although it seems to be beneficial to introduce the protocol into clinical practice. Iocal expertise may deviate considerable from expertise reported in the literature. In that case further protocol adaptations might be necessary to obtain an optimal local protocol.

Differences in technique, patient population, definitions of success, study design and site of stenosis (for stenting) make comparisons with other studies difficult. However, an attempt was made by comparing the present study results with the pooled results from the literature. 
Although the omissions to perform percutaneous punctions and brush cytology might be explained by limited diagnostic reliability, local expertise of percutaneous punctions and brush cytology showed to be comparable with that reported in the literature. Also the results concerning diagnostic ERCP and PTC were similar to those reported in the literature. On the other hand local expertise with endoscopic biliary drainage in patients with distal stenoses was less than reported in the literature. Since biliary drainage failed as often in patients with a distal stenosis as in patients with a proximal stenosis, it may be necessary to adapt some of the protocol recommendations. One adaptation could be to recommend percutaneous drainage as the second procedure (if endoscopic stent insertion fails) for distal stenoses also. Definite decisions about the adaptation of protocol recommendations might require further data collection in a prospective way. Especially since the only randomized trial ${ }^{\mathrm{H}}$ reported the second lowest success rate $(76 \%)$ for percutaneous internal drainage.

In summary it can be said that the introduction of the computerized protocol may reduce half of the superfluous diagnostic investigations and diagnostic omissions. It is however not always evident what kind of adaptations are needed to modify a nationaliy developed protocol to local circumstances. Since local expertise concerning endoscopic biliary drainage appeared not to be comparable with that reported in the literature, further protocol adaptations might be necessary. This may be achieved by additional prospective data collection of diagnostic and therapeutic procedures to establish definitive protocol recommendations that fit the local circumstances optimally.

Moreover, current insights concerning diagnostic work-up are still changing ${ }^{2}$. Diagnostic and therapeutic techniques are continuously being improved and developed, requiring information about local expertise with available techniques at any moment. Since ProtoVIEW will be used to provide physicians, with protocol support, patient data and results of diagnostic imaging procedures can easily be stored into the computer. This makes it possible to monitor local expertise of all diagnostic imaging procedures. which may be essential to develop optimal local protocols.

\section{References}

1 Andreasen PB. Consensus conferences in different countries. Int I Techn Assess Health Care 1988:4:305-308.

2. Bemelman WA, de Wit LT, van Delden OM, Smits NJ. Obertop H, Rauws EJA, Gouma DJ. Diagnostic laparoscopy combined with laparoscopic ultrasonography in staging of cancer of the pancreatic head region. Brit J Surg 1995;82;820-824.

3 Borsch G, Wegener M. Wedmann B. Kissler M, Glocke M. Clinical evaluation, ultrasound, cholescintigraphy, and endoscopic retrograde cholangiography in chlostasis. A prospective comparative clinical study. J Clin Gastroenterol 1988;10:185-190

4 van der Bosch RP, van der Schelling GP, Klinkenbịl JHG, Mulder PGH, van Blankenstein M, Jeekel J. Guidelines for the application of surgery and endoprostheses in the palliation of obstructive jaundice in advanced cancer of the pancreas. Ann Surg 1994;219:18-24

5 Carlucci M. Zerbi A, Parolini D, et al. CT-guided pancreatic percutaneous fine-needle biopsy in differential diagnosis between pancreatic cancer and chronic pancreatitis. HPB-surgery 1989; 1:309-314

6. Elsman BHP, de Graaf PW, van Leeuwen MS, Obertop H. Value and risks of fine needle 
aspiration biopsy for preoperative analysis tumours of the pancreas. Ned Tijdschr Geneeskd 1992;136:1459-1461.

7 Foutch PG, Harlan JR, Kerr D, Sanowski RA. Wire guided brush cytology a new endoscopic method for diagnosis of bile duct cancer. Gastrointest Endosc 1989;35:243-247.

8 Frederic N, Deltenre M, d'Hondt M, de Reuck M. Hermanus A, Potvliege R. Comparative study of ultrasound and ERCP in the diagnosis of hepatic, biliary and pancreatic diseases: a prospective study based on a continuous series of 424 patients. Eur J Radiol 1983:3:208-211.

9 Gibson RN, Yeung E, Hadijs N, Adam A, Benjamin IS, Allison DJ, Blumgart LH. Percutaneous transhepatic endoprostheses for hilar cholangioncarcinoma. Am J Surg 1988;156:363-367.

10 Gouma DJ, Oei TK, Soeters PB, van Engelshoven JMA, Greep JM. Percutane transhepatische galwegdrainage, tien jaar na de introductie. Ned Tijdschr Geneeskd 1989;133:2494-2499.

11 Grimşhaw J. Russell I. Achieving health gain through clinical guidelines. I: Developing scientifically valid guidelines. Qual Health Care 1993;2:243-248.

12 Grimshaw JM. Russell IT. Achieving health gain through clinical guidelines II: Ensuring guidelines change medical practice. Qual Health Care 1994:3:45-52.

13 Grol A, Wensing M. Jacobs A, Baker R. Quality of care standards protocol guideline general practitioner. Nederlands Huisartsen Genootschap, Utrecht, 1993.

14 Gross BH, Harter LP, Callen PW, Filly RA. Shapiro HA, Goldberg HI. Ultrasonic evaluation of common bile duct stones: prospective comparison with endoscopic retrograde cholangiopancreatography. Radiology 1983;146:471-474.

15 Jacoby 1: The consensus development program of the National Institutes of Health. Current practices and historical perspectives. int $J$ Tech Assess. Health Care 1985:2:420-432.

16 Kanouse DE, Jacoby I. When does information change practitioners' behavior? Int $J$ Tech Assess Health Care 1988:4:27.33

17 Kocjan G, Rode J, Wees. WR. Percutaneous fine needie aspiration cytology of the pancreas: advantages and piffalls. J Clin Pathol 1989;42:341-347.

18 Kosecolf J, Kanouse DE, Rogers WH, Mccloskey L. Winsiow CM. Brook RH. Etfects of the Nationa! Institute of Health Consensus Development Program on physician practice. JAMA. $1987 ; 258: 2708-2713$.

19 Kosecoff J, Kanouse DE, Brook RH. Changing practice patterns in the management of primary breast cancer: consensus development program. Health Serv Res 1990:25:809-823.

20 Lai ECS, Mok FPT, Tan ESY, Lo CM, Fan ST, You KT, Wong J. Endoscopic biliary drainage for severe acute cholecystitis. N Engl J Med. 1992;326:1582-1586.

21 Lameris JS, Stoker J, Dees J. Nix GAJJ, van Blankenstein M. Jeekel J. Non-surgical palliative treatment of patients with malignant bitiary obstruction- the place of endoscopic and percutaneous drainage. Clin Radiol 1987:38:603-608:

22 van Leeuwen DJ. Verbeek PCM. Smits NJ. Gonzalez Gonzalez D. Leidraad bij (vermoeden van) maligne obstructie van de proximale galwegen. Ned Tijdschr Geneesko 1990;134:2524-2529.

23 Lomas J, Anderson GM; Domnick-Pienre K, Vaydạ E, Enkin MW. Hạnah WJ. Do practice guidelines guide practice? $N$ Engl J Med 1989:321:1306-1311.

24 Lunderguist A. The radiplogy of jaundice. Baill Clin Gastroenteral 1989;3(2):387-405.

25 Lvgidakis. NJ, van der Heyde MN, Lubbers MJ. Evaluation of preoperative biliary drainage in the surgical management of pancreatic head carcinoma. Acta Chir Scan 1987:153:665-668.

26 Martin IG, Curley P, MCMahon MJ. Minimally invasive treatment for common bile duct stones. Brit J Surg 1993:80:103-106.

27 Naggar E, Krag E. Matzen P. Endoscopically inserted biliary endoprosthesis in malignant obstructive jaundice. A survey of the literature. Liver 1990:10:321-324.

28 North of England study of standards and performance in general practice. Medical audit in general practice: effects on doctors' clinical behaviour and the health of patients with common childhood conditions. BMJ 1992;304:1480-1488.

29 Obertop $H$, van Leeuwen DJ, van Leeuwen MS. The use of imaging techniques for the diagnosis and therapy in icterus with suspected malignant obstruction of the distal bile ducts. Ned Tijdschr Geneeskd 1992;136:1450-1458.

30 Pasanen PA, Partanen K, Pikkarainen P. Alhava E, Pirinen A, Janatuinen E. Diagnostic accuracy 
of ultrasound, computed tomography, and endoscopic retrograde cholangiopancreatography in the detection of obstructive jaundice. Scand J Gastroenterol 1991;26:1157-1164.

31 Putnam RW, Curry L. Impact of patient care appraisal on physician behavior in the office setting. Can Med Assoc J 1985;132:1025-1029.

32 Rigauts H, Marchal G, Var Steenbergen W. Ponette E. Comparison of ultrasound and ERCP in the detection of the cause of obstructive biliary disease. Rofo Fortschr Rontg 1992; 156:252-257.

33 Snady H, Cooperman A, Siegel J. Endoscopic ultrasonography compared with computed tomography with ERCP in patients with obstructive jaundice or small peri-pancreatic mass. Gastrointest Endosc 1992:38:27-34.

34 Speer AG, Russell RCG. Hatfield ARW, MacRae KD, Cotton PB, Mason RR et al. Randomised trial of endoscopic versus percutaneous stent insertion in malignant obstructive jaundice. Lancett 1987:2:57-62.

35 Speer AG, Cotton PB.Endoscopic stents for biliary obstruction due to malignancyin: ERCP: diagnostic and therapeutic applications Eds: Jacobsen IM, pp 203-224. Elsevier, New York (1989).

36 Trede M. Schwall G. Saeger H. Survival after pancreatoduodenectomy. Ann Surg 1990:$211: 447-458$.

37 Tytgat GN, Bartelsman JF, Den Hartog-Jager FC, Huiberegtse K, Mathus-Vliegen EMH. Upper intestinal and biliary tract endoprostheșis. Dig Diș Sçi 1986;31:57S-76S.

$38 \mathrm{Vang} \mathrm{J}$. The consensus development conference and the European experience. Int J Tech Assess Health Care 1986:2:65-76.

39 Venu RP, Geenen JE, Kini M, Hogan WJ. Payne M, Johnson GK. Schmalz MJ. Endoscopic retrograde brush cytology, a new technique. Gastroenterol 1990;99:1475-1479.

40 Vissers MC. Hasman A, Donkers HHLM, van der Linden CJ. Development, implementation and a first evaluation of a protocol processing system (PtotoV!EW). Comp. Meth Prog Biomed 1995:47:81-92.

41 Vissers MC, Hasman A, van der Linden CJ. Consultation behaviour of residents supported with a protocol processing system (ProtoVIEW) at the emergency ward. Int $J$ of Biomedical Computing 1995:38:18१-187.

42 Wang TH, Yue CH. Wang JT, Lin JT. Endoscopic approaches in the diagnosis of obstructive jaundice -- with special reference to endoscopic, retrograde cholangiopancreatography. J Formos Med Assoc 1992:91:164-167.

43 Warshaw AL, Fernandez-del Castillo. F. Pancreatic carcinoma. N Engl J Med 1992;326:455-465.

44 Watanapa Pi. Williamson RCN. Surgica! palliation for pancreatic cancer: developments during the past two decades. Brit J Surg 1992;79:8-20. 

Chapter 9

Summary and closing remarks 

This thesis focuses on various aspects of protocol usage that may influence practice of physicians.

The first objective of this thesis:

to develop, implement, and evaluate an automated protocol processing system to solve some problems and limitations of paper based protocols

is dealt with in chapters 4 and 5. The protocol processing sysiem ProtoVIEW is presented in chapter 4. ProtoVIIEW has been programmed in TURBO PASCAL 6.0 making use of HYPERPAS to build a graphical user interface similar to Microsoft Windows or the Macintosh interface. Physicians can define or update a wide range of protocols with the help of WordPerfect using several macros especially developed for this purpose. The resulting WordPerfect protocol text document is subsequently converted into a number of database files to be used by ProtoVIEW. Physicians can enter patient data into ProtoVIEW for later use and the diagnostic and therapeutic choices made during ProtoVIEW consultation are stored automatically. Patient data and therapeutic choices can be retrieved during later ProtoVIEW sessions.

ProtoVIEW supports physicians in a passive way which means that physicians themselves have to search for the protocol information they want to view. Information can be retrieved using an index, by keyword searching, or via browsing through the protocol. A physician can also point on any word in the protocol text in order to obtain further information. The computer will search the database for additional information concerning that particular topic and present it if available. ProtoviEW has a flow char window which provides a graphical representation of the protocol. ProtoVIEW can be consulted using only a mouse. Finally ProtoVIEW can give an overview of the diagnostic and therapeutic choices made during ProtoVIEW consultation.

We selected two different surgical working environments with completely different characteristics in which we investigated several aspects of protocol usage. First, protocols assisting inexperienced residents in the management of common medical problems in the Accident \& Emergency (A\&E) department and second, a protocol to assist experienced physicians in the diagnosis and treatment of obstructive jaundice.

Before the introduction of ProtoVIEW into clinical practice it was evaluated on a smal! scale. Paper based protocols for traumatology were computerized and stored into ProtoVIEW. After a brief tutorial instruction, interns were asked to solve case histories with the help of ProtoVIEW. On average, consultation took. $2 \frac{1}{2}$ minutes per case which was considered acceptable for these inexperienced ProtoViEW users. Interns found their way easily through the system making use of both keyword search and the browsing facility. On average interns rated the system positive with respect to user friendliness and expected clinical value. It was concluded from this first evaluation that ProtoVIEW seemed to be an acceptable tooll to support clinicians in their daily work.

To investigate the impact of ProtoVIEW in daily practice a randomised two period crossover trial was carried out. All 8 surgical residents who worked in the A \& E department of the University Hospital in Nijmegen, The Netherlands, participated. For each resident ProtoVIEW consultation was mandatory for a period. of 4 months and the use of 
paper based protocols was optional for another 4 months. The results of this trial are presented in chapters 5,6 and 7.

Chapter 5 discusses the consultation behaviour of residents using ProtoVIEW. Residents consulted ProtoVIEW before final treatment decisions were made in $76 \%$ of the cases. This indicates that the system was used correctly most of the time.

In a questionnaire residents stated that they were positive about the way protocols were presented and that they found ProtoVIEW easy to use. Residents predominantly browsed through the protocol information and they succeeded in reaching the relevant information without browsing through irrelevant windows. This may explain that keyword search was hardly used although it was successful in most cases. Still, expanding the number of synonyms may stimulate the use of keyword search.

On average, residents felt positive about the information supplied by ProtoVIEW and from the monitored information it was verified that residents retrieved the relevant information in almost all cases. Yet it was deduced that residents looked for additional information not provided by ProtoVİEW.

Although consultation of ProtoVIEW in routine circumstances took on average only $1 \frac{1}{2}$ minutes, residents doubted whether the usage of ProtoVIEW would be faster than consultation of other information sources. More experienced residents doubted whether Proto VIEW would increase their clinical performance while less experienced residents thought they would use ProtoVIEW in daily practice.

We concluded that residents may be familiar with most information contained in ProtoVIEW after a few months of working at the A \& E department. When making P'rotoVIEW usage optional = so that it will be used for more complex cases only physicians have to decide whether they need to consult the information system.

This leads us to the second objective of this thesis

to imvesrigate the effect of mandatory protocol consultation on protocol adherence and treatment using an automated protocol processing system

which is dealt with in chapters 6 and 7 . In chapter 6 the impact of mandatory protocol consultation compared to optional protocol consultation on protocol adherence is discussed.

Besides protocols, discussions with colleagues were the main information source used. It appeared that the protocols were consulted in only $2 \%$ of the cases when their use was optional. In almost all cases residents indicated that their treatment proposals fobtained before consulting any information source) were correct although about half of their proposals deviated from the protocol. The confidence in their treatment proposals may explain the low consultation rate. Residents for whom ProtoVIEW consultation was mandatory were confronted with a protocol treatment in each case but they had the freedom 10 reject the protocol treatment. ProtoVIEW users changed their treatments (after consulting information sources) towards the protocol advice almost 4 times more often than residents for whom consultation of paper based protocols was optional. The result was that $50 \%$ of the treatments of ProtoV!EW users and $30 \%$ of the treatments of paper protocol users were in complete accordance with the protocol treatment. Because residents were very confident about their treatment proposals, optional protocol consultation is unlikely to 
cause increase of protocol adherence in routine circumstances. Because protocol consultation for each case is boring in routine circumstances, ProtoVIEW could serve as an instrument for medical audit. Evaluating the working strategy of physicians regularly and providing feedback to the physicians concerned increases awareness of their actual performance. Providing physicians with feedback as soon as their treatment deviates from the protocol can be another solution. In this case ProtoVIEW should not be used as a stand alone device and should be integrated with an electronic medical record system. However, this will only be possible if all necessary data is recorded unambiguously in the electronic medical record system which requires standardisation of clinical data.

Although protocol adherence was better for ProtoVIEW users, even for them complete protocol adherence seemed to be quite low. In chapter 5 it was deduced that residents found relevant information (related to their own diagnosis) in ProtovIEW in $98 \%$ of the cases. The low level of protocol adherence may be explained by frequent rejection of protocol advice by the residents. However, in almost half of the cases diagnoses were incorrect or incomplete which may be a better explanation of the low protocol adherence. In addition, imprecise descriptions of the treatments in the medical record may have caused us to judge some of these treatments as being not in complete accordance with the protocol treatment.

Whether the improved protocol adherence by mandatory protocol consultation resulted in a better treatment for the patient when compared to optional protocol consultation is discussed in chapter 7. We could not show that treatment was better for patients treated by residents for whom protocol consultation was mandatory as compared to patients treated by residents for whom consultation was optional. However, comparing subgroups, restricted to correctly diagnosed patients, revealed slight differences indicating that treatment had been improved by mandatory protocol consultation as compared to optional protocol consultation.

To really demonstrate improved treatment either a much larger trial is needed or protocol adherence has to be improved further. The latter might be achieved by extending the trauma protocol with diagnostic information and/or providing residents with computer support during follow-up.

The third objective of this thesis:

to investigate to what extent nationally developed protocols are transferable to a local situation

is discussed in chapter $\mathbf{8}$.

Because a local protocoll for the diagnosis and treatment of obstructive jaundice was not available, a surgeon at the university hospital in Maastricht adapted a nationally developed protocol, to fit the local circumstances. Before storing the adapted protocol into ProtoVIEW and introduce it into clinical practice, the potential benefit of the protocol was assessed by comparing its recommendations with the strategies, actually followed in patients with obstructive jaundice. It was found that $30 \%$ of the diagnostic decisions in patients with, a malignancy deviated from the protocol of which almost half may be avoidable with the introduction of the protocol.

Protocol recommendations based on reported expertise, may have to be adapted if local 
expertise differs from that found in the literature. Local expertise with diagnostic procedures such as percutaneous punctions, bile and brush cytology was comparable with that reported in the literature. Success rates of endoscopic and percutaneous stent insertion tended to be lower than those found in the literature. We concluded that protocol recommendations concerning biopsies, punctions, bile and brush cytology seem to be valid while those concerning endoscopic and percutaneous stent insertion might have to be adapted.

From this study we conclude that introduction of the local protocol into clinical practice may be beneficial if its recommendations are followed. Prospective data collection of diagnostic investigations may be useful in order to modify the protocol further.

\section{Future research}

\section{Proto VIEW functions}

When interns and residents used the protocol processing system ProtoVIEW, they were positive about the way protocols were presented and they found ProtoVIEW easy to use. Because keyword search was not used very often, extending the number of synonyms may improve the keyword facility. This may stimulate the use of this facility especialiy when more (and larger) protocols are stored into ProtoVIEW.

It would also be useful to link ProtoVIEW with a literature data base (such as MEDLINE) to make justification of recommended actions possible. Furthermore, when ProtoVIEW would be extended with multimedia information (text, graphics, sound and video) it would be possible to watch a video tape of, for instance, a recommended surgical technique without leaving ProtoVIEW. To support physicians adequately in diagnosing fractures ProtoVIEW should be able to present high-resolution $X$-ray images next to the textual protocol information.

\section{ProtoVIEW integration}

We concluded that ProtoVIEW probably would not be very useful when available in daily clinical practice on a voluntary basis. If ProtoVIEW is integrated with an electronic medical record system it will be possible to feedback the protocol treatment information immediately when diagnostic or treatment choices deviate from the protocol. Integration of ProtovIEW with an electronic medical record system will solve the problems of a standalone system but will also create some new ones, e.g. standardisation of clinical data. Further research will be needed to solve these problems.

When integration with an electronic medical record system is not (yet) possible, it would be worthwhile to make ProtoVIEW available via a network. The storage and retrieval of patient data in the hospital at any location any time would make cooperation between various disciplines easier and would make ProtoVIEW support during follow-up at the outpatient clinic possible. Furthermore, it would be possible to monitor local expertise by collecting prospective patient data not recorded by the Hospital Information System. 
The evaluation of Computerized Decision Support Systems (CDSSs).

Investigators who attempt to measure the effect of CDSSs on physicians' performance and patient outcome encounter specific problems. The standard method to evaluate medical interventions is the randomized controlled trial (RCT). However, in the evaluation of a CDSS it is not always possible to conduct a RCT. Blinding is not possible and other specific problems may occur. One problem is that impact of CDSSs is often, although not necessarily, measured at two levels: physicians and patients. Therefore, both physicians and patients should be randomized which is not always feasible due to practical reasons. Especially the impact of CDSSs on patient outcome is difficult to assess because a large number of patients is required, especially if the CDSS supports a wide range of medical problems. Moreover, many other factors (besides protocol adherence) may interfere with carrying out the system's advice and, as a result, the treatment eventually received by the patient. Because the evaluation of patient outcome becomes more important than evaluating CDSS-effects on doctors' decisions (only an intermediate variable), much further thinking needs to be done in this area to clarify how this has to be done. 



\section{Samenvatting}

De nederlandse samenvatting tracht het onderzoek en de resultaten voor een breed publiek te beschrijven. Diegenen die diepgaander geïnformeerd willen worden kunnen de engelse samenvatting of de betreffende hoofdstukken raadplegen.

\section{Inleiding}

De enorme toename van kennis op het terrein van de geneeskunde heeft ertoe geleid dat er een breed scala aan diagnostische en therapeutische mogelijkheden beschikbaar is. De individuele arts kan zich de kennis, die nodig is om deze mogelijkheden optimaal in te zetten en bovendien verspreid is over boeken, tijdschriften en congresverslagen, onmogelijk geheel eigen maken. Een gevolg is dat er grote verschillen bestaan in het medisch handelen van artsen en dat de onzekerheid over de te nemen medische beslissingen toeneemt. Protocollen kunnen zorgen voor grotere eenvormigheid van medisch handelen en de onzekerheid (deels) wegnemen. Met een protocol bedoelen we een strategie voor het stellen van een diagnose en het kiezen van een behandeling bij een bepaalde ziekte, syndroom of klinische situatie. Een protocol is meestal het resultaat van overleg tussen een aantal artsen (met een bijzondere kennis op een bepaald gebied) over de wijze van diagnostisch of therapeutisch handelen die voor een specifieke groep patiënten, gemiddeld genomen, een optimaal resultaat zal opleveren. Overeenstemming (consensus) over een protocol kan zich beperken tot één afdeling of een heel ziekenhuis maar er zijn ook voorbeelden van overeenstemming op nationaal of zelfs internationaal niveau. Protocollen worden beschreven in zogenaamde protocollenboeken.

\section{De onderzoeksprotocollen}

In dit proefschrift onderzoeken we in hoeverre protocolgebruik en protocolontwikkeling van invloed zijn op medische beslissingen. We onderzochten dit aan de hand van twee totaal verschillende voorbeelden uit de chirurgische praktijk (Hoofdstuk 3). Eén betrof de behandeling van eenvoudige fracturen op de Ferste Hulp (EH) afdeling. De tweede situatic betrof (vooral) de diagnostiek van galwegobstructies.

\section{Protocolgebruik op de Eerste Hulp}

Het eerste aspect van ons onderzoek vormde het huidige gebruik van protocollen voor de behandeling van eenvoudige fracturen op de $\mathrm{EH}$ afdeling. Fen inventarisatie liet zien dat het beschikbare protocollenboek nauwelijks werd geraadpleegd. Fén mogelijke reden hiervoor was dat het protocollenboek in z'n huidige vorm niet voldeed. Het opzocken van een protocol kost tijd en moeite, vooral wanneer de protocollen uitgebreid en ingewikkeld zijn. Bovendien vereist het actualiseren yan een protocollenboek dat een nieuw of gedeeltelijk: nieuw protocollenboek wordt uitgegeven. Dit waren redenen om een protocol informa- 
tie systeem (ProtoVIEW) te ontwikkelen dat een aantal beperkingen van protocollenboeken oplost (Hoofdstuk 4).

\section{Beschrijving van ProtoVIEW}

ProtoVIEW is een computerprogramma dat protocollen op een overzichtelijke en gebruikersvriendelijke manier presenteert. Tevens kan hiermee een protocol snel en gemakkelijk geraadpleegd en geactualiseerd worden. ProtoVIEW heeft een grafische gebruikersinterface die lijkt op Microsoft Windows en op de Apple Macintosh interface en kan met behulp van een muis geraadpleegd worden. De artsen kunnen zelf protocollen invoeren of actualiseren met behulp van een veelgebruikte tekstverwerker (WordPerfect). Met ProtoVIEW kan de gewenste protocolinformatie worden geraadpleegd en kunnen patiëntgegevens worden ingevoerd. Er zijn verschillende manieren om naar de informatie te zoeken. Er kan door het protocol 'gebladerd' worden door met de muis te klikken op woorden in de protocoltekst, maar men kan ook. zoeken in de index of met sleutelwoorden. ProtoVIEW kan de structuur van het protocol grafisch weergeven in de vorm van een stroomdiagram. Tenslotte kan ProtoVIEW een overzicht geven van de diagnostische en therapeutische keuzes die gemaakt worden tijdens een ProtoVIEWconsultatie.

\section{Een eerste evaluatie van ProtoVIEW}

Voordat we ProtoVIEW introduceerden in het ziekenhuis voerden we eerst een evaluatie op kleine schaal uit (Hoofdstuk 4). De bestaande protocollenboek-informatie voor de behandeling van fracturen werd in ProtoVIEW ingevoerd. $\mathrm{Na}$ een korte instructie in het gebruik van ProtoVIEW werd aan co-assistenten (medisch studenten) gevraagd een aantal medische problemen op te lossen door de benodigde informatie op te zoeken in ProtoVIEW. Gemiddeld kostte het raadplegen van ProtoVIEW $2 \frac{1}{2}$ minuut per probleem, wat we een acceptabele tijdsduur vonden voor deze onervaren ProtoVIEW gebruikers. Co-assisten(cn vonden gemakkelijk hun weg in ProtoVIEW. Ze maakten zowel gebruik van sleutelwoorden als van de 'blader' faciliteit. De meeste co-assistenten vonden ProtoVIEW gemakkelijk te bedienen. Op grond van deze kleinschalige evaluatie werd besloten dat ProtoVIEW gereed was voor de introductie op de EH afdeling van het Academisch Ziekenhuis in Nijmegen.

\section{ProtoVIEW in de dagelijkse praktijk}

Het tweede aspect van ons onderzoek vormde het gebruik van ProtoVIEW in de dagelijkse praktijk. Hiertoe werd het systeen acht maanden op een EH afdeling geplaatst. Met dit onderzoek wilden we twee vragen beantwoorden. De eerste vraag was of ProtoVIEW in de praktijk voldeed. Hiervoor werden vooral gebruikersaspecten van de interface onderzocht (Hoofdstuk 5). De tweede vraag was of de protocoltrouw en kwaliteit van behandeling zouden verbeteren wanneer het raadplegen van protocollen verplicht werd (Hoofdstuk 6-7).

Alle acht chirurgische assistenten (artsen) die regelmatig op de EH afdeling werkten namen deel aan het onderzoek en werden willekeurig in twee groepen van vier verdeeld. Eén groxp werd verplich ProtoVIEW te raadplegen voor elke patiènt met een fractuur terwijl de andere groep, als ze dit wensten, over het protocollenboek kon beschikken (de 
normale situatie) en zo de controlegroep vormde. Na 16 weken werden de rollen omgekeerd wat betekent dat de groep met ondersteuning van ProtoVIEW nu vrij was het protocollenboek te raadplegen terwijl de controlegroep ondersteuning van ProtoVIEW kreeg. Dit onderzoek had dus een zogenaamd cross-over design.

\section{Het functioneren van ProtoVIEW}

Om het ProtoVIEW gebruik te kunnen beoordelen werden de zoektochten in ProtoVIEW gedurende het onderzoek automatisch geregistreerd waardoor we deze achteraf nauwkeurig konden reconstrueren (Hoofdstuk 5). Zo konden we vaststellen dat assistenten in bijna alle gevallen de relevante informatie opvroegen. Tevens bleek soms dat assistenten nar aanvullende informatie zochten die ProtoVIEW niet bevatte. Assistenten maakien hoofdzakelijk gebruik van de 'blader' faciliteit en slaagden er meestal in om op die manier de gewenste informatie langs de snelste weg te vinden. In mindere mate werd gebruik gemaakt van zoeken met behulp van sleutelwoorden. Toch was ook dan het resultaat meestal succesvol, Een uitbreiding van het aantal synoniemen zou het gebruik van sleutelwoorden mogelijk kunnen stimuleren.

In een enquête gaven de acht assistenten aan dat ze tevreden waren over de manier waarop de protocollen werden gepresenteerd en dat ProtoVIEW gemakkelijk te bedienen was. De assistenten waren meestal tevreden over de informatie die gegeven werd door ProtoVIEW. Ondanks dat het raadplegen van ProtoVIEW gemiddeld slechts $1 \frac{1}{2}$ minuut per patiënt in beslag nam, twijfelden assistenten of het gebruik van ProtoVIEW sneller zou zijn dan het raadplegen van andere informatiebronnen. De meer ervaren assistenten dachten niet dat ProtoVIEW hun klinisch handelen verbeterde en verwachtten ProtoVIEW nauwelijks vrijwillig te zullen raadplegen. De minder ervaren assistenten meenden vaker dat ProtoVIEW hun klinisch handelen verbeterde en dachten ProtoVIEW ook vrijwillig te zullen raadplegen.

\section{Invloed van protocolgebruik op protocoltrouw en kwaliteit van buthandeling}

Wanneer assistenten verplicht werden de protocollen te raadplegen (met de vrijheid om de geadviseerde behandeling af te wijzen) veranderden ze hun behandeling bijna vier keer zo vaak overeenkomstig het advies dan assistenten uit de controlegroep. Dit resulteerde in een grotere eenvormigheid van werken (grotere protocoltrouw) voor assistenten die ondersteund werden met ProtoVIEW (Hoofdstuk 6).

Omdat assistenten eerst een correcte diagnose moesten stellen om de corresponderende protocollaire behandeling in ProtoVIEW (of in het protocollenboek) te kunnen vinden, werd ook gekeken hoe goed hun diagnoses waren. De diagnoses bleken in beide groepen ongeveer even vaak correct te zijn. Ook bleek dat de diagnostiek voor verbetering vatbaar was omdat van alle diagnoses bijna de helft niet. (of niet helemaal) correct. was. Ondersteuning met diagnostische protocol-informatie zou de diagnostiek kunnen verbeteren en als gevolg daarvan zou de protocoltrouw verder kunnen toenemen.

Met. gegevens uit de patiēntdossiers werd na éen jaar onderzocht of de grotere protocoltrouw de kwaliteit van behandeling had beinvloed (Hoofdstuk 7). De kwaliteit van behandeling werd afgemeten aan de behandelingsduur, het vóórkomen van complicaties, 
polikliniek-controles en veranderingen van de behandeling. Ofschoon de protocoltrouw groter was bij assistenten die de protocollen verplicht: moesten raadplegen, bleek de kwali-teit van hun behandelingen niet duidelijk te verschillen van de behandelingskwaliteit van assistenten die de protocollen vrijwillig raadpleegden. Bij patiènten waarbij assistenten de juiste diagnose stelden, waren wel verschillen te zien ten gunste van patiënten die behandeld waren door assistenten met ondersteuning van ProtoVIEW. Deze resultaten doen vermoeden dat kwaliteit van behandeling kan verbeteren als assistenten ook diagnostische ondersteuning krijgen waardoor ze vaker de juiste protocollaire behandeling overwegen.

\section{Protocolgebruik}

Uit ons onderzoek bleek ook dat assistenten zo zeker waren over hun behandelingsvoorstellen dat ze het protocollenboek bijna nooit raadpleegden (Hoofdstuk 6). We verwachten daarom ook niet dat het systeem vaak geraadpleegd zal worden als het gebruik van ProtoVIEW niet verplicht is. Het verplicht stellen van ProtoVIEWgebruik is echter moeilijk te realiseren in de dagelijkse praktijk. Eén van de oplossingen is het integreren van ProtoVIEW in een geautomatiseerd medisch dossier. In dat geval hoeft de arts niet zelf de protocollen te radplegen maar controleert de computer automatisch op protocoltrouw nadat de patiëntgegevens, diagnose en therapie door de arts zijn ingevoerd.

\section{De invoering van een nationaal protocol op lokaal niveau}

Een derde aspect van protocolgebruik dat we onderzochten, is de mate waarin een op nationaal niveau ontwikkeld protocol voor de diagnostiek van galwegobstructie toepasbaar is in lokale situaties. Het ontwikkelen en wetenschappelijk funderen van een goed protocol kost veel tijd en geld. Daarom zijn de op national niveau ontwikkelde protocollen over het algemeen van een hogere kwaliteit dan die op lokaal niveau worden ontwikkeld. Het nadeel van nationaal ten opzichte van lokaal ontwikkelde protocollen is echter dat het meer moeite kost om de protocollen onder de aandacht van de betreffende artsen te brengen en deze te overtuigen van het nut ervan. Eerder onderzoek toonde aan dat wanneer (vertegenwoordigers van) de artsen bij de ontwikkeling van het protocol worden betrokken en er meer aandacht is voor de aanpassing van nationale protocollen aan de lokale situatie, de protocoltrouw positief beinvloed wordi.

\section{Vergelijking protocol voor galwegobstructies met gangbare diagnostiek}

De buiten de lever gelegen galwegobstructie is een weinig voorkomend medisch probleem ( \pm 25 nieuwe patiënten per jaar in het academisch ziekenhuis Maastricht (azM)), heeft een complexe diagnostiek en vereist samenwerking tussen chirurgen, internisten en radiologen. Bovendien worden de diagnostiek en therapie nogal eens aangepast op geleide van nieuwe inzichten. Daarom werd voor alle betrokken disciplines, op landelijk niveau. een protocol 'obstructie icterus' ontwikkeld dat vooral ondersteuning zou moeten bieden bij de diagnostiek van galwegobstructies. Dit protocol werd aangepast voor de situatie in het azM.

Wij wilden weten of de invoering van dit aangepaste protocol in het az $\mathrm{M}$ het diagnostische proces zou kunnen verbeteren (Hoofdstuk 8). Bij patiēnten die tussen juni '90 en juni 
'92 voor het eerst met een (buiten de lever gelegen) galwegobstructie in het azM kwamen, werden de protocoladviezen vergeleken met de strategie die daadwerkelijk was gevolgd. Bij $30 \%$ van de patiēnten met een kwaadaardige galwegobstructie bleken de genomen diagnostische beslissingen af te wijken van het protocol. De helft van deze protocolafwijkingen kan waarschijnlijk worden vermeden door invoering van het protocol. Therapeutische protocolafwijkingen die moeilijker te vermijden zijn, werden bij $11 \%$ van de patiēnten vastgesteld.

Daarnaast werd ook bekeken in hoeverre de resultaten van diagnostische en therapeutische technieken in het az $\mathrm{M}$ met de resultaten in de literatuur overeenstemmen. Hierop zijn de meeste protocoladviezen immers gebaseerd. De resultaten van cytologische puncties en diagnostische endoscopische en percutane procedures bleken vergelijkbaar met die in de literatuur. De resultaten van therapeutische endoscopische en percutane procedures bleken echter minder goed overeen te: komen met die in de literatuur. Het is dus mogelijk dat de nationale protocoladviezen over diagnostische procedures geldig zijn in het az $\mathrm{M}$, terwijl de therapeutische endoscopische en percutane procedures mogelijk verder aangepast dienen te worden aan de situatie in het azM.

Doordat de patiēntgegevens achteraf (retrospectief) vergeleken werden met de protocoladviezen moeten we voorzichtig zijn met het trekken van conclusies. Voordat er definitieve beslissingen genomen worden omtrent verdere protocolaanpassingen dient nader onderzoek gedaan te worden. 



\title{
Curriculum Vitae
}

\author{
Marieke Vissers
}

1963

$1975-1981$

$1981-1986$

1986-1988

December 1990

February 1991

October 1991-1995

February 1996
September 2, born in Arcen en Velden (The Netherlands)

Highschool

St. Thomascollege Venlo

Medical School

University of Nijmegen

Studied Computer Science

University of Nijmegen

M.D. Thesis, Analysis of Tumour Shadow Characteristics In Digitized Mammograms

Dept. of Radiology, University Hospital, Nijmegen.

Masters degree Medicine

PhD Student Medical Informatics

University of Limburg, Maastricht

- Post-doc Researcher

Dept. Medical Informatics

University of Limburg, Maastricht 



\section{Publications}

\section{Abstracts in conference proceedings:}

1 Tange HJ, Vissers M. Hasman A. Computer Supported Patient Management, Proc 2nd Conf Engin Med 1994:47.

2 Biert J, Vissers M, vd Linden CJ. Hasman A. Effecten van een computergestuurd protocol op het functioneren van arts-assistenten op de spoedeisende hulpafdeling. Ned Tijdschr Traum 1994:6:166-167.

\section{Papers in conference proceedings:}

1 Dessel PFHM, Hasman A, Linden van der CJ. ProtoVIEW: a workstation for the use of clinical algorithms. In: Lecture notes in medical informatics, 45 1991:233-237. Eds: Adlassnig KP.

Grabner G, Bengtsson S, Hansen R. (Springer verlag. Berlin 1991).

2 Vissers M, Hasman A, van der Linden CJ. Protocol processing system (ProtoVIEW) to support residents at the emergency ward. In: Proc MIE'94:138-143. Eds: Barahona P, Veloso M, Bryant J.

3 Vissers MC, Hasman A, van der Linden CJ. Effects of a protocol processing system 'Proto. VIEW' to support residents at the emergecy ward. In: Proc 8th European Health Records Conference 1995 Eds: Runnenberg J, van der Haagen MAM, Hogeboom JW. (Marcelis \& van der Lee, Alkmaar 1995).

\section{Publications in national journals}

1 Vissers MC. Hasman A van der Linden CJ. Effecten van een protocol informatio systeem (ProtoVIEW) gebruikt door assistent-chirurgen op een Eerste Hulp. Ned Tijdschr Med Adm $1995 ; 80: 23-27$

\section{Publications in international journals}

1 Tange HJ, Vissers M, Hasman A, Donkers. HHLM ، van der Linden CJ. Computer supported patient management. Techn Health Care 1994;1:253-264

2 Vissers. MC. Hasman A. Donkers. HHLM, van der Linden CJ. Development, imptementation and a first evafuation of a protocol processing system (ProtoVIEW). Comp Meth Prog Biomed $1995 ; 47: 81-92$

3 Vissers; MC, Hasman A, yan der Linden. CJ. Consultation behaviour of residents supported with a protocol processing system (ProtoVIEW) at the emergency ward. Int J Biomed Comput 1995:38:181-18:7

4 Vissers M. Hasman A, van der Linden CJi. Protocoll processing system (ProtoVIEW) to support residents at the emergency ward. Comp Meth Prog Biomed 1995:48:53-58

5 Vissers MC, Hasman A, van der Linden CJ. Impact of a protocol processing systemi (Proto. VIEW/ on clinical behaviour of residents and treatment. Int $J$ Biomed Comput [In press]

6 Vissers MC, Biert J, van der Linden CJ, Hasman A. Effects of a supportive protocol display system (ProtoVIEW) on clinical behaviour of residents in the accident \& emergency depart ment. Comp Meth Prog Biomedi [in press]

7. Vissers MC. Greve JW, Gouma DJ, van der Linden CJ, Hasman. A. The introduction of a computerized protocol in clinical practice; is there anything to gain? [Submitted] 
